\title{
Replicação assíncrona em bancos de dados evolutivos
}

\author{
Helves Humberto Domingues
}

TESE APRESENTADA

$\mathrm{AO}$

INSTITUTO DE MATEMÁTICA E ESTATÍSTICA

DA

UNIVERSIDADE DE SÃO PAULO

PARA

OBTENÇÃO DO TÍTULO

$\mathrm{DE}$

DOUTOR EM CIÊNCIAS

\author{
Programa: Ciência da Computação \\ Orientador: Prof. Dr. Fabio Kon \\ Coorientador: Prof. Dr. João Eduardo Ferreira
}

Durante o desenvolvimento deste trabalho o autor recebeu o auxílio financeiro da FAPESP, Microsoft Research e CAPES

São Paulo, 29 de julho de 2011 


\section{Replicação assíncrona em bancos de dados evolutivos}

Esta tese contém as correções e alterações sugeridas

pela Comissão Julgadora durante a defesa realizada por Helves Humberto Domingues em 02/06/2011.

O original encontra-se disponível no Instituto de Matemática e Estatística da Universidade de São Paulo.

Comissão Julgadora:

- Prof. Dr. Fabio Kon (orientador) - IME-USP

- Prof. Dr. João Eduardo Ferreira (coorientador) - IME-USP

- Prof. Dr. Marcelo Finger - IME-USP

- Prof. Dr. Jorge Rady de Almeida Junior - EP-USP

- Prof. Dr. Eduardo Martins Gerra - ITA

- Prof. Dr. Luiz Camolesi Junior - Unicamp 
A vida é curta, a arte é longa. A ocasião, fugidia. A esperança, falaz. E o julgamento, difícil. Hipócrates, Aforismos, 1,1. 


\section{Agradecimentos}

Agradeço de modo especial ao professor Fabio Kon e João Eduardo Ferreira que, com suas competentes orientações, constantemente me motivaram a superar os desafios da carreira acadêmica. Agradeço aos membros da banca pelos comentários e sugestões que contribuíram para a melhora desta tese. A CAPES, FAPESP e Microsoft Research, pelo seu apoio financeiro durante todos esses anos.

A todos meus amigos que me deram forças para superar este grande desafio que é o doutorado. E um agradecimento especial àqueles que ainda contribuiram com meu trabalho de doutorado.

À minha família, por todo o apoio e carinho que possibilitaram o meu amadurecimento e a conclusão deste doutorado. 


\section{Resumo}

A modelagem evolutiva de bancos de dados é necessária devido às frequentes mudanças de requisitos das aplicações. O desafio é ainda maior quando o banco de dados tem de atender simultaneamente a várias aplicações. A solução proposta por Scott Ambler para evolução utiliza refatorações e define um período de transição, durante o qual tanto o esquema antigo quanto o novo coexistem e os dados são replicados por meio de um processo síncrono que apresenta várias dificuldades, como a interferência no funcionamento normal das aplicações. Para minimizar essas dificuldades, esta tese propõe um processo assíncrono para manter atualizados esses esquemas e apresenta um protótipo de uma ferramenta para auxiliar as evoluções dos bancos de dados. A proposta foi validada por meio de um experimento em laboratório que comparou a solução aqui apresentada com a proposta por Ambler.

Palavras-chave: Banco de Dados Evolutivos, Métodos Ágeis, Refatoração, Replicação de Dados. 


\section{Abstract}

Evolutionary database modeling is necessary due to the frequent changes in application requirements. The challenge is greater when the database must support multiple applications simultaneously. The solution for evolution proposed by Scott Ambler is refactoring with a transition period, during which both the old and the new database schemas coexist and data is replicated via a synchronous process, what brings several difficulties, such as interference with the normal operation of applications. To minimize these difficulties, this thesis proposes an asynchronous process to keep these schemas updated and presents a prototype tool to evolve databases. The proposal was validated by a laboratory experiment in which the solution presented here was compared with the one proposed by Ambler.

Keywords: Evolutionary Database, Agile Methods, Refactoring, Data Replication. 


\section{Sumário}

1 Introdução 1

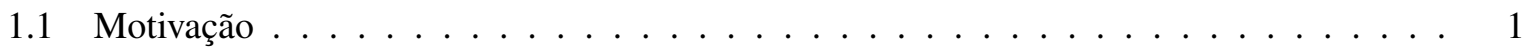

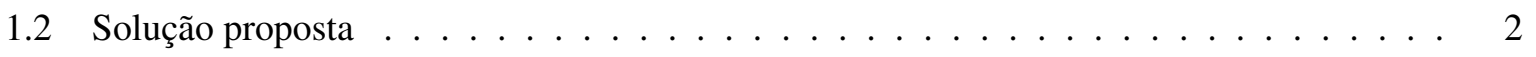

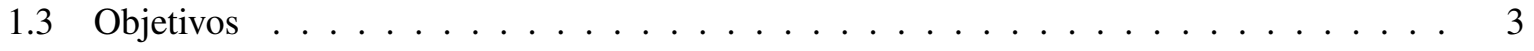

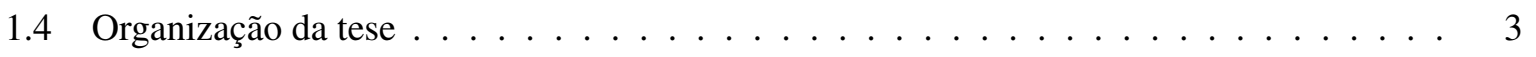

2 Evolução de bancos de dados 5

2.1 Métodos ágeis . . . . . . . . . . . . . . . . . . . 6

2.2 Refatoração de banco de dados . . . . . . . . . . . . . . . . . . . 7

2.3 Período de transição e código de apoio . . . . . . . . . . . . . . 8

2.4 Exemplo de refatoração: Dividir tabela . . . . . . . . . . . . . . . . . 9

2.5 Limitações na utilização de triggers . . . . . . . . . . . . . . . . . . . . . 10

3 Refatorações de banco de dados 13

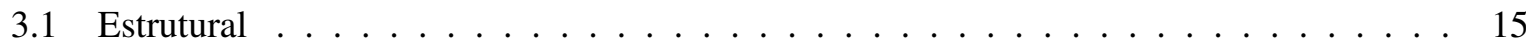

3.1 .1 Eliminar coluna . . . . . . . . . . . . . . . 16

3.1 .2 Eliminar tabela . . . . . . . . . . . . . . . . 17

3.1 .3 Eliminar visão . . . . . . . . . . . . . . . . . . . . 18

3.1 .4 Introduzir coluna calculada . . . . . . . . . . . . . . . . . . . . 19

3.1.5 Introduzir chave de identificação (replicação de dados) . . . . . . . . . 20

3.1.6 Unir colunas (replicação de dados) . . . . . . . . . . . . . . . 21

3.1.7 Unir tabelas (replicação de dados) . . . . . . . . . . . . . . 22

3.1.8 Mover coluna (replicação de dados) . . . . . . . . . . . . 23

3.1.9 Renomear coluna (replicação de dados) . . . . . . . . . . . . . 24

3.1.10 Renomear tabela (replicação de dados) . . . . . . . . . . . . 25

3.1 .11 Renomear visão . . . . . . . . . . . . . . . . . . 26

3.1.12 Trocar coluna complexa por tabela (replicação de dados) . . . . . . . . 27

3.1 .13 Trocar coluna (replicação de dados) . . . . . . . . . . . . 28 
3.1.14 Trocar um-para-muitos por tabela associativa (replicação de dados) . . . 29

3.1.15 Trocar chave de identificação por chave natural (replicação de dados) . . 30

3.1 .16 Dividir coluna (replicação de dados) . . . . . . . . . . . . 31

3.1 .17 Dividir tabela (replicação de dados) . . . . . . . . . . . 32

3.2 Qualidade de dados . . . . . . . . . . . . . . . . . . . . . 33

3.2 .1 Adicionar tabela descritiva . . . . . . . . . . . . . . . 34

3.2 .2 Introduzir restrição de coluna $\ldots \ldots \ldots \ldots \ldots$

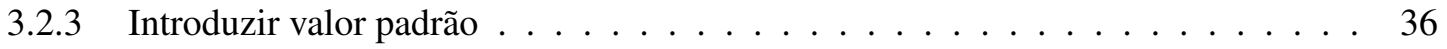

3.2 .4 Remover valor padrão . . . . . . . . . . . . . . . . . . . 37

3.2 .5 Alterar coluna para não nula . . . . . . . . . . . . . . . . . . . . 38

3.2 .6 Remover restrição de não nulo . . . . . . . . . . . . . . . . . . . . . . . 39

3.2 .7 Introduzir formato comum . . . . . . . . . . . . . . . . . . . 40

3.2 .8 Aplicar código padrão ～. . . . . . . . . . . . . . . . . . . . . . . . . 41

3.2.9 Aplicar tipo padrão (replicação de dados) . . . . . . . . . . . . . 42

3.2.10 Remover restrição de coluna . . . . . . . . . . . . . . . . . . . . . . . 43

3.2.11 Mover dados . . . . . . . . . . . . . . . . . . . . . 44

3.2.12 Consolidar estratégia de chaves (replicação de dados) . . . . . . . . 45

3.2.13 Trocar código de tipo por propriedades sinalizadoras (replicação de dados) 46

3.3 Integridade referencial . . . . . . . . . . . . . . . . . . 47

3.3.1 Adicionar restrição de chave estrangeira . . . . . . . . . . . . . . . . . 48

3.3.2 Introduzir exclusão em cascata . . . . . . . . . . . . . . . . . . . . . . . . . 49

3.3 .3 Introduzir exclusão lógica $\ldots \ldots \ldots \ldots \ldots \ldots$

3.3.4 Remover restrição de chave estrangeira . . . . . . . . . . . . . . . . 51

3.3 .5 Introduzir exclusão física . . . . . . . . . . . . . . . . . . . 52

3.3.6 Adicionar trigger para coluna calculada . . . . . . . . . . . . . . . . 53

3.3.7 Adicionar trigger para histórico . . . . . . . . . . . . . . . . . . . . 54

3.4 Arquitetural . . . . . . . . . . . . . . . . . . . . 55

3.4 .1 Adicionar métodos CRUD . . . . . . . . . . . . . . . 56

3.4 .2 Encapsular tabela com uma visão . . . . . . . . . . . . . . . . . . . 57

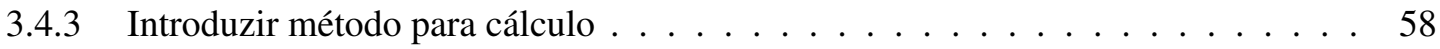

3.4 .4 Introduzir tabela espelho . . . . . . . . . . . . . . . . 59

3.4 .5 Adicionar método de leitura . . . . . . . . . . . . . . . . . . 60

3.4 .6 Introduzir índice . . . . . . . . . . . . . . . . . . . . . 61

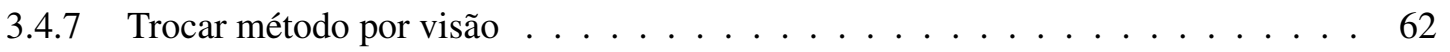

3.4 .8 Trocar visão por método . . . . . . . . . . . . . . . . . 63

3.4 .9 Usar fonte de dados oficial . . . . . . . . . . . . . . . . . . . . . 64

3.4.10 Migrar método de banco de dados . . . . . . . . . . . . . . . . 65 
3.4.11 Migrar método para banco de dados . . . . . . . . . . . . . . . . 66

3.4 .12 Introduzir tabela somente leitura . . . . . . . . . . . . . . . . . . 67

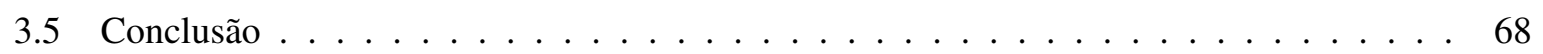

4 Replicação assíncrona em banco de dados evolutivos

4.1 Etapa de coleta de informações de transações . . . . . . . . . . . . . . . . . . . . 69

4.2 Etapa de mapeamento . . . . . . . . . . . . . . . . . . 70

4.3 Etapa de execução . . . . . . . . . . . . . . . . . . . . 71

4.4 Avaliação preliminar da replicação assíncrona . . . . . . . . . . . . . . . . . . . . 72

4.5 Premissas para a replicação assíncrona . . . . . . . . . . . . . . . . . . . . . . . . . . . . 73

4.6 Protótipo: Database Evolution Manager (DEM) . . . . . . . . . . . . . . . . . . 74

4.6 .1 Página Triggers . . . . . . . . . . . . . . . . . . . 76

4.6 .2 Página Maps . . . . . . . . . . . . . . . . . . . . . . 79

4.6 .3 Página $J o b s \ldots \ldots \ldots \ldots$. . . . . . . . . . . . . . . . . . 80

5 Experimento de replicação assíncrona $\quad \mathbf{8 1}$

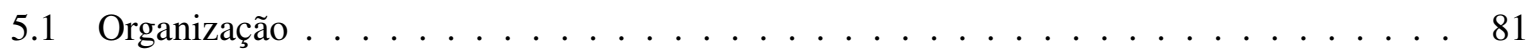

5.2 Descrição do sistema e dos objetivos do experimento . . . . . . . . . . . . 82

5.3 Seleção das métricas . . . . . . . . . . . . . . . . . . . . . . . 84

5.4 Seleção dos parâmetros . . . . . . . . . . . . . . . . . . . . . 85

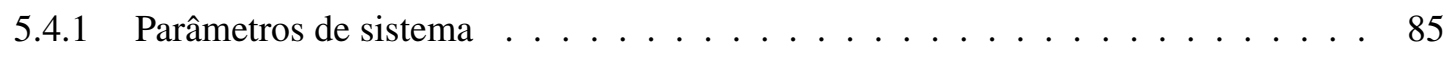

5.4.2 Parâmetros de carga do sistema . . . . . . . . . . . . . 86

5.5 Elaboração dos experimentos . . . . . . . . . . . . . . . 87

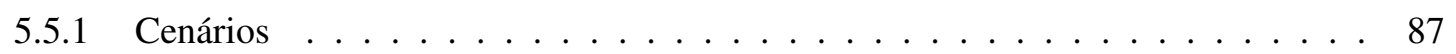

5.5.2 Etapas do experimento . . . . . . . . . . . . . . . . 88

5.5.3 Exemplo de uma execução do experimento . . . . . . . . . . . . . . . . . . . . . . . . . . . 90

5.5.4 Simulação da concorrência . . . . . . . . . . . . . . . . . . 91

5.5 .5 Simulação de isolamento . . . . . . . . . . . . . . . . . . . . . . . . . . . . . .

5.6 Análise e interpretação dos dados . . . . . . . . . . . . . . . . . . . . 92

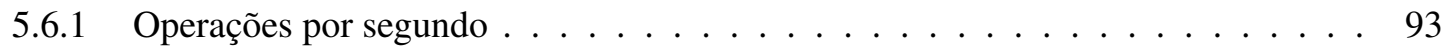

5.6 .2 Taxa de operações que bloqueiam . . . . . . . . . . . . . . . . . 94

5.6 .3 Operações por segundo em ambiente isolado . . . . . . . . . . . . . . . 95

5.6 .4 Duração do processamento . . . . . . . . . . . . . . . . 96

5.6 .5 Tempo de fila em segundos . . . . . . . . . . . . . . . . . . . . . . . . . . . . . 97

5.7 Apresentação dos resultados . . . . . . . . . . . . . . . . . . . 98 
6 Trabalhos relacionados $\quad 99$

6.1 Banco de dados ativos . . . . . . . . . . . . . . . . . . . . . . . . . . 999

6.2 Replicação de dados . . . . . . . . . . . . . . . . . . . . . . . . . 100

6.3 Ferramentas ETL . . . . . . . . . . . . . . . . . . . . . 100

6.4 Evolução de esquemas . . . . . . . . . . . . . . . . . . . . 102

6.5 Ferramentas de gerenciamento de alterações de banco de dados . . . . . . . . . . . . . 103

7 Conclusões $\quad 105$

7.1 Trabalhos futuros . . . . . . . . . . . . . . . . . 106

7.2 Contribuições originais . . . . . . . . . . . . . . . . . . 107

7.3 Publicações . . . . . . . . . . . . . . . . . . . . . . . 108

$\begin{array}{ll}\text { A Dados do experimento } & 109\end{array}$

B Configuração do PostgreSQL 113

C Códigos utilizados no experimento $\quad 115$

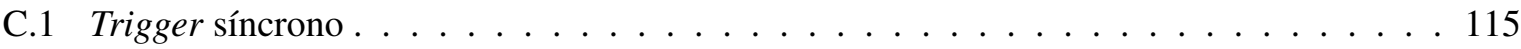

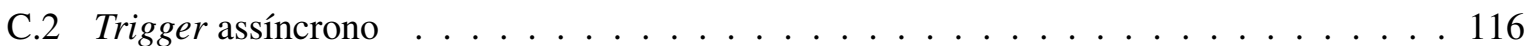

C.3 Processo de replicação . . . . . . . . . . . . . . . . . . . . . . . . . . . 119

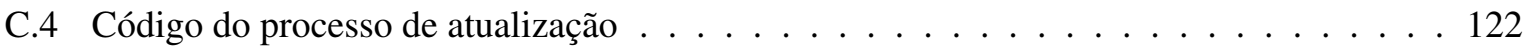

C.5 Código do processo de atualização, ambiente isolado . . . . . . . . . . . . . . . . . . 124

$\begin{array}{ll}\text { Referências Bibliográficas } & 127\end{array}$ 


\section{Lista de Figuras}

2.1 Linha do tempo de uma refatoração $\ldots \ldots \ldots \ldots$

2.2 Exemplo da refatoração Dividir tabela . . . . . . . . . . . . . . . . . . . . 10

3.1 Refatoração estrutural eliminar coluna . . . . . . . . . . . . . . . . . . 16

3.2 Refatoração estrutural eliminar tabela . . . . . . . . . . . . . . . . . . . . . . . . . . . . . . . . . . . . .

3.3 Refatoração estrutural eliminar visão . . . . . . . . . . . . . . . . . . . . . . . 18

3.4 Refatoração estrutural introduzir coluna calculada . . . . . . . . . . . . . . . . . 19

3.5 Refatoração estrutural introduzir chave de identificação . . . . . . . . . . . . . . . . 20

3.6 Refatoração estrutural unir colunas . . . . . . . . . . . . . . . . . . . . . . . 21

3.7 Refatoração estrutural unir tabelas . . . . . . . . . . . . . . . . . . . . . 22

3.8 Refatoração estrutural mover coluna . . . . . . . . . . . . . . . . . . . . . . . . 23

3.9 Refatoração estrutural renomear coluna . . . . . . . . . . . . . . . . . . . . . . . . . 24

3.10 Refatoração estrutural renomear tabela . . . . . . . . . . . . . . . . . . . . 25

3.11 Refatoração estrutural renomear visão . . . . . . . . . . . . . . . . . . . . . 26

3.12 Refatoração estrutural trocar coluna complexa por tabela . . . . . . . . . . . . . . . . 27

3.13 Refatoração estrutural trocar coluna . . . . . . . . . . . . . . . . . . . . 28

3.14 Refatoração estrutural trocar um-para-muitos por tabela associativa . . . . . . . . . . . 29

3.15 Refatoração estrutural trocar chave de identificação por chave natural . . . . . . . . . . 30

3.16 Refatoração estrutural dividir coluna . . . . . . . . . . . . . . . . . . . . . . . . 31

3.17 Refatoração estrutural dividir tabela . . . . . . . . . . . . . . . . . . . . 32

3.18 Refatoração qualidade dos dados adicionar tabela descritiva . . . . . . . . . . . . . 34

3.19 Refatoração qualidade dos dados introduzir restrição de coluna . . . . . . . . . . . . . . 35

3.20 Refatoração qualidade dos dados introduzir valor padrão . . . . . . . . . . . . . 36

3.21 Refatoração qualidade dos dados remover valor padrão . . . . . . . . . . . . . . . . . . 37

3.22 Refatoração qualidade dos dados alterar coluna para não nula . . . . . . . . . . . . . 38

3.23 Refatoração qualidade dos dados remover restrição de não nulo . . . . . . . . . . . . . . 39

3.24 Refatoração qualidade dos dados introduzir formato comum . . . . . . . . . . . . . . . 40

3.25 Refatoração qualidade dos dados aplicar código padrão . . . . . . . . . . . . . . . . . 41 
3.26 Refatoração qualidade dos dados aplicar tipo padrão . . . . . . . . . . . . . . . . 42

3.27 Refatoração qualidade dos dados remover restrição de coluna . . . . . . . . . . . . . 43

3.28 Refatoração qualidade dos dados mover dados . . . . . . . . . . . . . . . . . . . . 44

3.29 Refatoração qualidade dos dados consolidar estratégia de chaves . . . . . . . . . . . . 45

3.30 Refatoração trocar código de tipo por propriedades sinalizadoras . . . . . . . . . . . . 46

3.31 Refatoração de integridade adicionar restrição de chave estrangeira . . . . . . . . . . . 48

3.32 Refatoração de integridade introduzir exclusão em cascata . . . . . . . . . . . . . . . 49

3.33 Refatoração de integridade introduzir exclusão lógica . . . . . . . . . . . . . . . . . 50

3.34 Refatoração de integridade remover restrição de chave estrangeira . . . . . . . . . . . . 51

3.35 Refatoração de integridade introduzir exclusão física . . . . . . . . . . . . . . . . . 52

3.36 Refatoração de integridade adicionar trigger para coluna calculada . . . . . . . . . 53

3.37 Refatoração de integridade adicionar trigger para histórico . . . . . . . . . . . . . . 54

3.38 Refatoração arquitetural adicionar métodos CRUD . . . . . . . . . . . . . . . 56

3.39 Refatoração arquitetural encapsular tabela com uma visão . . . . . . . . . . . . . . . 57

3.40 Refatoração arquitetural introduzir método para cálculo . . . . . . . . . . . . . . 58

3.41 Refatoração arquitetural introduzir tabela espelho . . . . . . . . . . . . . . . . . . 59

3.42 Refatoração arquitetural adicionar método de leitura . . . . . . . . . . . . . . . 60

3.43 Refatoração arquitetural introduzir índice . . . . . . . . . . . . . . . . . . . . 61

3.44 Refatoração arquitetural trocar método por visão . . . . . . . . . . . . . . . . . . . 62

3.45 Refatoração arquitetural trocar visão por método . . . . . . . . . . . . . . . 63

3.46 Refatoração arquitetural usar fonte de dados oficial . . . . . . . . . . . . . . . . . . . 64

3.47 Refatoração migrar método de banco de dados . . . . . . . . . . . . . . . . . . . 65

3.48 Refatoração migrar método para banco de dados . . . . . . . . . . . . . . . . . . 66

3.49 Refatoração introduzir tabela somente leitura . . . . . . . . . . . . . . . . . . . 67

4.1 Etapa de coleta de informações de transações . . . . . . . . . . . . . . . . . . . 69

4.2 Informações armazenadas das transações . . . . . . . . . . . . . . . . . . 70

4.3 Etapa de mapeamento . . . . . . . . . . . . . . . . . . 71

4.4 Etapa de execução da replicação . . . . . . . . . . . . . . . . . . . 72

4.5 Página inicial do DEM . . . . . . . . . . . . . . . . . . . 75

4.6 Página de Trigger do DEM . . . . . . . . . . . . . . . . . . . 76

4.7 Página de Maps do DEM . . . . . . . . . . . . . . . . . . . . . . . . 79

4.8 Página de jobs do DEM . . . . . . . . . . . . . . . . . . . . 80

5.1 Tabela de encontros do projeto Borboleta $\ldots \ldots \ldots \ldots$

5.2 Máquina do experimento . . . . . . . . . . . . . . . 85

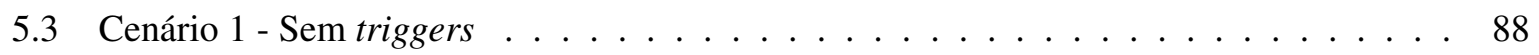




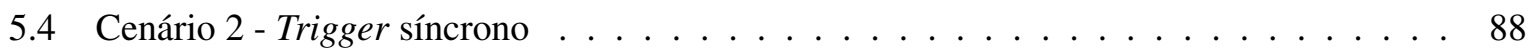

5.5 Cenário 3 - Trigger assíncrono . . . . . . . . . . . . . . . . . . . . 89

5.6 Desempenho (vazão) por nível de concorrência . . . . . . . . . . . . . . . . . 93

5.7 Evolução da taxa de operações que bloqueiam por nível de concorrência . . . . . . . . . 94

5.8 Desempenho (vazão) por nível de concorrência (ambiente isolado) . . . . . . . . . . . 95

5.9 Evolução da duração do processamento por nível de concorrência . . . . . . . . . . . . 96

5.10 Evolução do tempo de fila por nível de concorrência . . . . . . . . . . . . . . . . . 97

6.1 Protocolo de replicação postergada de dados . . . . . . . . . . . . . . . . . . 101 


\section{Lista de Tabelas}

3.1 Grupos de refatorações $\ldots \ldots \ldots \ldots \ldots \ldots$

3.2 Refatorações estruturais . . . . . . . . . . . . . . . . . . . . 15

3.3 Refatorações de qualidade de dados . . . . . . . . . . . . . . . . . . . . 33

3.4 Refatorações de integridade referencial . . . . . . . . . . . . . . . . . . . . 47

3.5 Refatorações arquiteturais . . . . . . . . . . . . . . . . 55

5.1 Parâmetros do exemplo de execução do experimento . . . . . . . . . . . . . . . 90

5.2 Níveis de concorrência . . . . . . . . . . . . . . . . . . . . . . . 91

5.3 Parâmetros de carga do sistema . . . . . . . . . . . . . . . . . . . 92

5.4 Níveis de cobertura para uma tabela de 2000 linhas . . . . . . . . . . . . . . . . 92

5.5 Operações por segundo . . . . . . . . . . . . . . . . . . . . . . 93

5.6 Taxa de operações que bloqueiam . . . . . . . . . . . . . . . . . . . . . 94

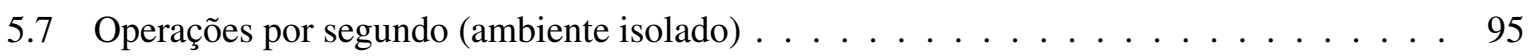

5.8 Duração do processamento . . . . . . . . . . . . . . . . . . . 96

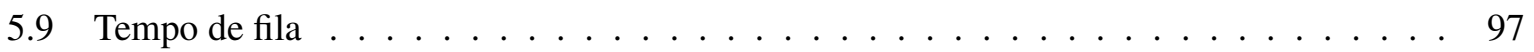

A.1 Cenário 1 - Sem trigger - Operações por segundo - Figura 5.6 . . . . . . . . . . . . . 109

A.2 Cenário 2 - Trigger síncrono - Operações por segundo - Figura 5.6 . . . . . . . . . . . 109

A.3 Cenário 3 - Trigger assíncrono - Operações por segundo - Figura 5.6 . . . . . . . . . . 110

A.4 Cenário 1 - Sem trigger - Taxa de operações que bloqueiam - Figura 5.7 . . . . . . . . 110

A.5 Cenário 2 - Trigger síncrono - Taxa de operações que bloqueiam - Figura 5.7 . . . . 110

A.6 Cenário 3 - Trigger assíncrono - Taxa de operações que bloqueiam - Figura 5.7 . . . . 110

A.7 Cenário 1 - Sem Trigger - Operações por segundo - Ambiente isolado - Figura 5.8 . . . . 110

A.8 Cenário 2 - Trigger síncrono - Operações por segundo - Ambiente isolado - Figura 5.8 . 111

A.9 Cenário 3 - Trigger assíncrono - Operações por segundo - Ambiente isolado - Figura 5.8111

A.10 Duração do processamento - Figura $5.9 \ldots \ldots \ldots \ldots$. . . . . . . . . . . . . . . . . . . .

A.11 Tempo de fila - Figura $5.10 \ldots \ldots \ldots \ldots \ldots \ldots$ 


\section{Listagem de código}

4.1 Objetos temporários para o trigger coletor . . . . . . . . . . . . . . . 77

4.2 Código exemplo do trigger coletor para a tabela de pacientes . . . . . . . . . . . 78

B.1 Arquivo postgresql.conf . . . . . . . . . . . . . . . . 113

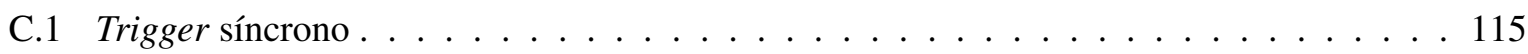

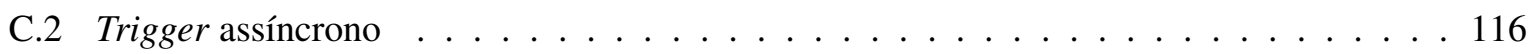

C.3 Processo de replicação . . . . . . . . . . . . . . . . . . . . . . . . 119

C.4 Processo de atualização . . . . . . . . . . . . . . . . . . . . . 122

C.5 Processo de atualização, ambiente isolado . . . . . . . . . . . . . . . . . . 124 


\section{Capítulo 1}

\section{Introdução}

A realização da modelagem conceitual, lógica e física, completa e detalhada do banco de dados antes de se iniciar a implementação da aplicação, conforme Elmasri [EN06] pág. 59, tem se mostrado ineficiente para tratar a complexidade do domínio da aplicação e a velocidade das mudanças dos requisitos de negócio. A alternativa é usar a modelagem evolutiva [Amb02], um processo iterativo e incremental, para a criação do modelo de dados de um domínio de negócio. Porém, essa forma de trabalho gera a necessidade de evolução do banco de dados [Amb03,Fow03, OS89], pois, a cada iteração da modelagem, existem dados importantes em produção que devem ser preservados. A evolução do banco de dados deve levar em conta essa herança e permitir que alterações controladas e organizadas no modelo de dados sejam possíveis.

Existem trabalhos que tratam de evolução de esquemas [BdBC01], não se preocupando com os dados já existentes no banco e outros que se preocupam com a evolução das aplicações que utilizam esses bancos [HH06]. Quando o banco de dados é orientado a objetos, podemos recorrer a uma extensa literatura [RS05, RB06]. Entretanto, trabalhos na área de evolução de banco de dados relacionais são raros. Uma exceção é o livro Refactoring Databases: Evolutionary Database Design [AS06], que abordou evolução de banco de dados relacionais utilizando técnicas de métodos ágeis.

\subsection{Motivação}

O desafio de evoluir um banco de dados incrementalmente é muito grande quando esse banco é utilizado simultaneamente por várias aplicações. Em geral, cada aplicação traz dificuldades distintas e seus desenvolvedores necessitarão de tempos diferentes para realizar as adaptações previstas. Esse desafio é importante porque é frequente que tais dificuldades provoquem o "congelamento" do modelo de dados de muitas aplicações - não se altera um banco de dados com o receio de prejudicar as aplicações que utilizam esse banco. A consequência desse congelamento é um banco de dados obsoleto, incapaz de atender às demandas de um domínio de negócio dinâmico, em constante evolução. 
Quando não há um congelamento do modelo do banco de dados, o que se observa é uma prática de acumular todas as alterações no banco de dados para serem realizadas em um data em que todas as aplicações já foram alteradas e podem passar a usar o novo banco de dados. Como é uma grande mudança e todas as aplicações entrarão simultaneamente em produção, é comum que o uso do banco de dados seja interrompido por um longo período na data da mudança e que, nesta data, haja um grande esforço de testes e validação para certificar se tudo está funcionando corretamente. Dependendo da criticidade do ambiente, se apenas uma aplicação falhar nesses testes, todo o ambiente deve voltar ao estado anterior à mudança. Repetindo essas tentantivas várias vezes, é possível ter uma ideia da demora para se fazer uma grande alteração no banco de dados.

Os métodos ágeis de desenvolvimento de software surgiram como uma alternativa aos métodos tradicionais. A situação descrita acima, em que todas as alterações são acumuladas e se gasta um longo período para que todas as aplicações utilizem um novo esquema de banco de dados, está muito próxima às técnicas defendidas pelos métodos tradicionais e muito longe dos ciclos rápidos e modelagem evolutiva presentes em métodos ágeis.

A solução atual em Metódos Ágeis de Desenvolvimento de Software [Coc06] para evolução de banco de dados, proposta por Scott Ambler, utiliza refatorações - pequenas alterações para melhorar a estrutura interna sem acrescentar funcionalidade nova [AS06]. O processo ágil de realizar uma refatoração de banco de dados exige, para que não seja preciso esperar que todas as aplicações estejam adaptadas a essa refatoração, a definição de um período de transição. Nesse período, o esquema novo e o antigo coexistem, permitindo que as aplicações já adaptadas e aquelas ainda em manutenção funcionem simultaneamente no mesmo banco de dados. O trabalho adicional de manter os dados dos dois esquemas (o novo e o antigo) atualizados é feito, na solução proposta por Ambler, por um processo síncrono de replicação de dados utilizando triggers [EN06].

No entanto, esse processo síncrono de atualização dos esquemas apresenta várias dificuldades: é necessário escrever o código dos triggers, evitar o disparo circular de uma sequência de triggers de forma a não criar impasses (deadlocks), previnir o aumento do tempo de resposta das transações devido ao trabalho adicional de replicação de dados e realizar o tratamento de erros. Todas essas dificuldades restrigem a prática de evolução de banco de dados e motivou o desenvolvimento de um novo processo de replicação de dados para refatorações. A solução proposta é a replicação assíncrona durante o período de transição.

\subsection{Solução proposta}

O código de apoio, na forma de triggers síncronos, foi dividindo em três etapas: coleta de informações de transações, mapeamento e execução. A primeira etapa é realizada por um trigger bastante simples e genérico, denominado trigger coletor. O único objetivo desse trigger é capturar todas as informações de uma transação e armazená-las em uma tabela temporária. A segunda etapa é responsável 
em definir a origem e o destino das informações armazenadas. Por último, a etapa de execução, consome as informações armazenadas, lê o mapeamento definido na segunda etapa e, finalmente, reproduz a transação na tabela destino, alvo da replicação de dados.

A solução proposta recebeu o nome de replicação assíncrona porque a atualização da tabela destino é postergada até a etapa de execução. Após a etapa de coleta, a aplicação que estiver atualizando a tabela origem não participa mais da replicação. Situação totalmente diferente se compararmos com a replicação síncrona proposta por Ambler.

\subsection{Objetivos}

O principal objetivo desta tese é auxiliar a evolução de bancos de dados que são utilizados por um grande número de aplicativos em uma arquitetura complexa e com um alto nível de concorrência de acesso ao banco. Para alcançar esse objetivo, desenvolvemos um processo que resolve os problemas atuais decorrentes da utilização de triggers síncronos. Para validar esse processo, implementamos uma ferramenta que mostra a viabilidade dessa nova forma de trabalho e realizamos experimentos para avaliar o desempenho desse processo.

$\mathrm{Na}$ busca em atingir o objetivo principal, revisamos, organizamos e resumimos o catálogo de refatorações de banco de dados proposto por Ambler para auxiliar os administradores que iniciam um trabalho em um banco que nunca passou por refatorações. Nessa situação, a orientação sobre uma possível ordem de execução das refatorações possui um valor considerável. Entretanto, conforme a experiência dos administradores em executar refatorações vai aumentando, o catálogo revisado será útil para permitir uma consulta rápida aos principais pontos que se deve ter atenção para executar uma refatoração.

A ferramenta e o catálogo tem em comum o direcionamento de promover atividades de evolução de banco de dados, de modo que essas atividades se tornem menos complexas para os administradores.

\subsection{Organização da tese}

O Capítulo 2 descreve a evolução de bancos de dados, métodos ágeis e refatoração de bancos de dados, finalizando com um exemplo de refatoração e as limitações da solução atual. Todas as refatorações do catálogo propostas por Ambler estão descritas no Capítulo 3.

A solução proposta e o protótipo de uma ferramenta são descritos no Capítulo 4. Em seguida, apresentamos todas as informações e os resultados do experimento para validação da replicação assíncrona (Capítulo 5). Para finalizar, descrevemos os trabalhos relacionados (Capítulo 6) e nossas conclusões (Capítulo 7). 


\section{Capítulo 2}

\section{Evolução de bancos de dados}

Em ambientes de desenvolvimento tradicionais de bancos de dados, em que não é utilizada uma metodologia ágil, o processo é composto por várias etapas preliminares que são longas e exigem um trabalho meticuloso para representar o máximo de entendimento do domínio nos modelos conceitual, lógico e físico. Somente quando o modelo conceitual foi amplamente discutido, aceito e validado, é que se pode começar o desenvolvimento do modelo lógico. O mesmo ocorre na transição do modelo lógico para o físico. Somente após a implementação do modelo físico, os desenvolvedores começam a escrever as primeiras linhas de código que acessam o banco de dados, possibilitando a escrita e a leitura de dados pela aplicação. Quando a aplicação estiver pronta, os usuários poderão confirmar se os requisitos de negócio foram atendidos.

Quando há necessidade de alguma modificação no modelo de dados, considera-se, frequentemente, que houve uma falha em uma etapa realizada do processo. Por exemplo, se a modelagem conceitual não representou corretamente o domínio após uma exaustiva análise dos requisitos, é porque a etapa anterior, a da coleta, foi equivocada por não capturar alguma necessidade do negócio. O mesmo raciocínio ocorre para as etapas de modelagem lógica e física. Desse modo, quando ocorre alguma modificação, deve-se alterar toda a documentação de todas as etapas para que o domínio esteja corretamente representado [TLN05].

Esse método de trabalho não considera dois fatores importantes que as metodologias ágeis ressaltam: a complexidade do domínio da aplicação e a velocidade das mudanças nos requisitos de negócio. O reconhecimento da complexidade do domínio e de sua constante evolução nos orienta a modelar não todo o negócio, mas somente uma parte do domínio: aquela que possibilite a implementação dos requisitos que trarão maior valor ao cliente. A velocidade das mudanças justifica uma modelagem evolutiva para capturar inicialmente os conceitos essenciais do domínio e, conforme as necessidades do cliente surjam, expandir a modelagem para outros conceitos [Amb02]. Utilizando essa forma de trabalho, os métodos ágeis são capazes de se adaptar às mudanças mais rapidamente do que os métodos tradicionais.

A modelagem evolutiva cria a necessidade de gerenciar corretamente a evolução do banco de dados. 
Logo após a entrada em produção do banco de dados, os usuários começam a armazenar e atualizar os dados do seu negócio. A partir desse momento, para cada evolução nesse banco, é necessário tratar os dados existentes. Neste trabalho, denominamos esse processo de evolução do banco de dados, ou seja, melhorias, modificações e correções nos modelos conceitual, lógico e físico que preservam os dados existentes. Chamamos um banco de dados que é desenvolvido dessa forma de banco de dados evolutivo.

Por outro lado, quando as alterações são muito extensas, por exemplo, aquelas que alteram mais de $50 \%$ do modelo de dados, temos uma migração de banco de dados; nesse caso é frequentemente gerado um novo modelo e os dados do antigo são migrados para o novo, realizando-se as conversões possíveis, conforme trabalhos nessa área [BLW ${ }^{+}$97,LFST08]. A modelagem evolutiva - devido à sua característica incremental, em pequenos passos - nunca provocará uma migração. Desse modo, não trataremos, neste trabalho, de migrações de dados, mas somente de evolução de banco de dados.

Apesar de existirem diversos desafios para a evolução de bancos de dados, como por exemplo, o desenvolvimento de banco de dados orientado a testes [Ou03], neste trabalho nos concentraremos somente no desafio de realizar alterações em bancos utilizados por várias aplicações, cada uma delas com equipes distintas de desenvolvedores e, possivelmente, utilizando diferentes tecnologias de acesso a esse banco. As equipes de desenvolvedores necessitarão de tempos diferentes para realizar as adaptações necessárias nas aplicações quando uma evolução do banco de dados ocorrer. Para tratar desse desafio, iremos, inicialmente, descrever alguns pontos relevantes de métodos ágeis.

\subsection{Métodos ágeis}

Existem vários métodos de desenvolvimento de software considerados ágeis, tais como Programação Extrema [BA04], Scrum [SB01], Crystal [Coc04] etc. Todos esses métodos buscam minimizar os riscos do desenvolvimento de software, definindo ciclos rápidos de entrega com um escopo reduzido. Dentro do ciclo, com duração de poucos meses, usa-se iterações de uma a quatro semanas para disponibilizar o software ao cliente, para que ele o avalie e possa verificar o progresso do projeto por meio de produtos concretos (as versões incrementais do software). Dentro da iteração, tarefas de desenvolvimento são quebradas com duração de um a três dias. Finalmente, as funcionalidades de maior prioridade - normalmente aquelas que trarão maior valor ao negócio do cliente - são desenvolvidas primeiro. Se houver alguma mudança nos requisitos, as funcionalidades menos importantes podem ser postergadas para que as novas funcionalidades sejam desenvolvidas.

Uma iteração inclui todas as atividades necessárias para desenvolver uma nova funcionalidade: planejamento, prospecção e análise de requisitos, modelagem, codificação, teste e documentação. Após cada iteração, a avaliação do sofware pelo cliente fornece valiosa informação para a modelagem evolutiva de todo o software, incluindo a modelagem do banco de dados.

Para melhorar a qualidade do código-fonte, antes do início do desenvolvimento de uma nova funcionalidade, é usada uma técnica imprescindível para métodos ágeis, a refatoração. Essa técnica consiste 
em reestruturar o código-fonte existente, alterando sua estrutura interna sem mudar o seu comportamento externo [ $\left.\mathrm{FBB}^{+} 99\right]$. Fowler et al. caracterizam refatoração como uma série de pequenas transformações que preservam comportamento. Cada transformação faz uma pequena modificação, mas uma sequência dessas transformações pode produzir uma reestruturação significativa do sistema. A estratégia presente nessa forma de alterar o código-fonte é minimizar os efeitos colaterais de qualquer alteração, evitando a introdução de erros no funcionamento do software.

As técnicas de refatoração de código-fonte em Engenharia de Software, principalmente no contexto de linguagens orientadas a objetos, são amplamente difundidas entre as boas equipes de desenvolvimeto de software. Existe uma grande quantidade de ferramentas de apoio à automatização desse processo, o catálogo de refatorações é bem definido e ele foi testado em várias linguagens e ambientes de programação. Por outro lado, as refatorações de bancos de dados enfrentam várias limitações e carecem de ferramentas que auxiliem o trabalho do administrador do banco. Na próxima seção, discutiremos os problemas encontrados atualmente em refatoração de banco de dados.

\subsection{Refatoração de banco de dados}

Por analogia com a definição de refatoração de código [FBB ${ }^{+99}$ ], poderíamos definir refatoração de banco de dados como uma técnica para reestruturar os objetos de um banco, antes de implementar uma nova funcionalidade, alterando o modelo de dados sem afetar o seu comportamento externo. No entanto, a definição mencionada é problemática, pois precisaríamos estabelecer o que é um comportamento externo de um banco de dados. Para resolver o problema em questão, usamos, no lugar de comportamento externo, o conceito de semântica informacional [AS06]. Ambler define semântica informacional como o significado das informações do banco de dados a partir do ponto de vista dos usuários dessas informações. Preservar a semântica informacional obriga que os clientes de uma informação não sejam afetados por qualquer que seja a alteração dos valores dos dados armazenados em um banco.

Um exemplo de refatoração, em um banco de dados com informações de saúde, é dividir uma coluna que contém o nome completo do paciente, gerando duas novas colunas: nome e sobrenome, considerando que a coluna original tenha somente essas duas informações. Os usuários não serão afetados por essa refatoração se existir o cuidado em juntar os dados dessas duas colunas alterando o código das aplicações ou utilizando uma visão do banco de dados.

Refatorar um banco de dados é mais trabalhoso do que refatorar um código-fonte, pois devemos nos preocupar com as diversas aplicações que acessam o banco de dados e com os extratores de dados que estão acoplados. Além disso, é necessário realizar transformações ou reorganizações dos dados existentes antes da refatoração, enquanto que o código-fonte antigo é simplesmente descartado quando uma nova versão está disponível. Ao refatorar um código-fonte, o programador está modificando um código que não está sendo executado; ele pode editar o código, recompilá-lo, testá-lo e implantá-lo novamente em produção com relativa facilidade. Já no caso de bancos de dados, estamos refatorando algo que está 
em produção, muitas vezes com dados sensíveis e estratégicos que não podem ser perdidos em hipótese alguma. É como remodelar um avião em pleno voo.

A estratégia de refatoração defendida por Ambler é direcionada para ambientes complexos nos quais existem várias aplicações acessando o mesmo banco de dados. Quando esse banco é refatorado, todas as aplicações precisam sofrer algum tipo de modificação. Considerando que cada aplicação pode utilizar linguagens e tecnologias distintas e possuir uma equipe de desenvolvedores para a manutenção, não é possível supor que todas essas aplicações serão alteradas e implantadas no mesmo momento. Por esse motivo, Ambler considera imprescindível um período de transição que permita a coexistência dos esquemas antigo e novo do banco de dados.

Um outro motivo para a existência desse período de transição é a busca de agilidade nas refatorações. Não devemos esperar que todas as aplicações se adaptem antes de realizarmos uma refatoração quando já temos alguma aplicação pronta para se beneficiar dela, mesmo porque pode demorar meses ou até anos para que todas as aplicações sejam adaptadas. Na próxima seção, detalharemos o período de transição e o código de apoio necessário para que os esquemas novos e antigos coexistam.

\subsection{Período de transição e código de apoio}

O período de transição, em que os esquemas novo e antigo do banco de dados coexistem, exige um código de apoio para manter os dois esquemas sincronizados. No caso mais simples - quando as alterações dos dados ocorrem somente no esquema novo e o antigo é utilizado para consultas - temos um código de apoio que deve replicar todas as alterações do modelo novo para o antigo. Desse modo, o código de apoio permite que as aplicações não sejam afetadas pela existência de dois esquemas - elas sempre acessam os dados atualizados. A Figura 2.1 mostra, na linha do tempo, o período de transição.

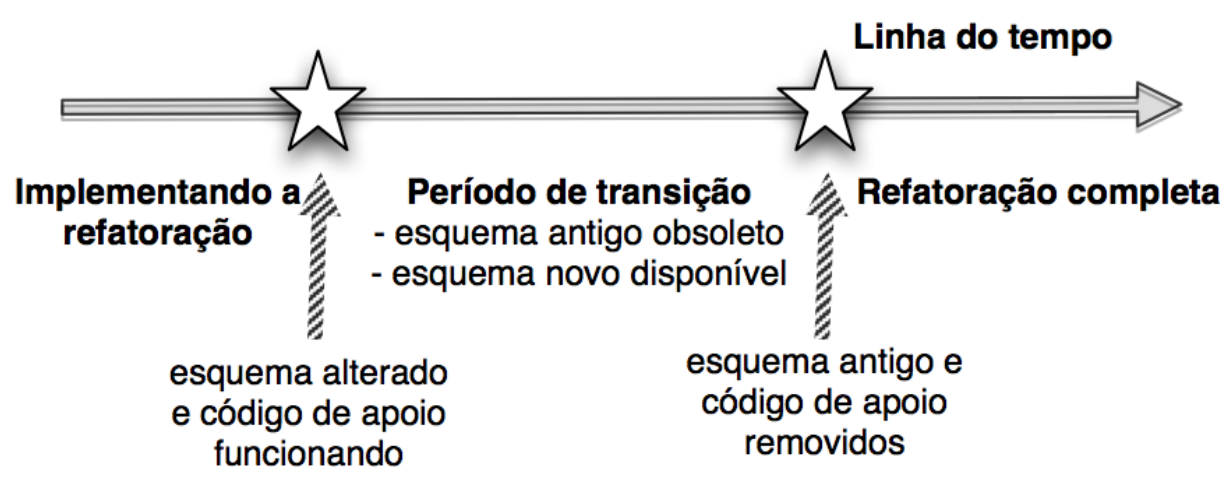

Figura 2.1: Linha do tempo de uma refatoração

Ao final do período de transição, quando todas as aplicações que acessam o banco de dados se adaptaram ao esquema novo, o esquema antigo e o código de apoio são eliminados. Por ser um código 
que será usado somente no período de transição, é de se esperar que esse código seja fácil, simples e rápido de escrever.

Dependendo do contexto do ambiente de desenvolvimento, da equipe de programadores e da cultura da empresa, o período de transição pode durar um dia, um mês ou até um ano. Independente da duração do período de transição, no final da refatoração o código de apoio sempre será descartado.

Ambler propõe três estratégias para manter os dados atualizados e duas delas são alternativas para o código de apoio: triggers e processos em lote. A terceira estratégia, visão, tem uso restrito a poucos casos, mas quando é utilizada não existe a necessidade de sincronizar dados entre modelos. Considerando as três estratégias, Ambler afirma: "Nossa experiência é que triggers é a melhor alternativa para a vasta maioria das situações" (pág. 63 do seu livro [AS06]).

O código do trigger é acoplado a uma tabela e é disparado a cada transação executada. O banco de dados executa o código, passando para o trigger todas as informações da transação: qual operação foi executada, os dados antigos da linha alterada, os dados novos etc. Em posse dessas informações, é possível atualizar todas as tabelas necessárias para manter a sincronização dos dados.

$\mathrm{Na}$ segunda alternativa, um processo em lote (batch) percorre toda a tabela origem para descobrir o que foi alterado e acrescentado, comparando com a tabela destino. No momento em que alguma diferença entre as tabelas é encontrada, é feita a atualização da tabela destino para manter a sincronização dos dados. Esse processo é lento devido à necessidade de se percorrer frequentemente todas as linhas das tabelas envolvidas na sincronização. Em tabelas com milhões de linhas, esse problema fica muito mais evidente.

A lentidão do processo em lote pode provocar a lentidão de transações que concorrem para terem acesso às mesmas tabelas envolvidas na sincronização. Por esse motivo, é comum que esse tipo de processo seja executado somente no período noturno, para evitar a concorrência de acesso. O problema é maior quando o banco de dados tem grande utilização durante o dia todo, mesmo no período noturno.

Como já apresentado, Ambler afirma que a melhor alternativa é o uso de triggers, mas a forma que propõe para escrevê-los apresenta vários problemas. Antes de abordarmos os problemas, descreveremos um exemplo de refatoração de banco de dados no formato proposto por Ambler.

\subsection{Exemplo de refatoração: Dividir tabela}

Para descrever um exemplo de refatoração, usaremos uma simplificação da modelagem do banco de dados do Projeto Borboleta [DCK ${ }^{+} 08$ ], que envolve um sistema de gerenciamento de centros de saúde do SUS (Sistema Único de Saúde brasileiro). Esse banco serve de fundamento para um sistema integrado de prontuário eletrônico para serviços de atenção primária à saúde. A modelagem, realizada de forma evolutiva, preocupou-se primeiramente com o cadastro de pacientes de um centro de saúde.

Considerando o contexto de modelagem evolutiva, temos uma tabela de pacientes que contém todos os atributos que gostaríamos de capturar no momento do cadastro: nome, profissão, salário e um 
indicador informando se ele paga ou não aluguel. Antes de começar uma iteração, percebemos que seria apropriado agrupar os dados socioeconômicos em uma tabela separada. A partir dessa constatação, decidimos fazer a refatoração Dividir tabela. A Figura 2.2 mostra os esquemas da refatoração.

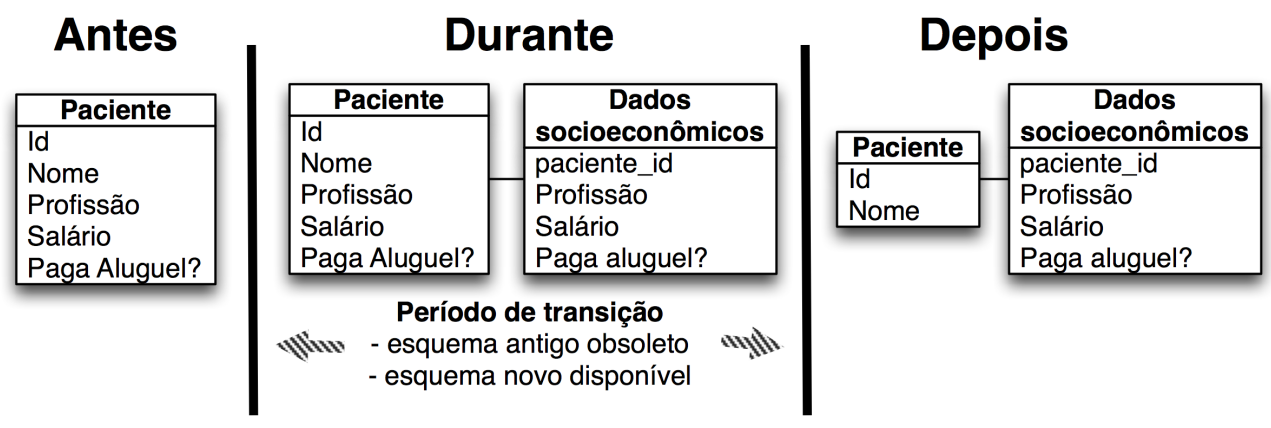

Figura 2.2: Exemplo da refatoração Dividir tabela

Durante o período de transição, mantivemos os atributos que originaram a tabela Dados socioeconômicos na tabela Paciente. Também desenvolvemos dois triggers, um em cada tabela, para que os dados ficassem sincronizados. Com esses cuidados, todas as aplicações continuam funcionando normalmente durante a refatoração.

Dividir tabela é uma refatoração muito utilizada quando fazemos modelagem evolutiva. Inicialmente, a tabela de pacientes tinha somente o nome e a profissão. Na iteração seguinte, recebeu os outros atributos (salário e o indicador de se ele paga aluguel). Antes da próxima iteração, uma tabela contendo os atributos de dados socioeconômicos começou a fazer sentido.

\subsection{Limitações na utilização de triggers}

A utilização de triggers como código de apoio, conforme proposto por Ambler, apresenta as seguintes limitações:

1. Codificação específica: é necessário escrever um trigger diferente para cada refatoração que precisa de replicação de dados. Para a mesma refatoração, se mudarem as tabelas envolvidas, também há necessidade de implementar um código diferente. Assim, temos uma codificação específica, não genérica, para cada refatoração e para cada tabela envolvida em replicação de dados.

2. Código de tratamento de ciclos: para cada trigger criado, deve-se verificar se existe a possibilidade de ocorrer ciclos; isto é, se um trigger poderá disparar, por meio de uma sequência de triggers, a si próprio novamente criando um ciclo. Se houver a possibilidade, é necessário escrever um código adicional para evitar o problema. 
3. Transação lenta: quando a aplicação realiza uma transação em uma tabela que possui uma sequência de triggers, a transação só será finalizada após a execução do último trigger. Caso algum desses triggers seja lento ou bloqueado ao tentar acessar algum recurso com alta concorrência, a transação da aplicação terá um aumento no seu tempo de resposta.

4. Possível erro desconhecido para a aplicação: a aplicação não sabe da existência das sequências de triggers do código de apoio. Desse modo, se algum trigger da sequência terminar com erro, a transação iniciada pela aplicação será abortada. O pior é que a aplicação, devido ao seu desconhecimento do código de apoio, pode não tratar corretamente o erro para que o usuário saiba o que está ocorrendo.

Considerando o exemplo da Seção 2.4, constatamos que as dificuldades apresentadas realmente ocorrem. Precisamos realizar uma codificação específica para a refatoração Dividir tabela, pois dois triggers serão necessários, um na tabela de pacientes para capturar as alterações relevantes (aquelas que envolvem os atributos profissão, salário e pagamento de aluguel), outro na tabela de dados socioeconômicos. Cada trigger deve levar os dados alterados para a outra tabela que faz parte da refatoração.

Além disso, teremos de nos preocupar com o ciclo: o trigger da tabela de pacientes atualiza a tabela de dados socioeconômicos, que, por sua vez, tem um trigger que altera a tabela de pacientes novamente. Esta situação ocorre quando temos duas aplicações atualizando a profissão do paciente durante o período de transição. Uma aplicação atualizando a tabela de pacientes, esquema antigo, e outra atualizando a tabela dados socioeconômicos, novo esquema.

O código dos triggers que trata do ciclo deve, pelo menos, verificar se os dados que se pretende alterar são diferentes dos dados coletados da transação. Um exemplo de verificação de ciclos ocorre, quando, para um certo paciente, se altera a profissão: o trigger da tabela de pacientes deve verificar se a profissão da tabela de dados socioeconômicos é diferente. Caso a profissão seja igual, pode ter ocorrido um ciclo e, consequentemente, não se deve alterar a tabela de dados socioeconômicos.

$\mathrm{O}$ administrador de banco de dados, que criou um trigger para realizar a replicação de dados, é a única pessoa que poderá resolver um possível erro desse código. Entretanto, o trigger proposto por Ambler, devolverá um erro para a aplicação. Em uma arquitetura complexa, essa aplicação poderá não tratar corretamente o erro e o usuário final será informado incorretamente que ocorreu um erro e não saberá como resolvê-lo.

Considerando o que foi apresentado, a solução baseada em triggers na forma proposta por Ambler apresenta vários problemas para a realização de refatorações em banco de dados. Podemos agrupar as dificuldades em dois grandes grupos: dificuldades de codificação e interferência no funcionamento normal das aplicações. Antes de apresentar, no Capítulo 4, a proposta desta tese para minimizar essas dificuldades, iremos, no próximo capítulo, descrever o catálogo de refatorações de banco de dados. 


\section{Capítulo 3}

\section{Refatorações de banco de dados}

As refatorações de banco de dados são organizadas, segundo Ambler [AS06], em quatro grupos: estrutural, qualidade de dados, integridade referencial e arquitetural. Descreveremos, nas próximas seções, todas as refatorações do livro de Ambler, usando exemplos do projeto Borboleta [ $\mathrm{DCK}^{+} 08$ ]. Essas descrições não abordam detalhes de execução das refatorações que podem ser obtidas no livro de Sadalage [Sad07]. A análise detalhada das refatorações permitiu separar quais precisam de replicação de dados no período de transição. Existem muitas refatorações em que nem o período de transição é especificado, outras têm o período, mas não têm a replicação de dados. A Tabela 3.1 descreve, para cada grupo de refatorações, quantas existem (Qtde. total) e quantas possuem replicação de dados (Qtde. replicação).

\begin{tabular}{|l|l|r|r|}
\hline Seção & Refatorações & Qtde. total & Qtde. replicação \\
\hline 3.1 & Estrutural & 17 & 12 \\
\hline 3.2 & Qualidade de dados & 13 & 3 \\
\hline 3.3 & Integridade referencial & 7 & 0 \\
\hline 3.4 & Arquitetural & 12 & 0 \\
\hline Total & & 49 & 15 \\
\hline
\end{tabular}

Tabela 3.1: Grupos de refatorações

Podemos verificar que, das 49 refatorações apresentadas por Ambler, somente 15 têm replicação de dados, o que representa por volta de $30 \%$ do total. Apesar de não serem a maioria das refatorações, essas provocam as maiores dificuldades para o administrador de banco de dados. Por isso, em cada seção, tabulamos as refatorações com replicação e colocamos, no tíulo de cada uma, um alerta sobre essa característica.

A descrição de cada refatoração é organizada pelas seguintes partes:

- Motivação: descreve o funcionamento básico da refatoração e as principais vantagens.

- Avaliação: expõe alguns pontos que devem ser avaliados para verificar se a refatoração pode ser realizada e se é realmente útil. Apesar de a avaliação ser uma orientação geral, os administradores 
de banco de dados devem, no mínimo, analisá-la. Conforme a experiência com as situações específicas do seu ambiente, os administradores possivelmente acrescentarão outros pontos de avaliação.

- Esquema: orienta os passos para as possíveis alterações do esquema do banco de dados. Descreve o que deve ser feito durante o período de transição e as ações para finalizar a refatoração. As principais atividades do administrador de banco de dados para realizar uma refatoração estão nesta seção. Não descrevemos os comandos específicos para realizar as alterações dos esquemas, pois consideramos que o administrador tem esse conhecimento ou pode encontrá-lo facilmente na documentação do gerenciador de banco de dados utilizado.

- Dados: esta seção descreve com o que é necessário se preocupar caso a refatoração tenha de alterar os dados já existentes ou gerar novos a partir dos antigos, para começar o período de transição. Novamente não informamos detalhadamente cada comando para o administrador de banco de dados.

- Aplicativo: as atividades de uma refatoração demandam alterações dos aplicativos que acessam o banco de dados refatorado. Descrevemos as orientações gerais para os aplicativos se adaptarem a uma refatoração, mas os desenvolvedores devem ser capazes de tomar os cuidados necessários ao realizar as alterações específicas para cada linguagem ou tecnologia usada nos aplicativos.

- Exemplo: utilizamos o projeto Borboleta $\left[\mathrm{DCK}^{+} 08\right]$ em todos os exemplos das refatorações. As entidades e relacionamentos utilizados fazem parte do domínio de uma aplicação da área de saúde pública. Esta seção não faz parte da organização de uma refatoração apresentada por Ambler, mas foi acrescentada devido à necessidade de explicar um caso prático de realização da refatoração, facilitando o seu entendimento.

No início de um grupo de refatorações, apresentamos uma classificação que servirá para aconselhar uma ordem de execução delas. É importante ressaltar que essas orientações estão fundamentadas na experiência de desenvolvimento e manutenção do projeto Borboleta. Apesar de não termos realizado um trabalho de validação dessas orientações para vários projetos, acreditamos que elas poderão ser úteis para os administradores de banco de dados que estão iniciando um trabalho e não têm ideia de por onde começar neste catálogo.

As contribuições originais deste capítulo em relação ao livro do Ambler [AS06] são as seções de exemplo, a forma resumida de uma página por refatoração, as sugestões de ordem de execução das refatorações e por último o alerta, no nome da refatoração, se há a necessidade de replicação de dados.

Neste ponto do texto, o leitor pode tomar 2 caminhos: aqueles que quiserem se aprofundar poderão ler todas as refatorações deste capítulo. Por outro lado, quem quiser ter apenas uma noção do assunto, poderá ler a primeira página de cada grupo de refatorações, a conclusão do capítulo (totalizando 5 páginas das Seções 3.1 até Seção 3.4, para os grupos de refatorações e a conclusão na Seção 3.5) e prosseguir a leitura no Capítulo 4. 


\subsection{Estrutural}

As refatorações estruturais têm como objetivo melhorar o esquema do banco de dados, realizando limpezas, padronizações, organizações e alterações das colunas, tabelas e visões. Na Tabela 3.2, podemos visualizar qual a seção da refatoração, se possui replicação de dados e a sua classificação, que é útil para organizar uma ordem de execução das refatorações.

\begin{tabular}{|l|l|l|l|}
\hline Seção & Refatoração & $\begin{array}{l}\text { Replicação } \\
\text { de dados }\end{array}$ & Classificação \\
\hline 3.1 .1 & Eliminar coluna & Não & Limpeza \\
\hline 3.1 .2 & Eliminar tabela & Não & Limpeza \\
\hline 3.1 .3 & Eliminar visão & Não & Limpeza \\
\hline 3.1 .4 & Introduzir coluna calculada & Não & Lógica no banco de dados \\
\hline 3.1 .5 & Introduzir chave de identificação & Sim & Padronização \\
\hline 3.1 .6 & Unir colunas & Sim & Melhorar a estrutura \\
\hline 3.1 .7 & Unir tabelas & Sim & Melhorar a estrutura \\
\hline 3.1 .8 & Mover coluna & Sim & Melhorar a estrutura \\
\hline 3.1 .9 & Renomear coluna & Sim & Organização \\
\hline 3.1 .10 & Renomear tabela & Sim & Organização \\
\hline 3.1 .11 & Renomear visão & Não & Organização \\
\hline 3.1 .12 & Trocar coluna complexa por tabela & Sim & Melhorar a estrutura \\
\hline 3.1 .13 & Trocar coluna & Sim & Melhorar a estrutura \\
\hline 3.1 .14 & Trocar um-para-muitos por tabela associativa & Sim & Melhorar a estrutura \\
\hline 3.1 .15 & Trocar chave de identificação por chave natural & Sim & Padronização \\
\hline 3.1 .16 & Dividir coluna & Sim & Melhorar a estrutura \\
\hline 3.1 .17 & Dividir tabela & Sim & Melhorar a estrutura \\
\hline
\end{tabular}

Tabela 3.2: Refatorações estruturais

Dentre as refatorações estruturais, podemos aconselhar, considerando a nossa experiência, a seguinte ordem para facilitar o trabalho do administrador para melhorar o banco de dados:

1. Limpeza: é o primeiro passo para trabalhar com o banco de dados.

2. Organização: o trabalho de renomear colunas, tabelas e visões trará benefícios para o entendimento do modelo de dados e evitará documentação desnecessária.

3. Padronização: facilitará o entendimento do modelo de dados.

4. Melhorar a estrutura: neste ponto é possível melhorar a estrutura do banco.

5. Lógica no banco de dados: início de um trabalho de tirar algumas regras dos aplicativos e colocar no banco de dados. O trabalho completo, com esse objetivo, são as refatorações arquiteturais, expostas na Seção 3.4 . 


\subsubsection{Eliminar coluna}

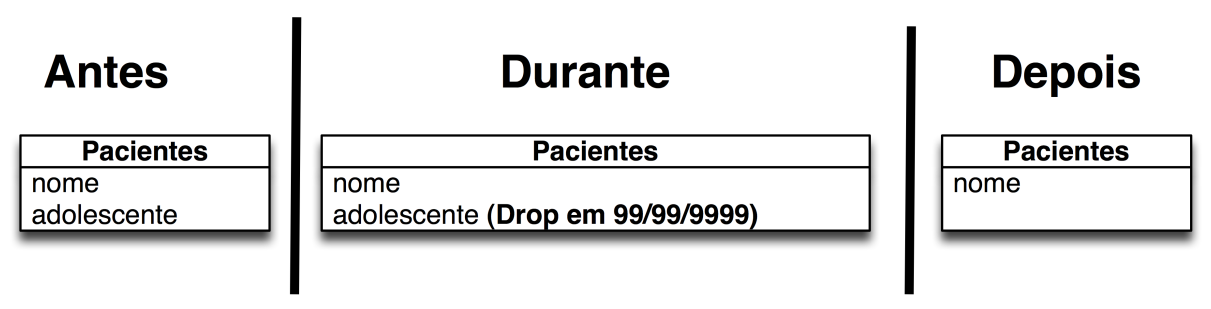

Figura 3.1: Refatoração estrutural eliminar coluna

Motivação - Em um banco de dados, após evoluções, poderá existir alguma tabela com uma coluna que não é mais utilizada. Nessa situação é muito importante eliminar a coluna para limpar o modelo de dados e evitar o seu uso inadequado. Esta refatoração pode ser um dos passos da refatoração mover coluna.

Avaliação - É necessário avaliar, antes de eliminar a coluna, o que fazer com os dados existentes. Uma segunda avaliação é verificar a possibilidade de lentidão na execução do comando para eliminar uma coluna. Uma causa provável da lentidão é a quantidade de linhas da tabela.

Esquema - Durante o período de transição, deve-se alertar todos os desenvolvedores de que a coluna será eliminada. Pode ser útil renomear a coluna para verificar se realmente não ocorrerão problemas para as aplicações após sua eliminação. Para finalizar a refatoração é necessário: remover a coluna de chaves estrangeiras, das visões e dos índices e, depois, eliminar a coluna da tabela.

Dados - Caso seja necessário preservar os dados da coluna, deve-se armazená-los em outro esquema.

Aplicativo - Remover todas as referências a essa coluna nos aplicativos.

Exemplo - A tabela Pacientes tem uma coluna adolescente, que não é mais utilizada. Durante o período de transição, temos somente um alerta sobre a data em que a coluna será eliminada. Após a refatoração, a tabela Pacientes estará limpa. 


\subsubsection{Eliminar tabela}

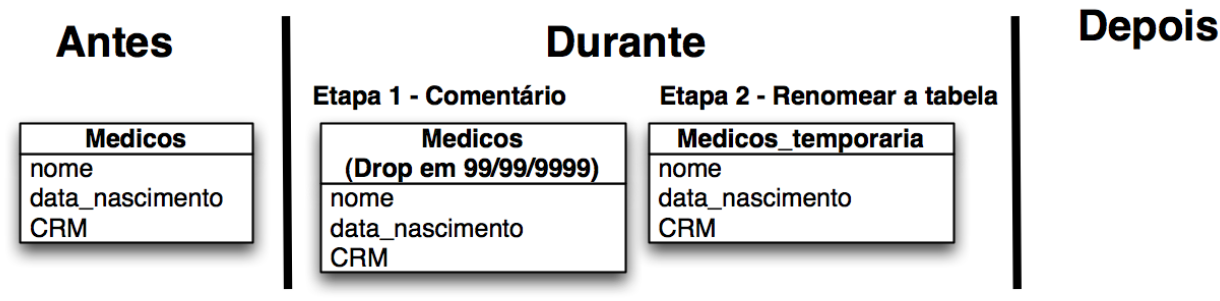

Figura 3.2: Refatoração estrutural eliminar tabela

Motivação - Quando uma tabela não é mais utilizada, é necessário eliminar essa tabela para limpar o esquema do banco e evitar possíveis erros de consulta em dados desatualizados.

Avaliação - Deve-se avaliar se os dados existentes na tabela que será eliminada podem ser importantes para consultas futuras.

Esquema - Durante o período de transição, deve-se alertar os desenvolvedores de que a tabela será removida. Um pouco antes do término da refatoração, é aconselhável renomear a tabela para verificar se todas as aplicações já se adaptaram. Para finalizar, deve-se remover as referências à tabela que será eliminada em chave estrangeira e visões. Por último, remover a tabela.

Dados - Se, durante a avaliação, foi verificada a necessidade de preservar os dados da tabela, deve-se armazená-los em outro esquema de banco de dados.

Aplicativo - Remover todas as referências à tabela no código dos aplicativos.

Exemplo - A tabela Medicos não será mais utilizada porque foi criada a tabela Pessoas, que é mais genérica e conterá todas as informações dos médicos. Durante o período de transição, alertamos os desenvolvedores sobre a data em que a tabela será eliminada. No final do período, trocamos o nome da tabela para o nome Medicos_temporaria. Com essa estratégia, confirmamos que todos os aplicativos foram adaptados para não utilizar mais a tabela Medicos. Desse modo, eliminamos a tabela com segurança e finalizamos a refatoração. 


\subsubsection{Eliminar visão}

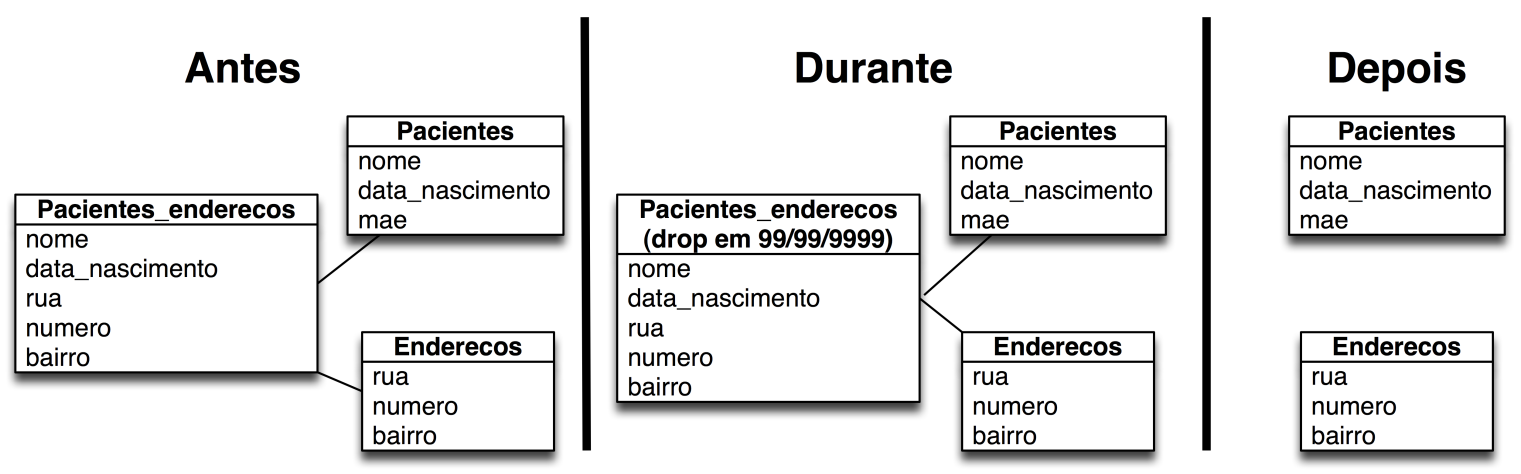

Figura 3.3: Refatoração estrutural eliminar visão

Motivação - Uma visão permite acesso aos dados de uma ou mais tabelas. Quando é necessário o acesso direto às tabelas, a visão geralmente não é mais utilizada e, consequentemente, deve ser eliminada.

Avaliação - Quando um aplicativo não usar mais uma visão, ele terá acesso a tabelas a que, possivelmente, não tinha permissão. Deve-se avaliar se o novo acesso viola alguma regra de segurança.

Esquema - Durante o período de transição, alerte os desenvolvedores sobre a eliminação da visão. Para finalizar a refatoração, é necessário remover todas as referências à visão antes de eliminá-la.

Dados - Esta refatoração é de baixo risco, pois a visão não contém nenhum dado de tabelas, mas somente a definição da consulta a elas. O que se deve guardar é a definição da visão em um arquivo temporário. Se houver algum problema, basta executar novamente a criação da visão.

Aplicativo - Todas as referências à visão existentes nos aplicativos devem ser eliminadas.

Exemplo - A visão Pacientes_enderecos não é mais utilizada, uma vez que não mostra todas as linhas da tabela Enderecos, mas somente as mais recentes. Neste exemplo, os aplicativos precisam do acesso direto à tabela para consultar todas as linhas. Deve-se somente alertar quando a visão será removida e, após esse trabalho, fornecer as permissões necessárias para os aplicativos utilizarem a tabela Enderecos. 


\subsubsection{Introduzir coluna calculada}

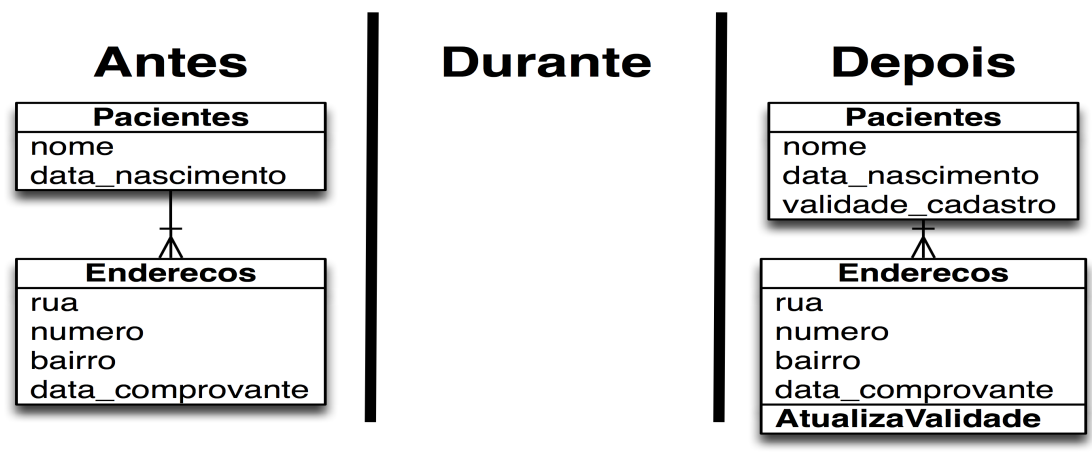

Figura 3.4: Refatoração estrutural introduzir coluna calculada

Motivação - É comum os aplicativos fazerem cálculos baseados somente nos valores das colunas de uma tabela. Nesse caso, o cálculo é repetido a cada consulta de uma linha da tabela. Introduzir uma coluna calculada é importante para evitar a repetição do cálculo e unificar a fórmula utilizada pelos vários aplicativos.

Avaliação - É necessário definir como será o código que fará o cálculo e armazenará o resultado na nova coluna. Basicamente existem duas opções: processo batch, que faz o cálculo para várias linhas com uma certa frequência, ou trigger, que realiza o cálculo no momento da atualização de uma linha.

Esquema - Esta refatoração não tem um período de transição, pois, somente é preciso incluir uma nova coluna na tabela para armazenar o resultado do cálculo e implementar o código de atualização da nova coluna (batch ou trigger).

Dados - Fazer o cálculo inicial para todas as linhas já existentes na tabela.

Aplicativo - Retirar dos aplicativos o método que fazia o cálculo antes da refatoração. No lugar desse método, os aplicativos devem consultar o valor da nova coluna.

Exemplo - O cadastro de um paciente tem uma validade que é calculada somando três anos à data do comprovante de endereço apresentado no centro de saúde. Os aplicativos, antes dessa refatoração, precisavam consultar a tabela de endereços, ler a coluna data_comprovante e fazer o cálculo da validade do cadastro. Com a refatoração e o trigger AtualizaValidade, basta agora consultar a nova coluna validade_cadastro. 


\subsubsection{Introduzir chave de identificação (replicação de dados)}
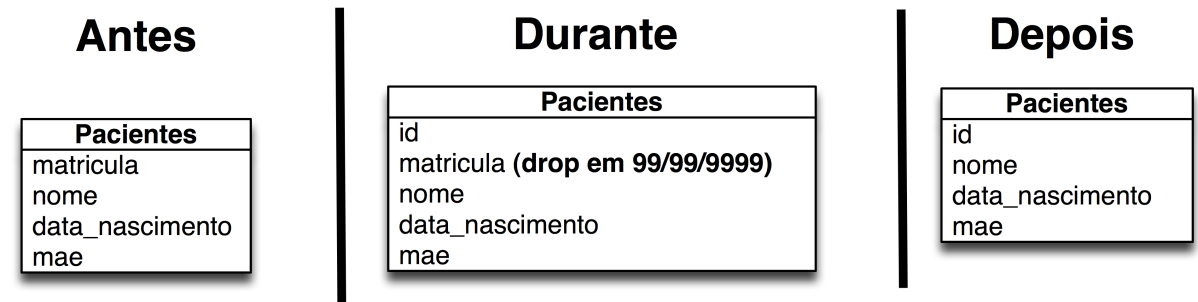

Figura 3.5: Refatoração estrutural introduzir chave de identificação

Motivação - Alguns arcabouços, como o Ruby on Rails, trazem grandes facilidades para realizar as operações básicas de inserção, exclusão, consulta e atualização. Por outro lado, exigem que a tabela tenha uma chave de identificação numérica autoincremental com o nome de id. Esta refatoração introduz uma chave de identificação com essa característica e retira a anterior, que é a chave natural.

Avaliação - Verificar se no domínio da aplicação é possível trocar uma chave natural por uma de identificação numérica incrementada pelo banco de dados. Esta refatoração poderá fazer parte de uma decisão estratégica de padronizar o nome e o tipo de chave.

Esquema - Durante o período de transição, é necessário incluir uma nova coluna, adicionar um novo índice para essa coluna, alertar que a chave original não será mais utilizada e, finalmente, escrever o código de apoio para manter as chaves sincronizadas. Para finalizar a refatoração, deve-se remover a chave antiga e desativar o código de apoio.

Dados - Após a inclusão da nova chave, deve-se gerar os valores para as linhas já existentes.

Aplicativo - Deve-se trocar todas as referências à chave antiga pela nova.

Exemplo - O cadastro de pacientes tinha uma chave chamada matricula. A refatoração troca essa chave por uma nova, chamada id. Durante o período de transição, é necessário fazer um código para manter a matrícula com valor válido. 


\subsubsection{Unir colunas (replicação de dados)}

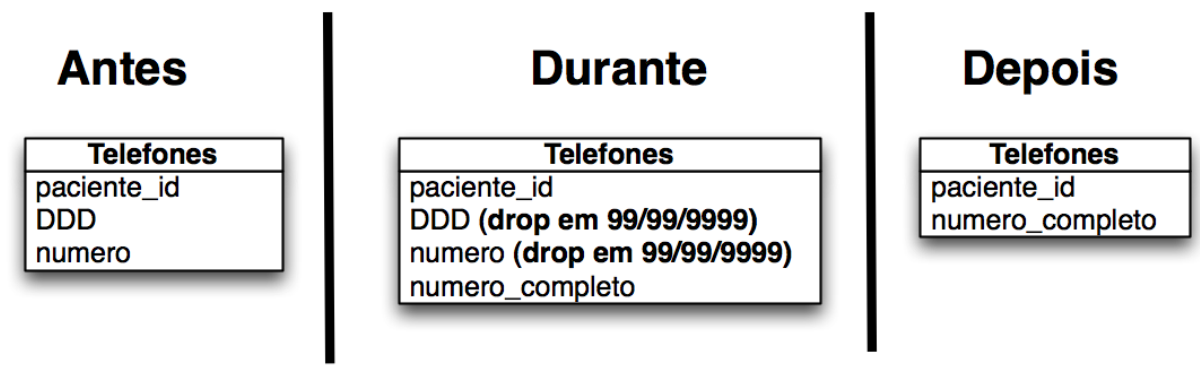

Figura 3.6: Refatoração estrutural unir colunas

Motivação - Durante a evolução do banco de dados, são criadas colunas que contêm valores complementares que nunca são utilizados isoladamente. Assim, a existência de duas colunas para armazenar os dados é desnecessária, motivando a realização da refatoração unir colunas.

Avaliação - Deve-se verificar se é necessário preservar os dados separados das duas colunas para futuro uso. Após a união das colunas, pode ser difícil a separação dos dados.

Esquema - Durante o período de transição, incluir uma nova coluna, escrever um código de apoio para manter as colunas (duas colunas antigas e a nova) atualizadas, alertar os desenvolvedores de que as colunas antigas serão removidas do banco de dados. Para finalizar a refatoração, deve-se remover as colunas antigas e o código de apoio.

Dados - Deve-se gerar os dados da nova coluna para todas as linhas existentes na tabela. Se for necessário, no final da refatoração, guardar os dados das colunas antigas em outro esquema de banco de dados.

Aplicativo - Trocar todas as referências às colunas antigas pela nova. Os aplicativos devem remover a parte do código que fazia a união das colunas. No caso dos aplicativos que trabalhavam com as colunas separadamente, deve-se verificar o impacto do aumento de tamanho da nova coluna.

Exemplo - Os telefones dos pacientes eram armazenados em duas colunas: ddd e numero. A refatoração criou uma coluna nova numero_completo, que é a união das duas colunas antigas. 


\subsubsection{Unir tabelas (replicação de dados)}

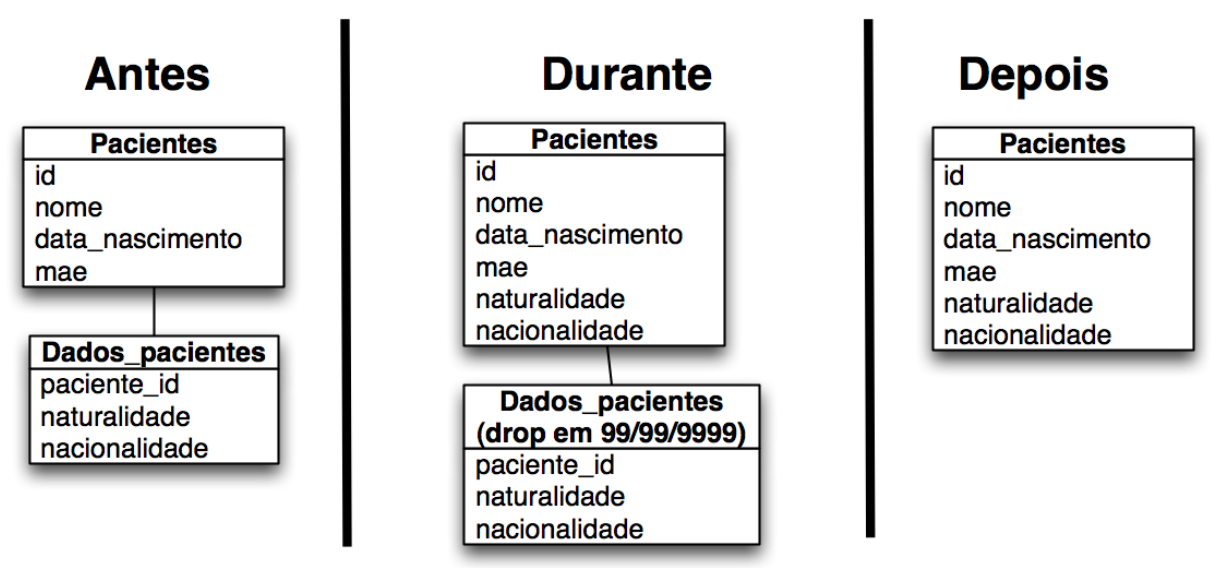

Figura 3.7: Refatoração estrutural unir tabelas

Motivação - Com várias equipes de desenvolvimento trabalhando no mesmo banco de dados, frequentemente ocorre a existência de duas tabelas para representar uma mesma entidade. Desse modo, as duas tabelas têm o mesmo uso e é aconselhável uni-las para melhorar o modelo do banco de dados.

Avaliação - Verificar se é necessário guardar os dados das tabelas antes da refatoração. Avaliar qual tabela terá todas as colunas após a refatoração. Se uma tabela tem maior quantidade de colunas e linhas, ela é uma boa candidata para conter as colunas da outra tabela. A tabela escolhida para receber as novas colunas chamaremos de tabela final.

Esquema - Durante o período de transição, devem-se criar as colunas na tabela final, escrever o código de apoio para manter as tabelas sincronizadas e alertar os desenvolvedores sobre qual tabela será removida. Para finalizar, elimine o código de apoio e a tabela que não é mais usada.

Dados - A tabela final irá receber todos os dados da tabela que será eliminada. Se necessário, guarde os dados da tabela que será removida em outro esquema de banco de dados.

Aplicativo - Retirar dos aplicativos todas as referências à tabela que será removida, trocando-as pelas referências à tabela final.

Exemplo - Foram criadas duas tabelas com dados de pacientes: Pacientes e Dados_pacientes. Para uni-las, foi escolhida a tabela Pacientes para conter todas as colunas. 


\subsubsection{Mover coluna (replicação de dados)}

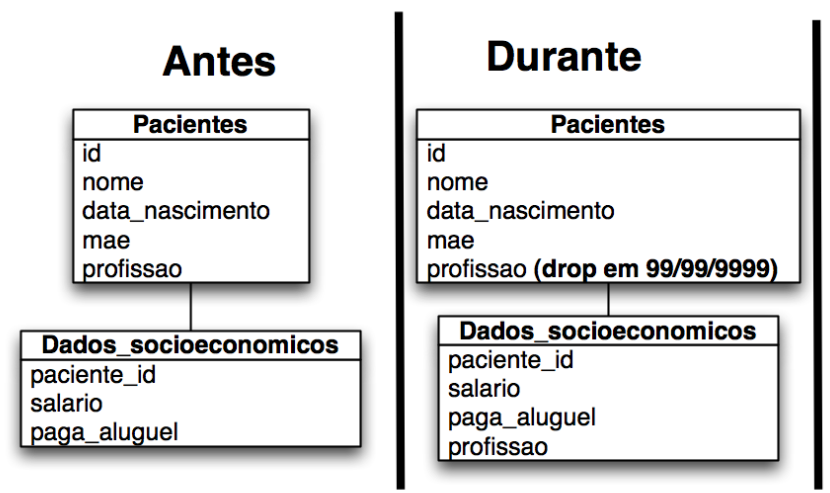

\section{Depois}

\begin{tabular}{|l|}
\hline \multicolumn{1}{|c|}{ Pacientes } \\
\hline $\begin{array}{l}\text { id } \\
\text { nome } \\
\text { data_nascimento } \\
\text { mae }\end{array}$ \\
\hline \\
Dados_socioeconomicos \\
paciente_id \\
salario \\
paga_aluguel \\
rofissao
\end{tabular}

Figura 3.8: Refatoração estrutural mover coluna

Motivação - A criação de uma nova tabela, devido à evolução de um banco de dados, pode provocar a movimentação de uma coluna de uma tabela antiga para a nova. A refatoração mover coluna faz essa reorganização, possibilitando que as tabelas tenham as colunas coerentes com os dados que estão armazenando.

Avaliação - É importante avaliar a consistência dos dados na tabela destino. Se, no destino, existir alguma coluna semelhante, deve-se, posteriormente, realizar a refatoração unir colunas.

Esquema - Durante o período de transição, escreva o código de apoio para manter os valores na tabela antiga, crie a nova coluna na tabela destino e alerte os desenvolvedores sobre qual coluna será removida. A refatoração é finalizada com a remoção do código de apoio e da antiga coluna.

Dados - A tabela que irá receber a coluna deverá ser atualizada com dados preexistentes.

Aplicativo - Todas as referências à coluna antiga devem ser trocadas para a nova. Os aplicativos possivelmente começarão a utilizar as duas tabelas devido à refatoração.

Exemplo - A coluna Profissão armazena um dado sobre a vida socioeconômica do paciente, mas essa coluna foi inicialmente criada na tabela Pacientes. Para resolver o problema, uma nova coluna profissao é criada na tabela Dados_socioeconomicos durante o período de transição. Para finalizar a refatoração, a coluna antiga é removida da tabela Pacientes. 


\subsubsection{Renomear coluna (replicação de dados)}

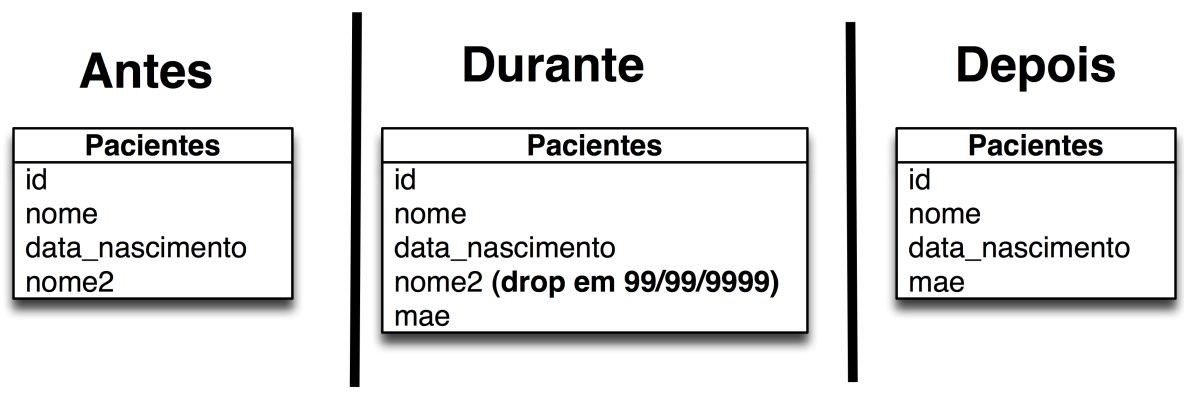

Figura 3.9: Refatoração estrutural renomear coluna

Motivação - É comum encontrar colunas com nomes estranhos e sem significado. O problema dificulta o entendimento do modelo de dados e a comunicação entre os desenvolvedores. Desse modo, é importante realizar a refatoração renomear coluna para organizar o banco de dados.

Avaliação - Verificar se os benefícios compensam o trabalho a ser feito, evitando renomear colunas utilizando nomes que sejam sinônimos.

Esquema - Durante o período de transição, é necessário incluir a nova coluna, escrever o código de apoio para manter o valor atualizado e alertar os desenvolvedores de que a coluna antiga será eliminada. Para finalizar, deve-se remover a coluna antiga e o código de apoio.

Dados - A nova coluna deve receber os dados da antiga coluna.

Aplicativo - Todos os aplicativos devem trocar o nome antigo pelo novo nome da coluna.

Exemplo - A tabela Pacientes tem a coluna nome2 que não tem nenhum significado aparente. Analisando o conteúdo, é verificado que o nome correto deve ser mae. A refatoração cria a nova coluna, alerta os desenvolvedores de que a coluna nome2 será removida e o resultado final é uma tabela com nomes de colunas de fácil entendimento. 


\subsubsection{Renomear tabela (replicação de dados)}

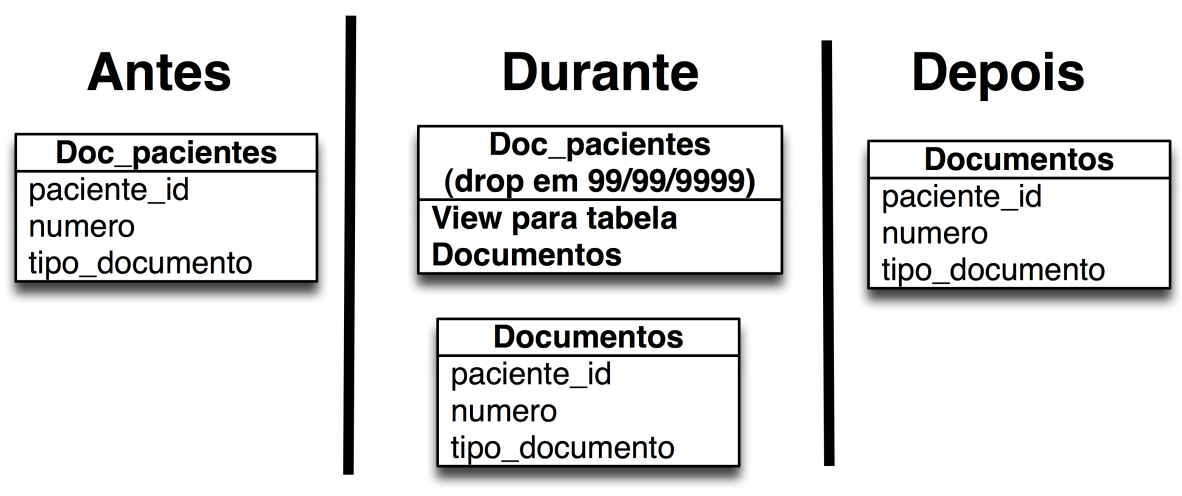

Figura 3.10: Refatoração estrutural renomear tabela

Motivação - A compreensão do modelo de dados fica muito mais fácil se os nomes das tabelas forem claros e autoexplicativos. O entendimento do modelo de dados é muito útil para um desenvolvimento ágil e na prevenção de erros de codificação.

Avaliação - Avaliar a possibilidade de usar uma visão atualizável ou sinônimo com o nome antigo no período de transição.

Esquema - No caso mais fácil, deve-se trocar o nome da tabela e criar uma visão ou sinônimo com o nome antigo. Quando não for possível usar visão ou sinônimos, deve-se criar uma nova tabela, alertar que a tabela antiga será renomeada e criar o código de apoio para manter os dados atualizados. Para finalizar a refatoração, é necessário remover o código de apoio e a tabela antiga. No caso mais simples, remover a visão ou o sinônimo.

Dados - No caso mais difícil, a nova tabela deve receber os dados da tabela antiga.

Aplicativo - Trocar as referências à tabela com o nome antigo pelo novo nome.

Exemplo - A tabela Doc_pacientes tem um nome ruim devido à abreviação e à composição com o nome pacientes que é redundante porque existe a chave estrangeira paciente_id na tabela. A tabela é renomeada para Documentos e uma visão com o nome antigo é criada durante o período de transição. 


\subsubsection{Renomear visão}

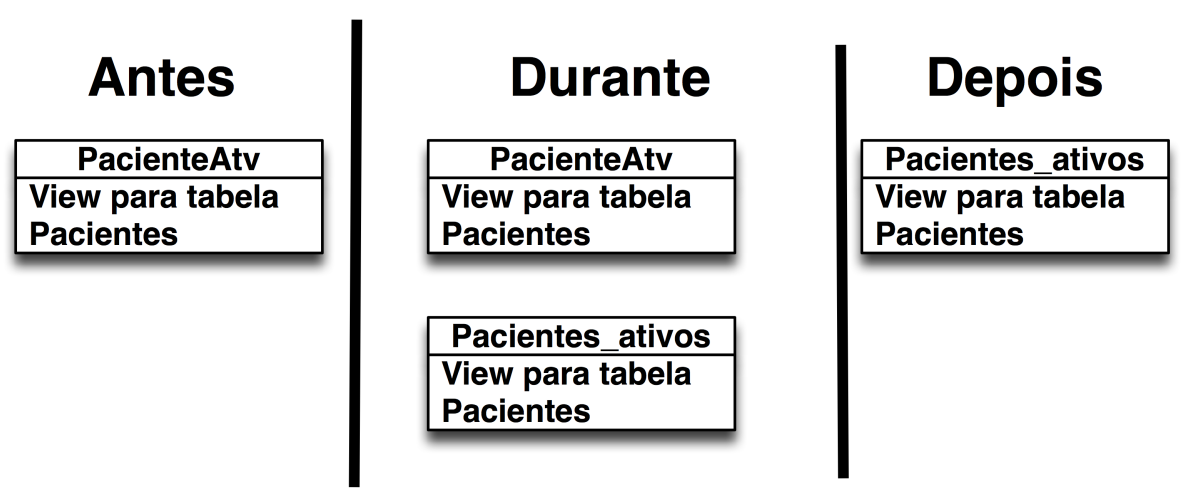

Figura 3.11: Refatoração estrutural renomear visão

Motivação - Para melhorar o entendimento do que faz a visão, é importante usar um bom nome e não usar abreviações. Esse tipo de cuidado irá melhorar o uso da visão e evitará documentação desnecessária para explicar algo simples que poderia ser entendido com um nome correto.

Avaliação - Como a visão não contém dados, é apenas uma definição de uma consulta a uma ou mais tabelas, a refatoração é fácil de implementar. O que se deve evitar é a troca de nomes devido a preferências, mas com o mesmo sentido.

Esquema - Para realizar a refatoração, basta criar uma nova visão, alertar os desenvolvedores de que a visão antiga será removida em uma certa data. Para finalizar, remover a visão antiga.

Dados - Não se aplica nenhum cuidado com os dados, pois estamos lidando somente com visões.

Aplicativo - Trocar todas as referências à visão antiga pela nova.

Exemplo - A visão PacienteAtv faz uma consulta à tabela de pacientes para selecionar somente os pacientes ativos. Os pacientes ativos são selecionados a partir de uma coluna chamada de status. O nome da visão foi abreviado e não ficou claro o que a visão faz. Para melhorar o entendimento, fizemos a refatoração renomear visão, trocando o nome da visão para Pacientes_ativos. 


\subsubsection{Trocar coluna complexa por tabela (replicação de dados)}

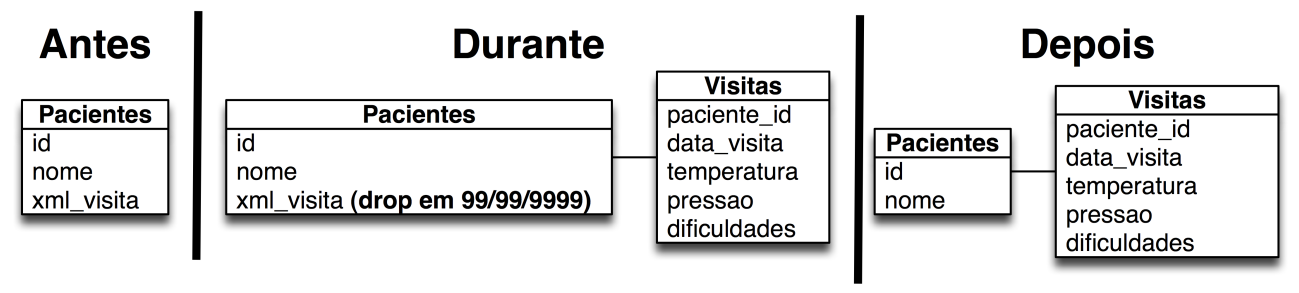

Figura 3.12: Refatoração estrutural trocar coluna complexa por tabela

Motivação - As colunas complexas, denominadas Large Object ( $L O B)$, facilitam o armazenamento de arquivos XMLs. Quando essa facilidade começa a ser superada pelas dificuldades de tratar partes de uma coluna complexa em uma consulta de banco de dados, é o momento de realizar a refatoração trocar coluna complexa por tabela.

Avaliação - Avaliar a necessidade de tratar partes da coluna complexa em consultas, pois a refatoração possivelmente exigirá maior processamento para as conversões de dados.

Esquema - Para trocar a coluna complexa é preciso criar uma tabela com as colunas necessárias, escrever o código de apoio para manter atualizada a nova tabela e alertar os desenvolvedores de que a coluna será eliminada. Para finalizar a refatoração, remover a coluna e o código de apoio.

Dados - Esta refatoração exige uma conversão dos dados da coluna complexa em uma tabela, pois é necessário carregar os dados já existentes. É interessante fazer um procedimento no banco de dados que receba um valor da coluna complexa e retorne o valor convertido em várias colunas simples. $\mathrm{O}$ procedimento poderá ser usado na carga inicial e no código de apoio durante o período de transição.

Aplicativo - Os aplicativos não devem usar a coluna complexa e começar a trabalhar com a nova tabela. O procedimento no banco de dados que faz a conversão para colunas simples pode ser útil para os aplicativos.

Exemplo - Os dados da visita ao paciente, coletados em dispositivos móveis, são exportados para o banco de dados em formato XML. A partir do momento em que foi necessário fazer consulta sobre a data da visita e outras colunas, fizemos essa refatoração, criando a tabela Visitas. 


\subsubsection{Trocar coluna (replicação de dados)}

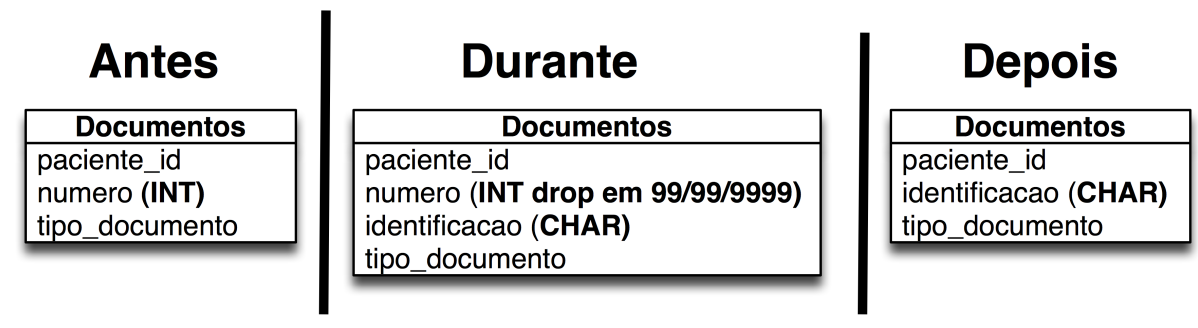

Figura 3.13: Refatoração estrutural trocar coluna

Motivação - Esta refatoração é usada para trocar o tipo de dado de uma coluna. Inicialmente, a coluna foi criada com um tipo de dado (inteiro, caractere ou lógico) e, conforme a evolução do banco de dados, foi necessário armazenar um outro tipo de dado.

Avaliação - Avaliar a possibilidade de perda de dados na conversão de tipos. O novo tipo de dado de uma coluna pode ser incompatível com o antigo, inviabilizando a refatoração.

Esquema - Para iniciar a refatoração, crie a nova coluna, alerte os desenvolvedores de que a antiga será eliminada e implemente o código de apoio para manter as colunas atualizadas. Para finalizar, remova o código de apoio e a coluna antiga.

Dados - É preciso carregar os valores existentes na nova coluna, fazendo as conversões necessárias.

Aplicativo - Deve-se trocar todas as referências à coluna antiga pela nova, verificando o tipo de dados das variáveis utilizadas.

Exemplo - A tabela Documentos guardava, inicialmente, o número do documento em uma coluna do tipo inteiro (numero). Durante o uso dos aplicativos, as opções de tipos de documento foram expandidas para contemplar documentos que têm uma identificação com caracteres e números. A refatoração criou uma nova coluna denominada identificação (identificacao), em que é possível armazenar caracteres. 


\subsubsection{Trocar um-para-muitos por tabela associativa (replicação de dados)}

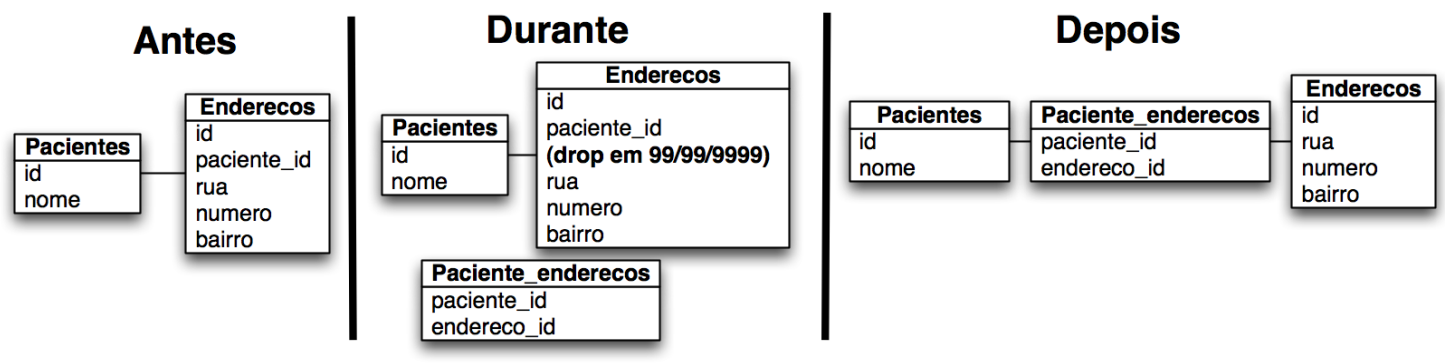

Figura 3.14: Refatoração estrutural trocar um-para-muitos por tabela associativa

Motivação - Em um relacionamento um-para-muitos, pode surgir a necessidade de evolução para um relacionamento muitos-para-muitos. Antes de modificar todos os aplicativos para trabalhar a nova forma de relacionamento, é possível usar uma tabela associativa para simular um-para-muitos. Quando todos os aplicativos estiverem utilizando a tabela associativa, será menos trabalhoso acrescentar a funcionalidade do relacionamento muitos-para-muitos.

Avaliação - Verificar o desempenho dos novos comandos SQL que terão mais trabalho para trazer os mesmos dados.

Esquema - Durante o período de transição, crie a tabela associativa, alerte os desenvolvedores para não utilizar a chave estrangeira que será removida e implemente o código de apoio para manter a tabela associativa atualizada. Para finalizar, remova o código de apoio e a chave estrangeira.

Dados - Carregue os dados dos relacionamentos já existentes na tabela associativa.

Aplicativo - Troque as referências à chave estrangeira pela tabela associativa. Nesse momento, os aplicativos ainda não devem trabalhar com o relacionamento muitos-para-muitos. Essa fase é somente uma adaptação para a utilização da tabela associativa para um relacionamento um-para-muitos.

Exemplo - O paciente tem muitos endereços no seu cadastro. O usuário do sistema solicitou que um endereço tivesse muitos pacientes para armazenar a localização de uma família. Antes de implementar a nova funcionalidade de famílias, a refatoração criou a tabela associativa Paciente_enderecos para manter os relacionamentos já existentes. 


\subsubsection{Trocar chave de identificação por chave natural (replicação de dados)}

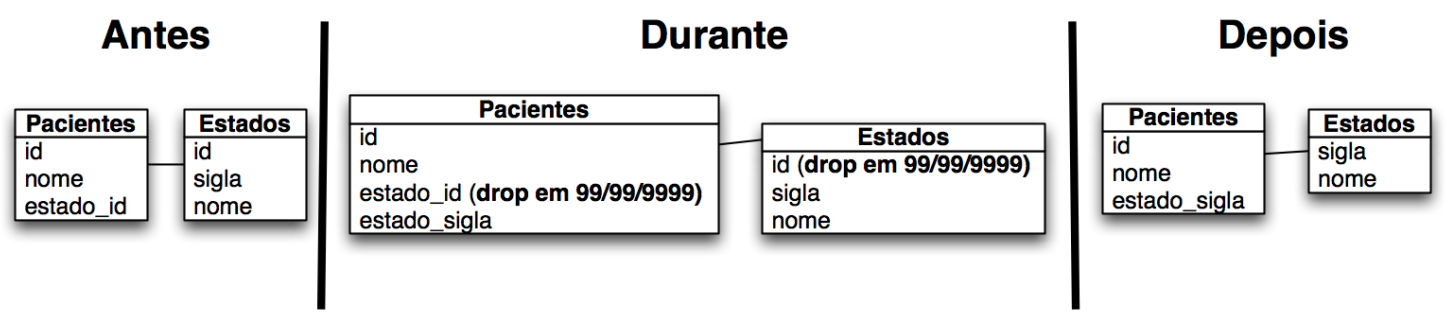

Figura 3.15: Refatoração estrutural trocar chave de identificação por chave natural

Motivação - Esta refatoração é o caminho inverso da refatoração introduzir chave de identificação, pois troca uma chave sequencial númerica por uma chave alfanumérica que tem significado para o domínio da aplicação, denominada chave natural. O uso da chave natural pode reduzir a sobrecarga do uso desnecessário de uma chave de identificação.

Avaliação - Verificar quais tabelas têm chaves estrangeiras para a tabela que será refatorada. A quantidade de chaves estrangeiras indicará o esforço necessário para realizar a refatoração.

Esquema - Consideramos que a chave natural já existe na tabela. Desse modo, essa refatoração irá, durante o período de transição, criar chaves estrangeiras usando a chave natural, alertará os desenvolvedores para começar a utilizar a nova chave e implementará o código de apoio para manter os dados atualizados. Para encerrar a refatoração, elimine o código de apoio, as chaves estrangeiras antigas e a chave de identificação substituída.

Dados - Carregue os valores corretos para os relacionamentos já existentes nas novas chaves estrangeiras.

Aplicativo - Os aplicativos devem ser alterados para trocar as referências às chaves antigas pela nova.

Exemplo - A tabela Pacientes armazena o estado da Federação em que o paciente nasceu. A tabela Estados tem a chave de identificação id e uma chave natural que é sigla. A refatoração irá remover a chave de identificação e a chave estrangeira estado_id. Uma nova coluna, estado_sigla, deve ser criada na tabela Pacientes para ser a chave estrangeira da tabela de estados da Federação. 


\subsubsection{Dividir coluna (replicação de dados)}

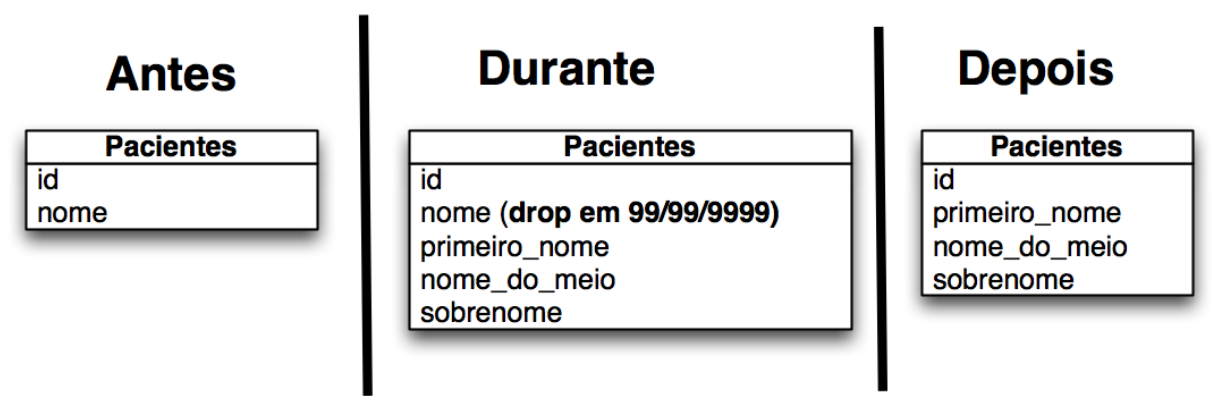

Figura 3.16: Refatoração estrutural dividir coluna

Motivação - A refatoração dividir coluna é o caminho inverso da refatoração unir colunas. Nesse caso, ocorre a necessidade de trabalhar com uma fração dos dados de uma coluna. Assim, é necessário a divisão da coluna para utilizar isoladamente uma parte dos seus dados.

Avaliação - Definir as regras de divisão da coluna: quais partes dos dados serão realmente utilizadas.

Esquema - Para iniciar a refatoração, adicione as novas colunas na tabela, alerte aos desenvolvedores qual coluna será removida e implemente o código de apoio para manter as colunas atualizadas. Para encerrar, remova a coluna que foi substituída pelas outras e desative o código de apoio.

Dados - É necessário carregar os dados nas novas colunas a partir dos valores já existentes na coluna que será eliminada.

Aplicativo - Os desenvolvedores devem trocar as referências à coluna antiga pelas novas colunas, fazendo a união, se for necessária.

Exemplo - A tabela Pacientes tem a coluna nome, que armazena o nome completo do paciente. Um requisito do usuário criou a necessidade de trabalhar com o nome do meio e o sobrenome do paciente. A refatoração dividir tabela foi utilizada para possibilitar a implementação do requisito. Novas colunas, primeiro_nome, nome_do_meio e sobrenome, foram criadas; e a coluna antiga, nome, foi removida. 


\subsubsection{Dividir tabela (replicação de dados)}

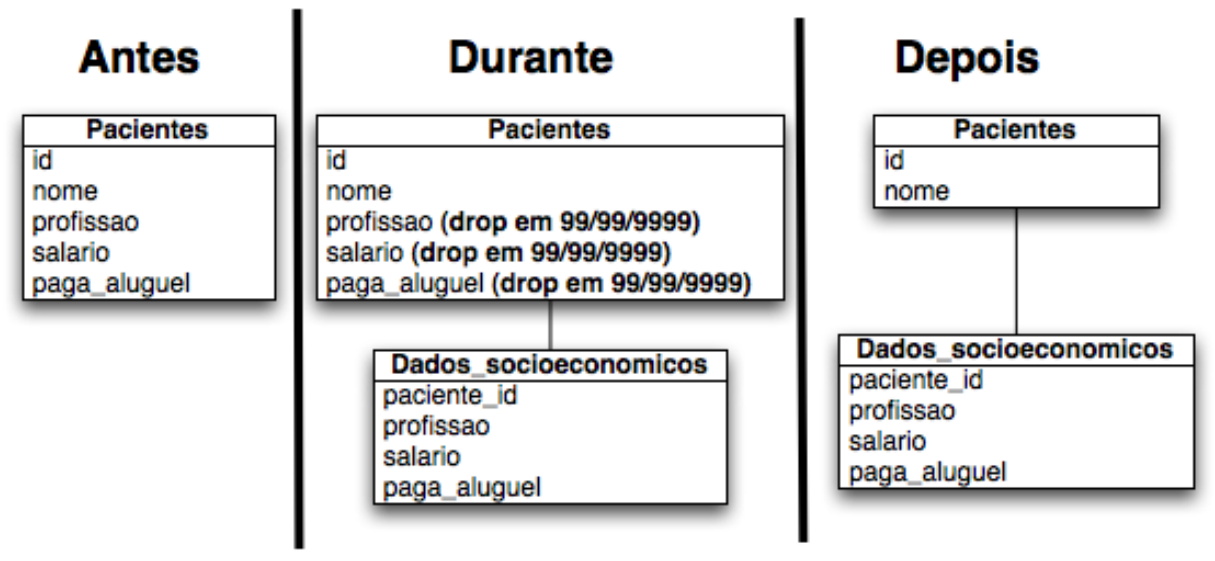

Figura 3.17: Refatoração estrutural dividir tabela

Motivação - A primeira motivação da refatoração dividir tabela é separar informações importantes das acessórias ou não obrigatórias. Para as informações importantes, podemos colocar um controle de acesso mais rígido. A segunda motivação é organizar as colunas em tabelas que fazem sentido no domínio da aplicação.

Avaliação - Avaliar e definir quais colunas devem sair ou ficar na tabela principal.

Esquema - No período de transição, é necessário criar a nova tabela, implementar o código de apoio para manter as tabelas atualizadas, alertar os desenvolvedores sobre quais colunas serão removidas da tabela principal e sobre o nome da tabela nova. Para finalizar, remova as colunas da tabela principal e o código de apoio.

Dados - Carregar a nova tabela com os valores já existentes na tabela principal.

Aplicativo - Trocar as referências às colunas da tabela principal pela nova tabela.

Exemplo - A tabela Pacientes, além das colunas id e nome, tem outras colunas que não são obrigatórias e estariam melhor organizadas se estivessem em outra tabela. A refatoração dividir tabela melhora a modelagem criando a tabela Dados_socioeconomicos com as colunas profissao, salario e paga_aluguel. 


\subsection{Qualidade de dados}

As refatorações do grupo de qualidade de dados têm como objetivo aumentar as validações e diminuir as inconsistências do banco, realizando padronizações, organizações e incluindo ou removendo regras inválidas. Após realizar as refatorações estruturais, teremos que nos preocupar com a qualidade dos dados existentes no banco. Na Tabela 3.3, podemos visualizar qual a seção que descreve as refatorações, os nomes de cada uma, se possuem replicação de dados e as suas classificações.

\begin{tabular}{|l|l|l|l|}
\hline Seção & Refatoração & $\begin{array}{l}\text { Replicação } \\
\text { de dados }\end{array}$ & Classificação \\
\hline 3.2 .1 & Adicionar tabela descritiva & Não & Padronização \\
\hline 3.2 .2 & Introduzir restrição de coluna & Não & Introduzir regra \\
\hline 3.2 .3 & Introduzir valor padrão & Não & Introduzir regra \\
\hline 3.2 .4 & Remover valor padrão & Não & Remover regra inválida \\
\hline 3.2 .5 & Alterar coluna para não nula & Não & Remover regra inválida \\
\hline 3.2 .6 & Remover restrição de não nulo & Não & Remover regra inválida \\
\hline 3.2 .7 & Introduzir formato comum & Não & Padronização \\
\hline 3.2 .8 & Aplicar código padrão & Não & Padronizção \\
\hline 3.2 .9 & Aplicar tipo padrão & Sim & Padronização \\
\hline 3.2 .10 & Remover restrição de coluna & Não & Remover regra inválida \\
\hline 3.2 .11 & Mover dados & Não & Organização \\
\hline 3.2 .12 & Consolidar estratégia de chaves & Sim & Padronização \\
\hline 3.2 .13 & Trocar código de tipo por propriedades sinalizadoras & Sim & Organização \\
\hline
\end{tabular}

Tabela 3.3: Refatorações de qualidade de dados

Uma ordem aconselhável para executar as refatorações deste grupo é a seguinte:

1. Remover regras inválidas

2. Organização

3. Padronização

4. Introduzir regra

Essa ordem segue o mesmo conceito já apresentado: primeiro remove o que é inválido, organiza, padroniza e, depois, introduz algo que irá melhorar efetivamente o banco de dados. 


\subsubsection{Adicionar tabela descritiva}

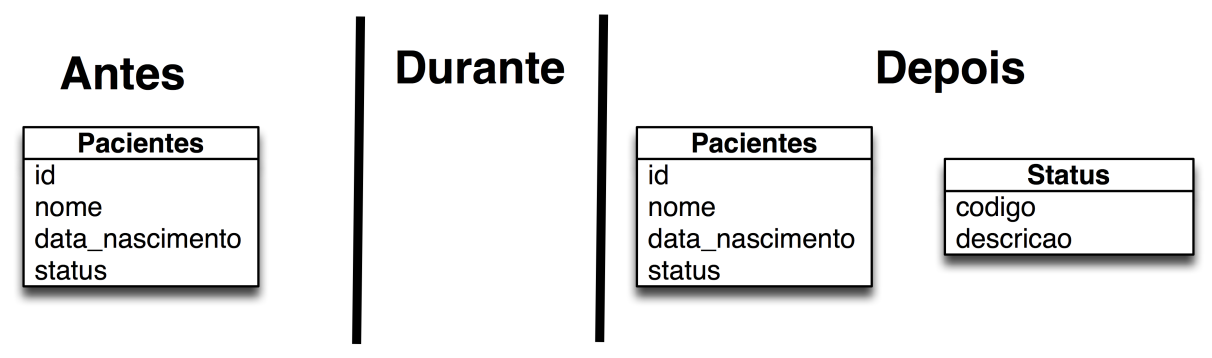

Figura 3.18: Refatoração qualidade dos dados adicionar tabela descritiva

Motivação - Tabelas descritivas são tabelas que contêm apenas duas colunas: código e descrição. Os aplicativos as utilizam como uma lista dos códigos possíveis e para padronizar as descrições que devem ser utilizadas.

Avaliação - Verificar se é possível obter uma lista completa de código e descrição para preencher a tabela descritiva.

Esquema - Para realizar esta refatoração é preciso criar a tabela descritiva. Como é uma tabela nova, e a tabela antiga, que possui somente a coluna código, não é alterada, não é preciso implementar o período de transição.

Dados - A tabela descritiva deve ser preenchida com todos os códigos e descrições existentes.

Aplicativo - Os aplicativos devem ser alterados para começar a usar a tabela descritiva.

Exemplo - A tabela Pacientes possui a coluna status que é um código que descreve a situação cadastral do paciente. Antes da refatoração, cada aplicativo fazia o controle dos códigos possíveis e mostrava uma descrição específica para o usuário do aplicativo. Esta refatoração adiciona a tabela descritiva St atus que contém todos os códigos possíveis para a situação cadastral e a descrição padronizada para ser visualizada em todos os aplicativos. 


\subsubsection{Introduzir restrição de coluna}

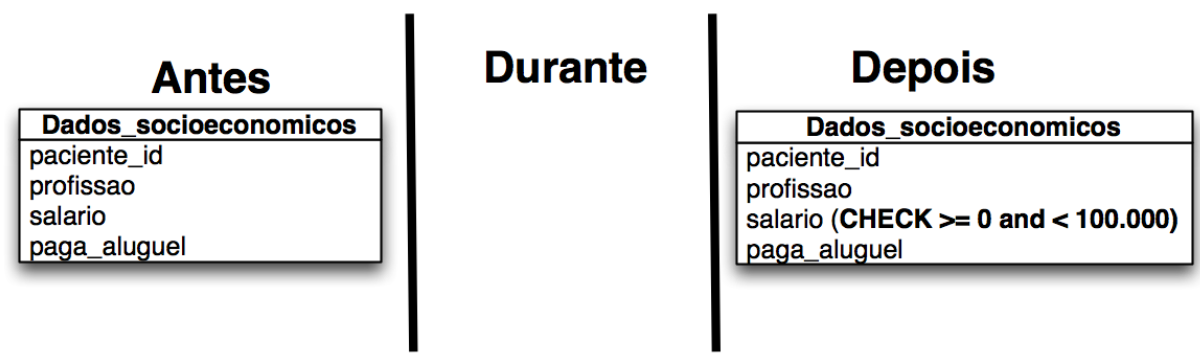

Figura 3.19: Refatoração qualidade dos dados introduzir restrição de coluna

Motivação - A principal motivação é implementar uma regra de validação dos dados comuns a todas as aplicações do banco de dados. Uma restrição de coluna é uma regra de validação que define um intervalo de valores válidos. Se o aplicativo tentar violar a restrição, o banco de dados provoca um erro, alertando que o valor não é válido para a coluna.

Avaliação - Em ambiente heterogêneo, avaliar se a restrição realmente atende a todas as aplicações.

Esquema - Esta refatoração não tem um período de transição, é necessário somente adicionar a restrição de coluna. O cuidado é alertar os desenvolvedores quando essa restrição entrará em vigor.

Dados - É importante verificar se os dados já existentes respeitam a restrição a ser criada. Se houver alguma linha que não atende a restrição, é preciso fazer uma limpeza da tabela.

Aplicativo - Os aplicativos devem tratar um possível erro proveniente da restrição de coluna. O banco de dados fornecerá uma mensagem sobre a restrição e o aplicativo deve mostrá-la de forma clara para o usuário.

Exemplo - A tabela Dados_socioeconomicos possui uma coluna salario que tem um valor mínimo e máximo como regra de validação. Esta refatoração inclui uma restrição de coluna que define esses limites no banco de dados. A restrição garante a qualidade de dados da coluna sa lario. 


\subsubsection{Introduzir valor padrão}

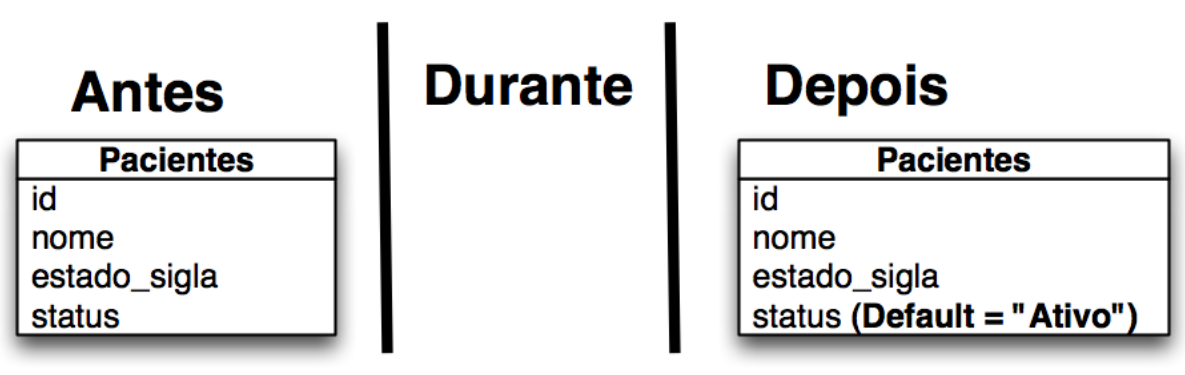

Figura 3.20: Refatoração qualidade dos dados introduzir valor padrão

Motivação - Os aplicativos frequentemente não atualizam todas as colunas de uma tabela. As colunas novas que o aplicativo ainda não utiliza ficam com valores nulos e sem sentido. Para resolver o problema, esta refatoração define um valor padrão para que a coluna tenha sempre algum dado.

Avaliação - É Ereciso avaliar e definir um valor padrão que sirva para todos os aplicativos.

Esquema - Esta refatoração não precisa de período de transição, basta alterar a tabela, definindo o valor padrão para a coluna.

Dados - É necessário atualizar as linhas já existentes em que a coluna esteja nula.

Aplicativo - Caso algum aplicativo tenha um tratamento especial para os valores nulos, ele precisará de manutenção para usar o valor padrão.

Exemplo - A tabela Pacientes tem uma coluna status para guardar a situação cadastral dos pacientes. Após a refatoração, caso um aplicativo insira uma linha na tabela e não informe o valor para a coluna status, o valor padrão será usado para definir a situação cadastral do paciente. 


\subsubsection{Remover valor padrão}

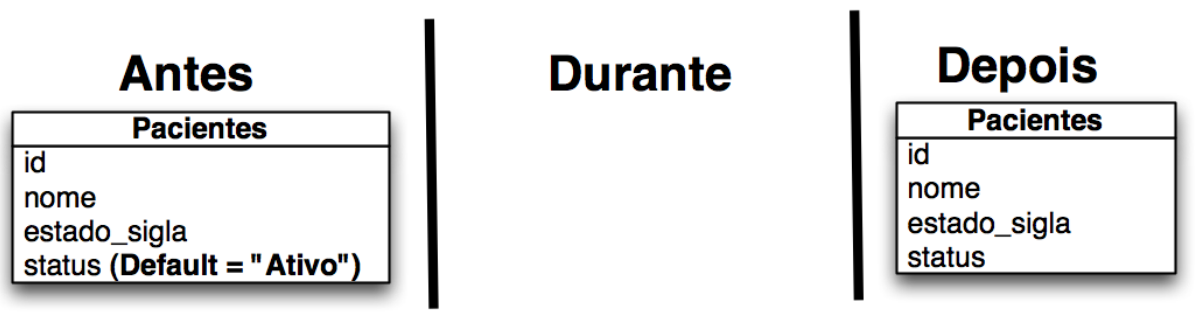

Figura 3.21: Refatoração qualidade dos dados remover valor padrão

Motivação - Quando se deseja que todas as aplicações informem algum valor para a coluna, não permitindo mais que um valor padrão seja inserido automaticamente, essa refatoração será útil.

Avaliação - Deve-se considerar alguns possíveis efeitos colaterais dessa refatoração. O principal é a ocorrência de erros nas aplicações quando possivelmente receberem um valor nulo na consulta da coluna refatorada. Com a regra de valor padrão, essa situação raramente ocorria mas, com essa refatoração, esse tipo de erro pode ser frequente.

Esquema - Para realizar esta refatoração é preciso utilizar a cláusula Modify do comando Alter Table.

Dados - Não se aplica.

Aplicativo - Os aplicativos devem ser alterados para começar a usar a coluna refatorada sem o valor padrão.

Exemplo - A tabela Pacientes tem uma coluna status para guardar a situação cadastral dos pacientes. Antes da refatoração, todos os aplicativos não incluiam um valor nessa coluna, mas o banco armazenava o valor padrão "Ativo". Após essa refatoração, a coluna status ficará com seu valor definido como NULL, obrigando os aplicativos informarem qual é a situação do paciente. 


\subsubsection{Alterar coluna para não nula}

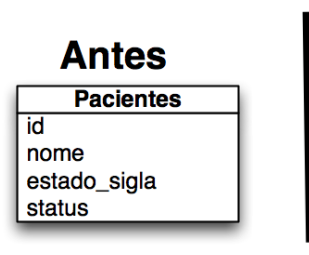

Durante

Depois

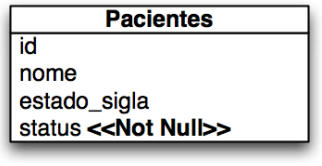

Figura 3.22: Refatoração qualidade dos dados alterar coluna para não nula

Motivação - Há duas razões principais para aplicar essa refatoração. A primeira é quando você quer forçar uma regra de negócio que obriga o preenchimento desta coluna; a segunda, quando se deseja retirar das aplicações todo o código que faz tratamento quando essa coluna não é preenchida.

Avaliação - Cada aplicativo que acessa esta coluna deve ser capaz de fornecer um valor válido para coluna. Conforme as regras de negócio, pode ser interessante considerar a refatoração Introduzir valor padrão.

Esquema - Para realizar esta refatoração é preciso utilizar a cláusula Modify do comando Alter Table adicionando NOT NULL.

Dados - É necessário atualizar as linhas já existentes em que a coluna esteja nula.

Aplicativo - Os aplicativos devem ser alterados para começarem a fornecer um valor válido para essa coluna, pois, após a refatoração, não será possível deixar a coluna com o valor nulo.

Exemplo - A tabela Pacientes tem uma coluna status para guardar a situação cadastral dos pacientes. Antes da refatoração, alguns aplicativos deixavam o valor nulo para essa coluna. Após essa refatoração a coluna status terá a restrição de NOT NULL, obrigando todos os aplicativos informarem qual é a situação do paciente. 


\subsubsection{Remover restrição de não nulo}

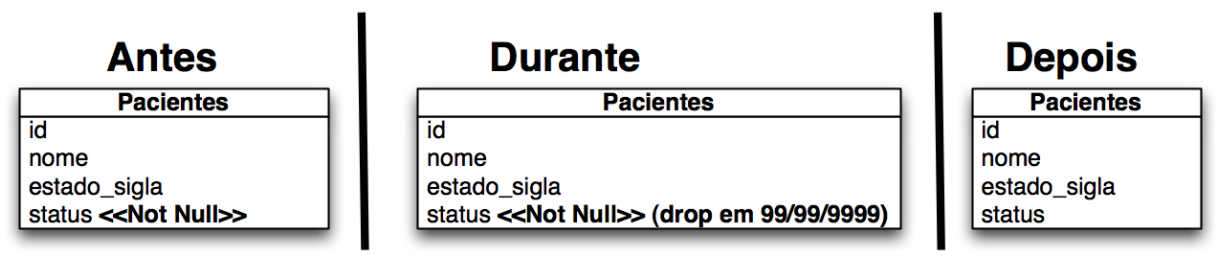

Figura 3.23: Refatoração qualidade dos dados remover restrição de não nulo

Motivação - Há duas razões principais para aplicar essa refatoração. A primeira, quando há dois aplicativos atualizando a mesma linha em momentos diferentes. Nessa situação, o primeiro aplicativo pode não atribuir valor para esta coluna, por causa da existência de um segundo aplicativo que irá atribuir um valor, posteriormente. Outra razão ocorre quando em um período de transição, durante alguma refatoração, há necessidade de eliminar a restrição de não nulo para que um aplicativo continue funcionando. Ao final do período de transição, será necessário aplicar a refatoração Alterar coluna para não nula, para voltar ao estado inicial.

Avaliação - Todos os aplicativos que acessam esta coluna devem estar preparados para aceitar um valor nulo. Caso os aplicativos introduzam um valor automático quando encontram a coluna nula, deve-se considerar a refatoração Introduzir valor padrão.

Esquema - Para realizar esta refatoração é preciso utilizar a cláusula Modify do comando Alter Table alterando NOT NULL para NULL.

Dados - Não se aplica.

Aplicativo - Os aplicativos devem ser alterados para começar a usar a coluna refatorada com valor nulo.

Exemplo - A tabela Pacientes tem uma coluna status para guardar a situação cadastral dos pacientes. Antes da refatoração, todos os aplicativos incluiam um valor nessa coluna. Após essa refatoração, a coluna status ficará com seu valor definido como NULL, desobrigando os aplicativos informarem a situação do paciente. 


\subsubsection{Introduzir formato comum}

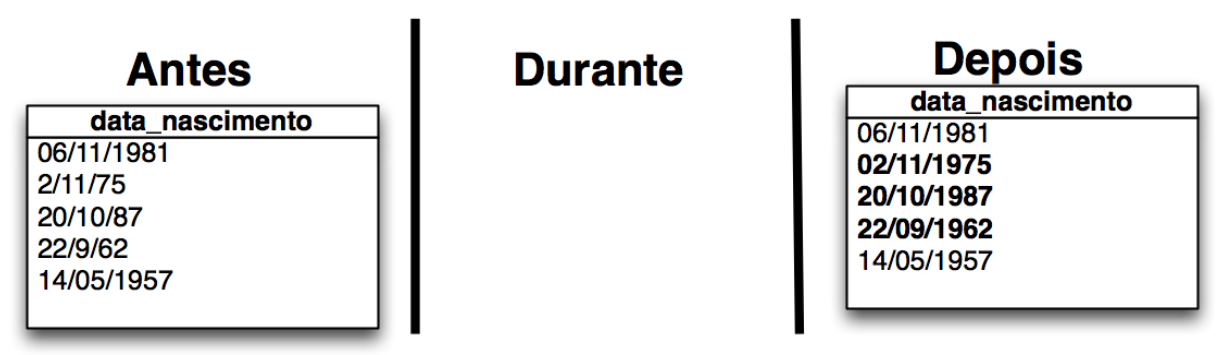

Figura 3.24: Refatoração qualidade dos dados introduzir formato comum

Motivação - Deve-se aplicar a refatoração Intruduzir formato comum para simplificar o código dos aplicativos ou quando o formato atual é diferente do formato definido pela corporação, assim os dados precisam ser reformatados para garantir a padronização.

Avaliação - A utilização de formatos não padronizados pode causar erros na identificação dos dados. Caso esta refatoração não seja realizada, cada aplicativo que acessa esta coluna deve ser capaz de detectar o formato existente da coluna e executar o seu código de reformatação.

Esquema - Para introduzir formato comum para uma coluna, deve-se primeiro identificar o formato padrão e torná-lo oficial. Em seguida, deve-se identificar em qual coluna o novo formato será aplicado. Se houver várias colunas para aplicar o novo formato, deve-se aplicar a refatoração sempre uma coluna por vez, executando refatoração quantas vezes forem necessárias.

Dados - É necessário atualizar as linhas já existentes em que os dados da coluna estejam em formato diferente do oficial.

Aplicativo - Os aplicativos devem ser alterados para usar o formato comum da coluna alterada.

Exemplo - A tabela Pacientes tem uma coluna data_nascimento para guardar a data de nascimento do paciente. Antes da refatoração, todos os aplicativos incluiam um valor nessa coluna sem exigir um formato comum, como por exemplo DD/MM/YYYY. Após essa refatoração, a coluna data_nascimento só aceitará dados digitados no formato comum. 


\subsubsection{Aplicar código padrão}

\begin{tabular}{|l|l|l|l|l|}
\multicolumn{2}{c|}{ Antes } & \multicolumn{2}{c|}{ Durante } & \multicolumn{2}{c|}{ Depois } \\
\hline Estado & \multicolumn{1}{c|}{ Cidade } \\
\hline Sp & São Paulo \\
SP & Bauru & \multicolumn{1}{|c|}{ Estado } & \multicolumn{1}{c|}{ Cidade } \\
\hline Sp & Campinas & SP & São Paulo \\
SP & Bauru \\
SP & Campinas \\
\hline
\end{tabular}

Figura 3.25: Refatoração qualidade dos dados aplicar código padrão

Motivação - Sempre que uma coluna possuir valores semânticos iguais para códigos diferentes, é necessário aplicar a refatoração Aplicar código padrão.

Avaliação - Ter códigos diferentes com mesmo valor semântico pode causar problemas quando várias tabelas utilizam esse código como chave estrangeira.

Esquema - Para aplicar a refatoração, deve-se primeiro definir o código padrão e torná-lo oficial. Em seguida, deve-se identificar em qual coluna o novo código será aplicado. Se houver várias colunas para aplicar o novo código, deve-se executar a refatoração sempre uma coluna por vez, executando refatoração quantas vezes forem necessárias.

Dados - É necessário atualizar as linhas já existentes em que os dados da coluna estejam com código diferente do oficial.

Aplicativo - Os aplicativos devem ser alterados para usar o código padrão na coluna refatorada.

Exemplo - A tabela Pacientes tem uma coluna naturalidade_estado para guardar a sigla do estado de nascimento do paciente. Antes da refatoração, todos os aplicativos incluiam um valor nessa coluna sem exigir um código padrão para os estados inseridos. Por exemplo, o usuário poderia digitar sp, Sp ou SP para identificar o estado de nascimento São Paulo, prejudicando o uso desse código em chaves estrangerias. Após essa refatoração, os dados da coluna naturalidade_estado serão uniformizados para que sempre que o estado for São Paulo, o código de identificação seja SP. 


\subsubsection{Aplicar tipo padrão (replicação de dados)}

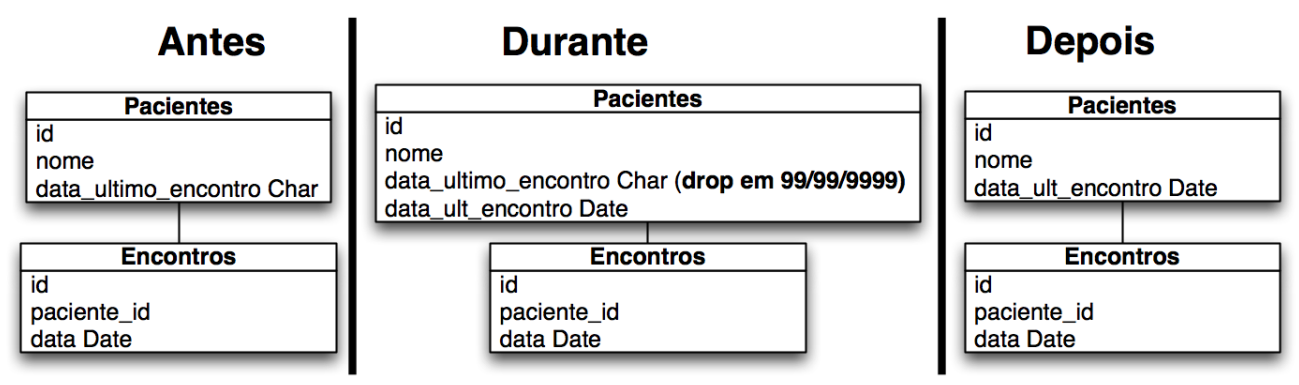

Figura 3.26: Refatoração qualidade dos dados aplicar tipo padrão

Motivação - Colunas com as mesmas informações devem ter o mesmo tipo, caso contrário será necessário aplicar esta refatoração.

Avaliação - Tipos de dados diferentes que representam o mesmo valor semântico podem prejudicar a adição de chaves estrangeiras ou de tabelas descritivas. O uso de um tipo padrão de dados permite adicionar restrições de integridade referencial.

Esquema - Para aplicar a refatoração, deve-se primeiro identificar o tipo padrão e torná-lo oficial. Em seguida, deve-se identificar em qual tabela e coluna o novo tipo será aplicado. Se houver várias tabelas ou colunas, deve-se aplicar a refatoração sempre uma coluna por vez, executando refatoração quantas vezes forem necessárias.

Dados - É necessário converter os dados já existentes para o tipo padrão para que seja possível inserilos na nova coluna.

Aplicativo - Os aplicativos devem ser alterados para trabalhar com o tipo padrão.

Exemplo - Antes da refatoração, a tabela Pacientes possuia uma coluna data_ultimo_encontro do tipo Char para armazenar a data do último atendimento, mas na tabela de encontros essa data é do tipo Date. Durante o período de transição é inserida a coluna data_ult_encontro com o tipo Date na tabela Pacientes e mantida a coluna data_ultimo_encontro com tipo Char para que os aplicativos continuem funcionando durante o período de transição. Após a refatoração a coluna data_ultimo_encontro é excluída e os aplicativos devem funcionar considerando a nova coluna data_ult_encontro do tipo Date. 


\subsubsection{Remover restrição de coluna}

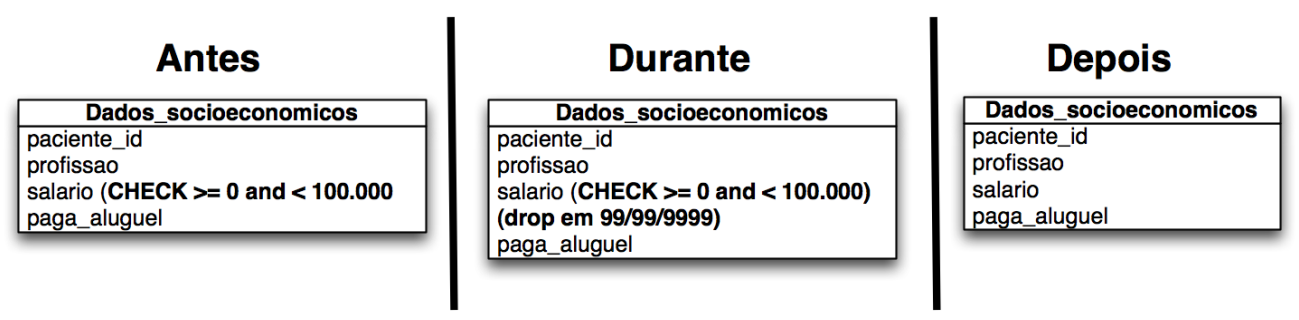

Figura 3.27: Refatoração qualidade dos dados remover restrição de coluna

Motivação - Sempre que as regras de negócio mudam e a restrição de coluna não é mais necessária, deve-se aplicar a refatoração remover restrição de coluna.

Avaliação - Em ambiente heterogêneo, avaliar se a restrição realmente atende a todas as aplicações e remover as restrições que não atendem mais às regras de negócio.

Esquema - Para realizar esta refatoração, é preciso utilizar a cláusula DROP do comando Alter Table para remover a restrição da coluna.

Dados - Não se aplica.

Aplicativo - Os aplicativos devem ser alterados para não validar a restrição excluída da coluna.

Exemplo - A tabela Dados_socioeconomicos tem uma coluna salario. Essa coluna antes da refatoração possuía uma restrição para validar os valores máximo e mínimo para o salário. Após a refatoração, a coluna salario aceitará qualquer valor permitido pelo tipo da coluna. 


\subsubsection{Mover dados}

\begin{tabular}{|c|c|c|c|c|c|c|c|c|c|}
\hline \multicolumn{3}{|c|}{ Antes } & Durante & \multicolumn{6}{|c|}{ Depois } \\
\hline \multicolumn{3}{|c|}{ Pacientes } & & \multicolumn{3}{|c|}{ Pacientes } & \multicolumn{3}{|c|}{ PacientesStatusHistorico } \\
\hline Id & Ativo & Nome & & Id & Ativo & Nome & \begin{tabular}{|l|} 
Pacienteld \\
\end{tabular} & Status & data \\
\hline $\begin{array}{l}1 \\
2 \\
3\end{array}$ & $\begin{array}{l}\text { sim } \\
\text { não } \\
\text { sim }\end{array}$ & $\begin{array}{l}\text { João da Silva } \\
\text { Maria Souza } \\
\text { Pedro Fortes }\end{array}$ & & \begin{tabular}{|l|}
1 \\
2 \\
3 \\
\end{tabular} & \begin{tabular}{|l|} 
null \\
null \\
null \\
\end{tabular} & $\begin{array}{l}\text { João da Silva } \\
\text { Maria Souza } \\
\text { Pedro Fortes }\end{array}$ & \begin{tabular}{|l|}
1 \\
2 \\
3 \\
\end{tabular} & $\begin{array}{l}\text { sim } \\
\text { não } \\
\text { sim }\end{array}$ & $\begin{array}{l}01 / 01 / 2010 \\
02 / 10 / 2009 \\
20 / 08 / 2008 \\
\end{array}$ \\
\hline \multicolumn{3}{|c|}{ PacientesStatusHistorico } & & & & & & & \\
\hline & cienteld & Status & & & & & & & \\
\hline
\end{tabular}

Figura 3.28: Refatoração qualidade dos dados mover dados

Motivação - Quando as regras de negócio mudam poderá aparecer a necessidade de mover dados de uma coluna para outra. Caso isso ocorra, deve ser aplicada a refatoração de mover dados.

Avaliação - Mover dados entre as colunas é particularmente difícil quando milhões de linhas estão envolvidas. Podem ocorrer problemas nos aplicativos que acessam os dados durante a movimentação. Assim é recomendado o bloqueio dos aplicativos durante o movimento.

Esquema - Para realizar esta refatoração, é preciso utilizar o comando INSERT para inserir os dados na tabela destino e o comando UPDATE para atualizar para NULL a coluna da tabela de origem.

Dados - Deve-se verificar se a coluna na tabela destino pode receber os dados que serão movidos sem ferir regras de integridade ou de domínio de dados. É preciso também decidir se a coluna de origem dos dados será mantida com valores nulos ou será excluída.

Aplicativo - O código das aplicações devem ser atualizados, assim como as cláusulas SELECT precisam ser refeitas para acessar os dados a partir de uma nova tabela.

Exemplo - A tabela Pacientes tem uma coluna at ivo. Essa coluna, antes da refatoração, guardava o valor sim ou não para a situação cadastral do paciente. Após a refatoração, os dados dessa coluna foram movidos para a coluna Status da tabela PacientesStatusHistorico e essa coluna atualizada para NULL. A partir desta refatoração, a cada mudança de status é feita uma inclusão na tabela de histórico, juntamente com a data da realização desta operação. 


\subsubsection{Consolidar estratégia de chaves (replicação de dados)}

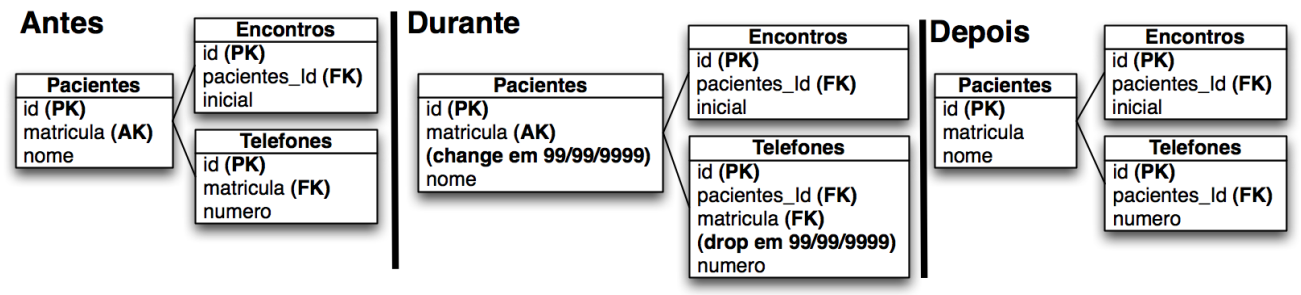

Figura 3.29: Refatoração qualidade dos dados consolidar estratégia de chaves

Motivação - Algumas tabelas podem possuir chaves primárias (PK) e candidatas (AK) e se relacionar com outras tabelas por meio dessas chaves. Para melhorar o desempenho de acesso, é possível aplicar a refatoração consolidar estratégia de chaves para que todas as tabelas do modelo utilizem a mesma estratégia de chaves.

Avaliação - Para aplicar essa refatoração é preciso alterar o schema do banco de dados, aplicando outras refatorações como introduzir chave de identificação, trocar coluna e introduzir índice.

Esquema - Para realizar esta refatoração, é preciso identificar as chaves adequadas. No período de transição deve-se marcar as chaves que serão excluídas, trocar as colunas das novas chaves e alertar os desenvolvedores da mudança na estratégia de chaves.

Dados - Os novos relacionamentos devem refletir a nova estratégia de chaves. É necessário atualizar os dados das novas colunas a partir dos dados das colunas que implementavam os relacionamentos.

Aplicativo - Os aplicativos devem ser alterados para validar a nova estratégia de chaves e tratar possíveis erros de integridade referencial.

Exemplo - No esquema original, a tabela Pacientes possuia duas colunas chave: coluna id e matricula. A chave id para relacionar com a tabela Encontros, usando a chave estrangeira pacientes_id. Por outro lado, a chave matricula era usada para relacionar com a tabela Telefones que possuia uma chave estrangeira de mesmo nome. Para melhorar o desempenho, todas as tabelas devem referenciar Pacientes somente por meio da chave id. Assim, na consolidação de chaves, foi excluída a chave matricula da tabela Telefones e criada a pacientes_id. 


\subsubsection{Trocar código de tipo por propriedades sinalizadoras (replicação de dados)}

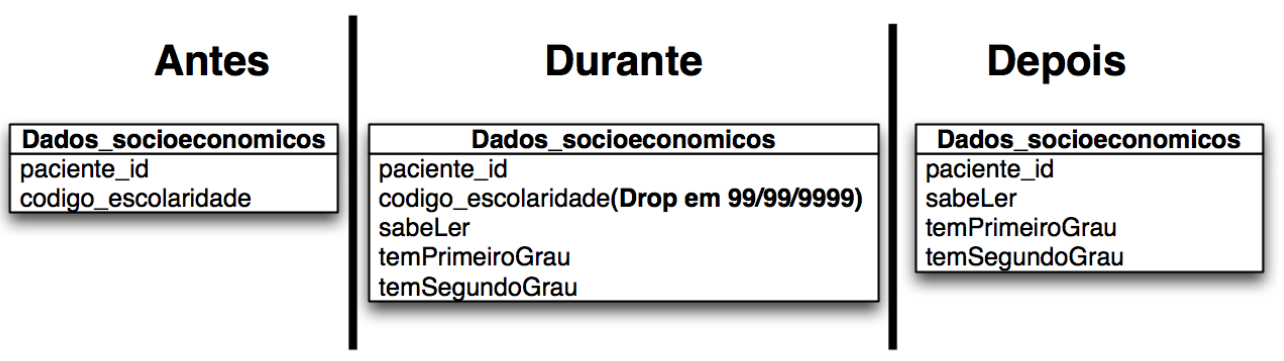

Figura 3.30: Refatoração trocar código de tipo por propriedades sinalizadoras

Motivação - Trocar código de tipo por propriedades sinalizadoras, geralmente implementadas por colunas do tipo booleanas, traz vários benefícios, tais como: desnormalização para melhorar o desempenho, simplificação nas consultas e retirada de tabelas de código das aplicações.

Avaliação - É necessário verificar se essa troca não irá aumentar muito o número de colunas da tabela. Quando a tabela tem muitas colunas, fica difícil de entender o seu conteúdo e realizar as consultas necessárias.

Esquema - No período de transição, será necessário identificar e alertar os desenvolvedores sobre qual coluna será eliminada e criar as novas colunas do tipo boolean. Como haverá replicação de dados, é preciso se preocupar com o código de apoio. No final do período, remova a coluna identificada para realizar a troca.

Dados - As colunas novas devem receber o valor falso ou verdadeiro conforme o valor da coluna antiga.

Aplicativo - Deve-se trocar todas as referências à coluna antiga pela nova. Os aplicativos devem tratar de forma diferente as novas colunas, pois agora o tipo é boolean.

Exemplo - A tabela Dados_socioeconomicos tinha uma coluna que guardava o tipo de escolaridade do paciente. Com esta refatoração, a coluna codigo_escolaridade será trocada pelas colunas sabeLer, temPrimeiroGrau e temSegundoGrau que coletam examente o que interessa para a aplicação. 


\subsection{Integridade referencial}

As refatorações de integridade referencial têm como objetivo manter consistentes as referências entre as tabelas, incluindo ou removendo regras, armazendo histórico ou implementando lógica da aplicação no banco de dados.

Após realizar as refatorações que trabalham na qualidade de dados, principalmente padronizando e organizando os dados existentes, teremos que nos preocupar com a integridade referencial existente no banco de dados. A Tabela 3.4 resume as refatorações deste grupo.

\begin{tabular}{|l|l|l|l|}
\hline Seção & Refatoração & Replicação de dados & Classificação \\
\hline 3.3 .1 & Adicionar restrição de chave estrangeira & Não & Introduzir regra \\
\hline 3.3 .2 & Introduzir exclusão em cascata & Não & Introduzir regra \\
\hline 3.3 .3 & Introduzir exclusão lógica & Não & Armazenar histórico \\
\hline 3.3 .4 & Remover restrição de chave estrangeira & Não & Remover regra inválida \\
\hline 3.3 .5 & Introduzir exclusão física & Não & Remover regra inválida \\
\hline 3.3 .6 & Adicionar trigger para coluna calculada & Não & Lógica no banco de dados \\
\hline 3.3 .7 & Introduzir trigger para histórico & Não & Armazenar histórico \\
\hline
\end{tabular}

Tabela 3.4: Refatorações de integridade referencial

Esse grupo de refatorações, além de não exigir replicação de dados, contém apenas sete itens, porém, ele possui refatorações importantes para que o banco de dados funcione corretamente e se mantenha íntegro. Além disso, é comum a falta de regras de integridade referencial resultar em diminuição da qualidade dos dados, e, consequentemente, exigir refatorações da seção anterior.

Uma ordem aconselhável para executar as refatorações deste grupo é a seguinte:

1. Remover regras inválidas

2. Introduzir regra

3. Armazenar histórico

4. Lógica no banco de dados 


\subsubsection{Adicionar restrição de chave estrangeira}

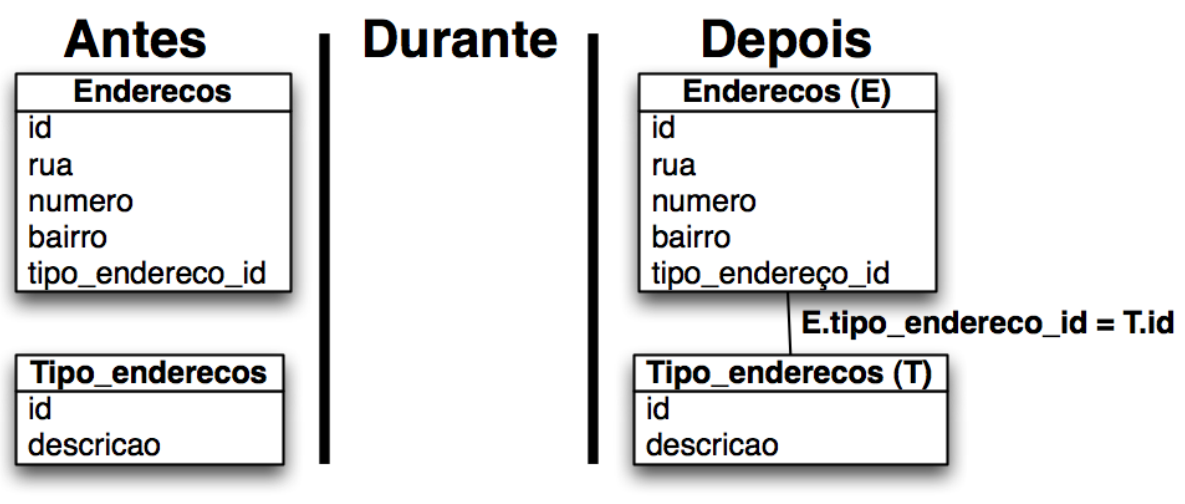

Figura 3.31: Refatoração de integridade adicionar restrição de chave estrangeira

Motivação - A principal motivação é garantir a integridade referencial utilizando regras no banco de dados, pois uma coluna que é chave estrangeira só poderá ter um valor que exista previamente.

Avaliação - Avaliar o impacto nas aplicações que fazem atualização na tabela com a restrição de chave estrangeira. Os gerenciadores de banco de dados disponibilizam duas estratégias de validação para este tipo de restrição: a cada comando ou somente no final da transação, na execução do commit. É necessário avaliar e escolher a melhor estratégia que atenda a todos os aplicativos.

Esquema - Esta refatoração não tem período de transição. Alerte os desenvolvedores sobre quando ela será feita e altere a tabela adicionando a restrição de chave estrangeira. É prudente verificar se a tabela referenciada tem índice na coluna usada como chave estrangeira.

Dados - Verifique os dados existentes na tabela alterada para garantir que a coluna afetada pela restrição só tenha valores válidos e que a tabela referenciada esteja completa.

Aplicativo - Os aplicativos devem ser alterados para tratar um possível erro caso alguma atualização viole a restrição de chave estrangeira.

Exemplo - A tabela Enderecos tem a coluna tipo_endereco_id que referencia a tabela Tipo_enderecos. Antes da refatoração, somente a aplicação que controlava se a coluna tipo_endereco_id tinha valores válidos. Com a refatoração, o banco de dados garante a restrição de chave estrangeira. 


\subsubsection{Introduzir exclusão em cascata}

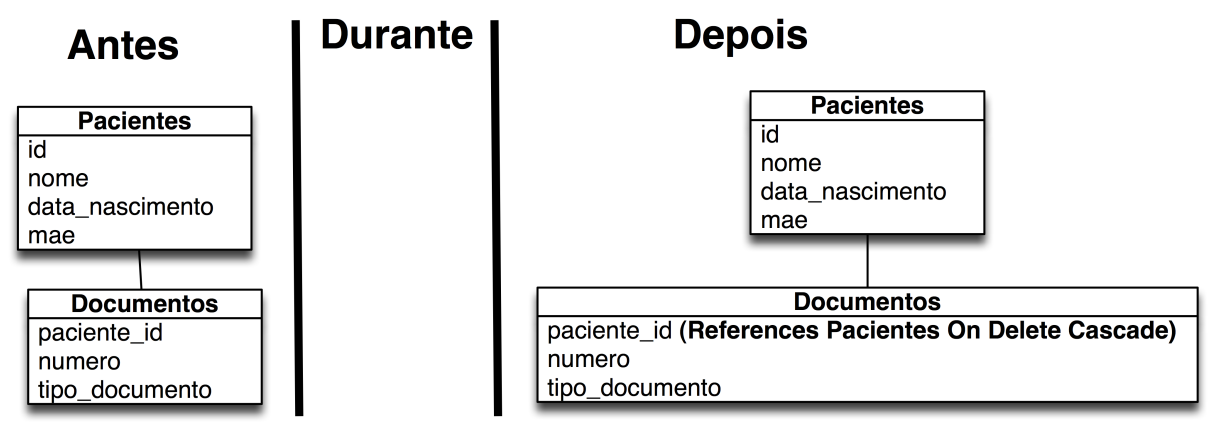

Figura 3.32: Refatoração de integridade introduzir exclusão em cascata

Motivação - Esta refatoração tem como objetivo preservar a integridade referencial durante a exclusão de uma linha que possua referências a ela em outras tabelas.

Avaliação - É imprescindível avaliar cuidadosamente se a exclusão em cascata é o funcionamento desejado. Podem existir situações em que o aplicativo não deseja a exclusão em cascata. Neste caso, a refatoração não poderá ser executada.

Esquema - Não é necessário período de transição, mas é importante alertar os desenvolvedores sobre quando a exclusão em cascata começará a vigorar. Para finalizar a refatoração, basta alterar a tabela para acrescentar a regra de exclusão em cascata.

Dados - É interessante verificar se existe algum registro orfão que deveria ser excluído. Pode ter ocorrido algum erro na aplicação que provocou a falta de exclusão desses registros.

Aplicativo - Os aplicativos devem ser alterados para retirar o código que fazia a exclusão em cascata, pois a exclusão será feita, após a refatoração, pelo banco de dados.

Exemplo - A tabela Documentos guarda as informações dos documentos dos pacientes. Quando as informações sobre um paciente, que estão na tabela Pacientes, são excluídas, os documentos do paciente também devem ser excluídos. A refatoração introduzir exclusão em cascata coloca essa regra no banco de dados. 


\subsubsection{Introduzir exclusão lógica}

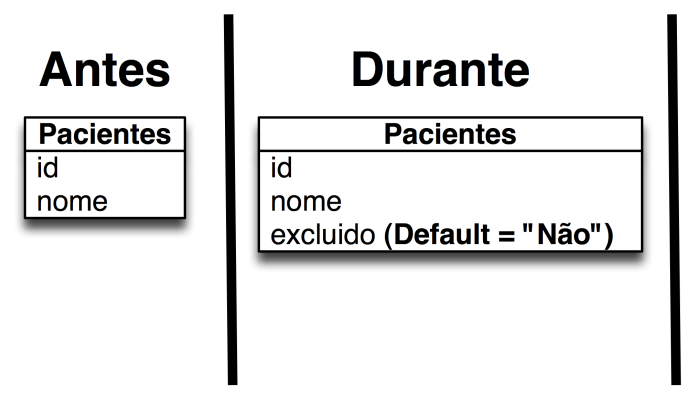

\section{Depois}

\begin{tabular}{|l|}
\hline \multicolumn{1}{|c|}{ Pacientes } \\
\hline $\begin{array}{l}\text { id } \\
\text { nome } \\
\text { excluido (Default }=\text { "Não") }\end{array}$ \\
\hline $\begin{array}{r}\{\text { Trigger when event }=\text { delete } \\
\text { set excluido }=\text { "Sim" }\}\end{array}$ \\
\hline
\end{tabular}

Figura 3.33: Refatoração de integridade introduzir exclusão lógica

Motivação - A principal motivação é preservar dados que seriam excluídos para permitir o armazenamento de um histórico. A exclusão lógica captura a exclusão real ou física e atualiza alguma coluna na tabela, sinalizando que aquela linha foi excluída.

Avaliação - É importante avaliar a perda de desempenho decorrente do volume de dados armazenados na tabela. Se a tabela sofrer muita inserção e exclusão, o volume de dados pode aumentar rapidamente e provocar problemas de desempenho para o banco de dados.

Esquema - Durante o período de transição, acrescente a coluna que indica se a linha foi excluída ou não. É interessante que a coluna tenha como valor padrão algum dado que indique que não foi excluída a linha. Para finalizar a refatoração, acrescente o código, possivelmente um trigger no banco de dados, que atualiza a coluna quando ocorrer uma exclusão.

Dados - Após a criação da nova coluna, é necessário atualizá-la com um valor escolhido para indicar que a coluna não foi excluída.

Aplicativo - Todos os aplicativos devem ser alterados para não mostrar os registros que foram excluídos logicamente. Pode ser útil escrever um novo módulo nos aplicativos para visualizar as linhas excluídas.

Exemplo - Os dados dos pacientes na tabela Pacientes devem ter exclusão lógica devido à necessidade de armazenar os dados clínicos por muitos anos. A coluna excluido é usada para realizar a exclusão lógica; quando tem o valor S im, sinaliza que foi feita a exclusão lógica. Um trigger foi criado para atualizar a coluna. 


\subsubsection{Remover restrição de chave estrangeira}

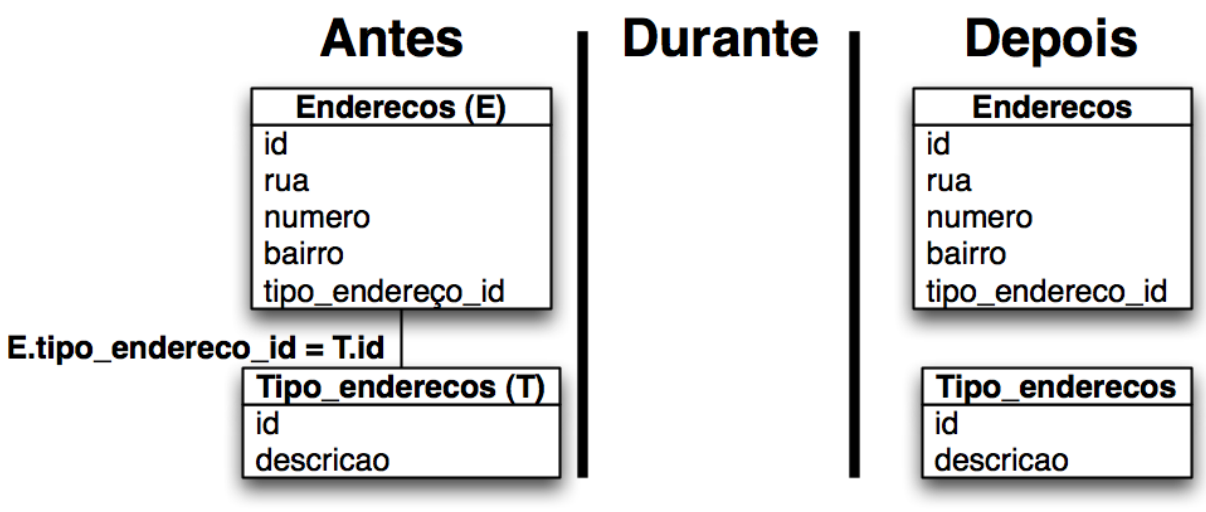

Figura 3.34: Refatoração de integridade remover restrição de chave estrangeira

Motivação - Essa refatoração deve ser usada quando a restrição de chave estrangeira não é mais válida.

Avaliação - Quando você aplica a refatoraçao, suas aplicações podem introduzir dados inválidos se não houver uma validação antes de gravar no banco de dados.

Esquema - Esta refatoração não tem período de transição. Alerte os desenvolvedores sobre quando a refatoração será feita e altere a tabela removendo a restrição de chave estrangeira. Para excluir uma restrição de chave estrangeira, você deve aplicar o comando ALTER TABLE DROP CONSTRAINT ou você pode apenas aplicar o comando ALTER TABLE DISABLE CONSTRAINT. A vantagem dessa última abordagem é que ela garante que a relação seja documentada, embora a restrição não seja imposta.

Dados - Não se aplica.

Aplicativo - Os aplicativos devem ser alterados, para validar os dados da coluna sem a restrição.

Exemplo - A tabela Enderecos tem a coluna tipo_endereco_id que referencia a tabela Tipo_enderecos. Antes da refatoração, o banco de dados garantia a restrição de chave estrangeira. Com a refatoração, somente a aplicação controlará os valores da coluna tipo_endereco_id. 


\subsubsection{Introduzir exclusão física}

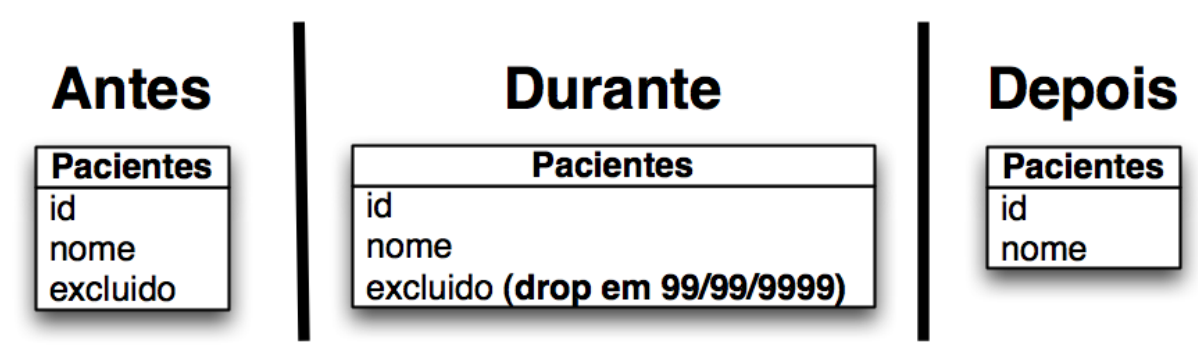

Figura 3.35: Refatoração de integridade introduzir exclusão física

Motivação - A principal motivação é excluir fisicamente do banco de dados a linha excluída pela aplicação.

Avaliação - Realizar uma exclusão física reduz o tamanho das tabelas, resultando em melhor desempenho e consultas mais simples, porque a aplicação já não tem que verificar se uma linha é marcada como excluída.

Esquema - Alertar os desenvolvedores sobre quais colunas serão removidas da tabela. Para finalizar, remova a coluna e, caso exista, o trigger que a mantinha atualizada.

Dados - Deve excluir do banco de dados todas as linhas marcadas como excluídas pela aplicação.

Aplicativo - Todos os aplicativos devem ser alterados para tirar qualquer referência à coluna excluída e implementar o código para exclusão física.

Exemplo - Os dados dos pacientes da tabela Pacientes podem ter a exclusão física, pois esses dados são arquivados em outra tabela. A coluna excluido era usada para realizar a exclusão lógica. Após a refatoração, essa coluna será eliminada. 


\subsubsection{Adicionar trigger para coluna calculada}

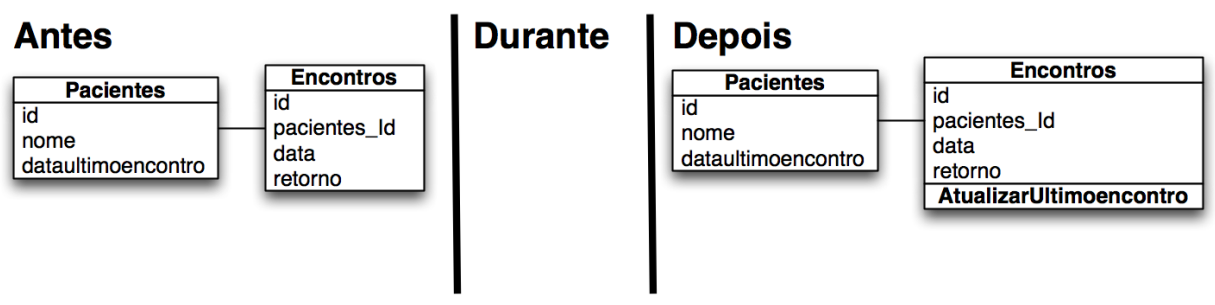

Figura 3.36: Refatoração de integridade adicionar trigger para coluna calculada

Motivação - Essa refatoração deve ser usada sempre que se desejar ter uma coluna com um valor calculado a partir de outra.

Avaliação - Quando uma coluna calculada é baseada em algoritmos complexos ou os dados estão localizados em várias tabelas, podem ocorrer inconsistências com a lógica de negócios dentro das aplicações. Neste caso, é interessante colocar essa lógica no banco de dados.

Esquema - Esta refatoração não tem período de transição. Alerte os desenvolvedores sobre quando a refatoração será feita e desenvolva o trigger que fará o cálculo.

Dados - Não se aplica.

Aplicativo - Os aplicativos devem ser alterados para trabalhar com a coluna calculada e, deste modo, é necessário remover o código que fazia o cálculo na aplicação.

Exemplo - A tabela Pacientes tem a coluna calculdada Datadoultimoencontro. O trigger Atualizarultimoencontro deve atualizar essa coluna com o último valor válido da coluna Data da tabela Encontros. 


\subsubsection{Adicionar trigger para histórico}

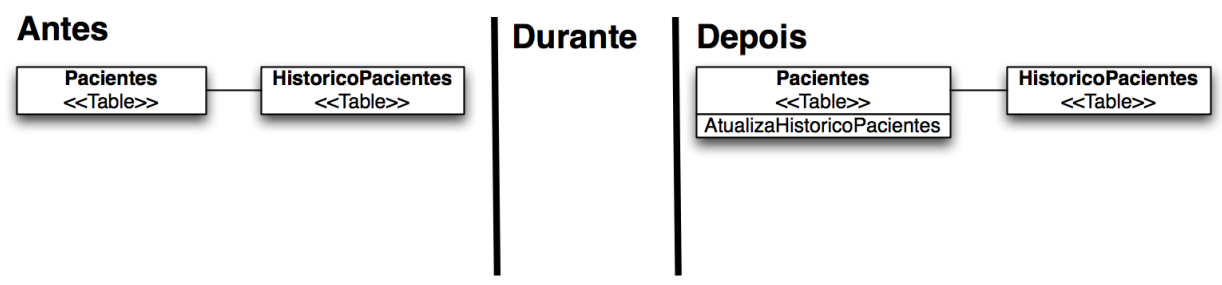

Figura 3.37: Refatoração de integridade adicionar trigger para histórico

Motivação - Essa refatoração deve ser usada sempre que se desejar garantir que alterações feitas em uma tabela sejam armazenadas no banco de dados, independente das aplicações.

Avaliação - Poderá haver perda de desempenho devido a execução do trigger para atualizar a tabela de histórico.

Esquema - Esta refatoração não tem período de transição. Alerte os desenvolvedores sobre quando ela será feita e escreva os triggers para coletar os dados da tabela de origem e armazenar na tabela de histórico.

Dados - Não se aplica.

Aplicativo - Os aplicativos devem ser alterados para não mais armazenar as alterações na tabela de histórico, mas somente exibir os dados da tabela.

Exemplo - Para que se tenha um histórico de todas as alterações da tabela Pacientes, já havia a tabela HistoricoPacientes. Esta refatoração criou um trigger que coleta todas as alterações da tabela de pacientes e grava essas alterações na tabela histórico. 


\subsection{Arquitetural}

O objetivo principal das refatorações arquiteturais é mover uma parte do código dos aplicativos para o banco de dados (lógica no banco de dados). Objetivos secundários são encapsular o acesso a tabelas, organizar, padronizar e melhorar o desempenho do banco de dados. A Tabela 3.5 resume as refatorações analisadas deste grupo.

\begin{tabular}{|l|l|l|l|}
\hline Seção & Refatoração & Replicação de dados & Classificação \\
\hline 3.4 .1 & Adicionar métodos CRUD & Não & Lógica no banco de dados \\
\hline 3.4 .2 & Encapsular tabela com uma visão & Não & Encapsular tabela \\
\hline 3.4 .3 & Introduzir método para cálculo & Não & Lógica no banco de dados \\
\hline 3.4 .4 & Introduzir tabela espelho & Não & Melhorar desempenho \\
\hline 3.4 .5 & Adicionar método de leitura & Não & Encapsular tabela \\
\hline 3.4 .6 & Introduzir índice & Não & Melhorar desempenho \\
\hline 3.4 .7 & Trocar método por visão & Não & Mudar forma de acesso \\
\hline 3.4 .8 & Trocar visão por método & Não & Mudar forma de acesso \\
\hline 3.4 .9 & Usar fonte de dados oficial & Não & Padronização \\
\hline 3.4 .10 & Migrar método de banco de dados & Não & Organização \\
\hline 3.4 .11 & Migrar método para banco de dados & Não & Organização \\
\hline 3.4 .12 & Introduzir tabela somente leitura & Não & Encapsular tabela \\
\hline
\end{tabular}

Tabela 3.5: Refatorações arquiteturais

Todas as refatorações arquiteturais não necessitam de replicação de dados, mas é um grupo complexo que exige a escrita de código de programação de banco de dados (por exemplo, na linguagem $P L / S Q L$ ).

Apesar das vantagens de implementar procedimentos no banco de dados para encapsular operações de inclusão, remoção ou atualização, é preciso comparar com as facilidades de vários arcabouços de acesso ao banco de dados que geram automaticamente o código dessas operações.

Uma possível ordem de execução das refatorações deste grupo é a seguinte:

1. Organização

2. Padronização

3. Melhorar desempenho

4. Encapsular tabela

5. Mudar forma de acesso

6. Lógica no banco de dados 


\subsubsection{Adicionar métodos CRUD}

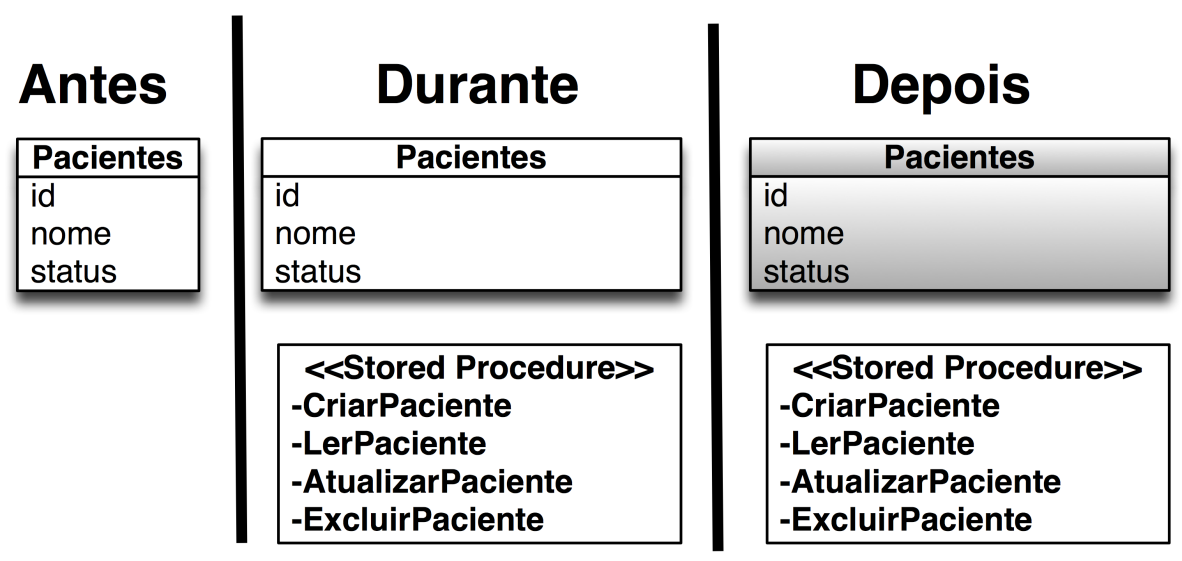

Figura 3.38: Refatoração arquitetural adicionar métodos CRUD

Motivação - Em ambientes heterogêneos, é interessante encapsular as operações CRUD (Create, Read, Update e Delete) em métodos ou procedimentos do banco de dados, devido às vantagens em diminuir o acoplamento entre a aplicação e o banco de dados.

Avaliação - As desvantagens da refatoração, que devem ser avaliadas, são a diminuição de portabilidade entre bancos de dados e a quantidade de código necessário para implementar os métodos.

Esquema - No período de transição, escreva os métodos CRUD e crie os procedimentos no banco de dados. Para finalizar, retire o acesso direto às tabelas, pois todas as aplicações devem usar os métodos CRUD.

Dados - Não há nenhuma operação sobre os dados da tabela.

Aplicativo - Os aplicativos devem ser alterados para utilizar os procedimentos armazenados no banco de dados. Todo o código que fazia acesso direto à tabela deve ser excluído das aplicações.

Exemplo - Foram criados os procedimentos no banco de dados: CriarPaciente, LerPaciente, AtualizarPaciente e ExcluirPaciente, para fazer todas as operações na tabela de pacientes. Nesses procedimentos foram colocadas todas as regras de negócio necessárias. Para finalizar a refatoração, o acesso à tabela Pacientes foi retirado de todas as aplicações. 


\subsubsection{Encapsular tabela com uma visão}

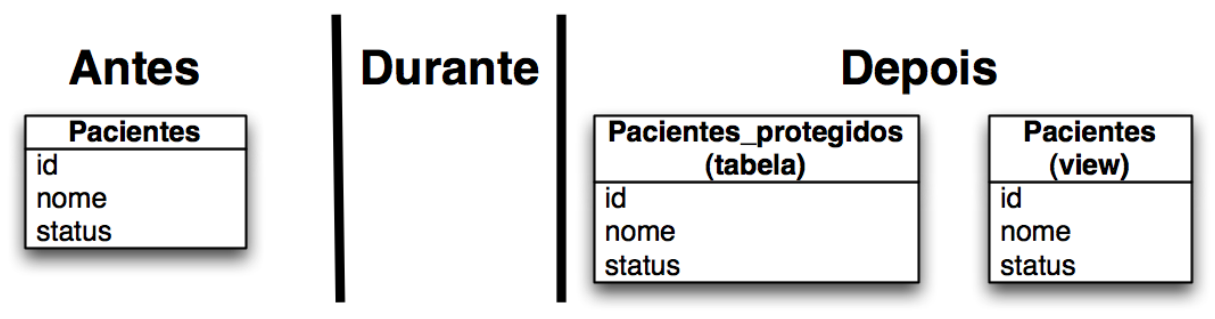

Figura 3.39: Refatoração arquitetural encapsular tabela com uma visão

Motivação - Permite a implementação de uma fachada para tabelas que serão refatoradas. As tabelas referenciadas pela visão podem ser alteradas sem impactos para os aplicativos, desde que seja possível manter o código da visão. Outra motivação é a implementação de regras de segurança; os aplicativos que acessam a visão só podem realizar consultas.

Avaliação - Faça um levantamento sobre quais aplicativos executam atualização na tabela que será encapsulada. Para esses aplicativos pode ser necessária a refatoração adicionar métodos CRUD.

Esquema - Não existe um período de transição, é necessário trocar o nome da tabela e criar uma visão com o nome antigo consultando a tabela com o novo nome. A partir desse momento, todos os aplicativos acessarão somente a visão.

Dados - Não há nenhuma atividade em relação aos dados da tabela encapsulada.

Aplicativo - Os aplicativos que precisam fazer manutenção (inclusão, alteração e exclusão) na tabela devem ser alterados para utilizar a tabela com um novo nome ou realizar a refatoração adicionar métodos CRUD.

Exemplo - A tabela Pacientes deve ser encapsulada para que somente um aplicativo faça a manutenção dos dados dos pacientes. A refatoração renomeou a tabela para Pacientes_protegidos e criou uma visão com o nome antigo da tabela. 


\subsubsection{Introduzir método para cálculo}

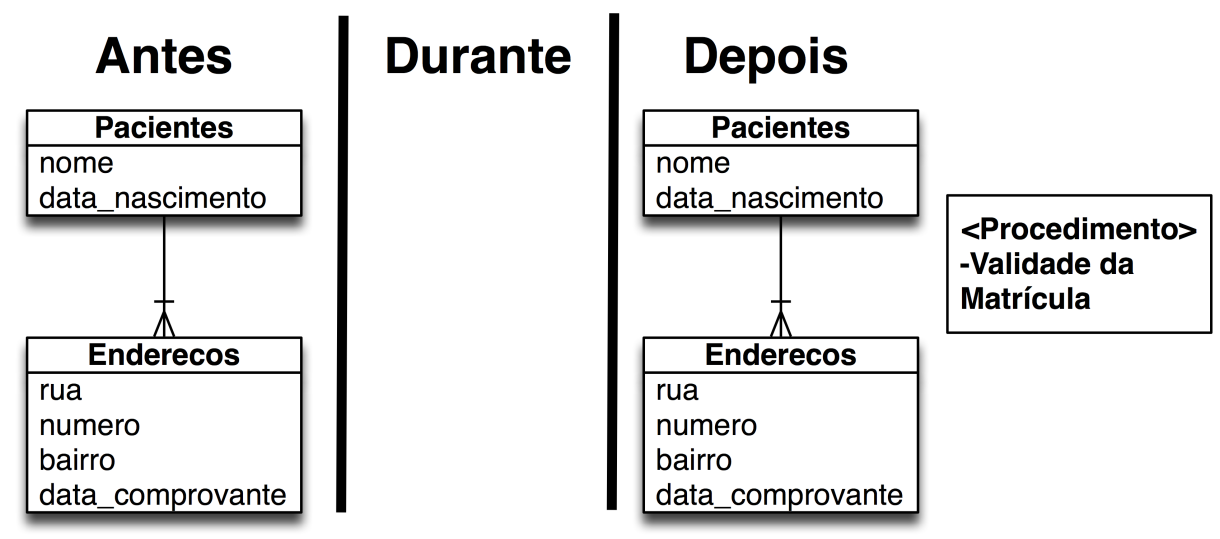

Figura 3.40: Refatoração arquitetural introduzir método para cálculo

Motivação - Melhorar o desempenho para cálculos que interagem com grande volume de dados e implementar uma regra única de cálculo que pode estar espalhada entre vários aplicativos.

Avaliação - No caso de grandes volumes de dados, avalie o desempenho desse novo método no banco de dados, fazendo as otimizações conforme a necessidade.

Esquema - A refatoração não tem um período de transição, somente escreva um procedimento no banco de dados que faz o cálculo necessário.

Dados - Não há nenhuma atividade em relação aos dados.

Aplicativo - Os aplicativos que implementavam o cálculo devem apagar esse código e fazer uma chamada ao procedimento no banco de dados para obter o resultado.

Exemplo - A validade da matrícula de um paciente é calculada a partir da data do comprovante do endereço, somando três anos a essa data. A refatoração criou o procedimento Validade da Matrícula no banco de dados para realizar esse cálculo. Todos os aplicativos que precisam saber a validade devem ser alterados para utilizar o novo procedimento. 


\subsubsection{Introduzir tabela espelho}

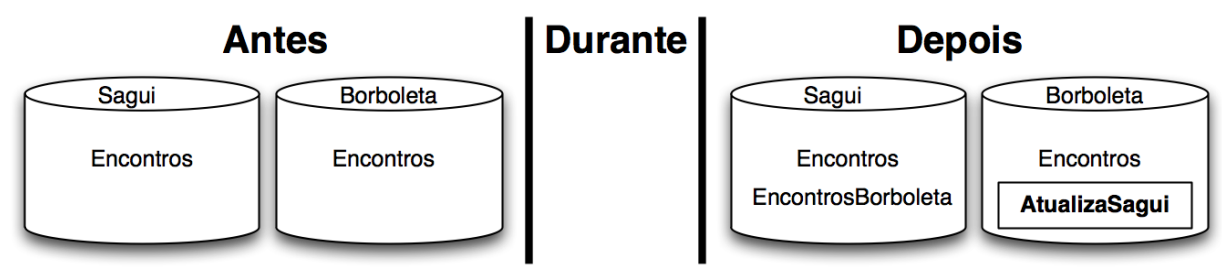

Figura 3.41: Refatoração arquitetural introduzir tabela espelho

Motivação - Uma consulta realizada em um banco de dados remoto pode ser lenta. Assim, uma cópia no servidor local melhora o desempenho da consulta. Manter uma tabela espelho em um servidor local, auxilia também aplicações de consulta de tempo real, pois evita problemas com outros banco de dados quando estes não estiverem com o acesso disponível.

Avaliação - É preciso implementar uma estratégia de replicação da tabela original com suas tabelas espelhos, para que os dados estejam sempre atualizados.

Esquema - Não existe um período de transição. É necessário determinar o local onde ficará a tabela espelho, e criá-la usando o comando CREATE TABLE.

Dados - É preciso determinar e aplicar uma estratégia para replicação de dados da tabela de origem com suas tabelas espelho.

Aplicativo - Os aplicativos que precisam fazer consulta aos dados remotos devem ser alterados para consultarem localmente os mesmos dados.

Exemplo - A aplicação Sagui necessita de uma cópia da tabela Encontros da aplicação Borboleta em sua base de dados, assim é aplicada a refatoração introduzir tabela espelho e a aplicação Borboleta sincroniza seus dados de encontros na base do Sagui. 


\subsubsection{Adicionar método de leitura}

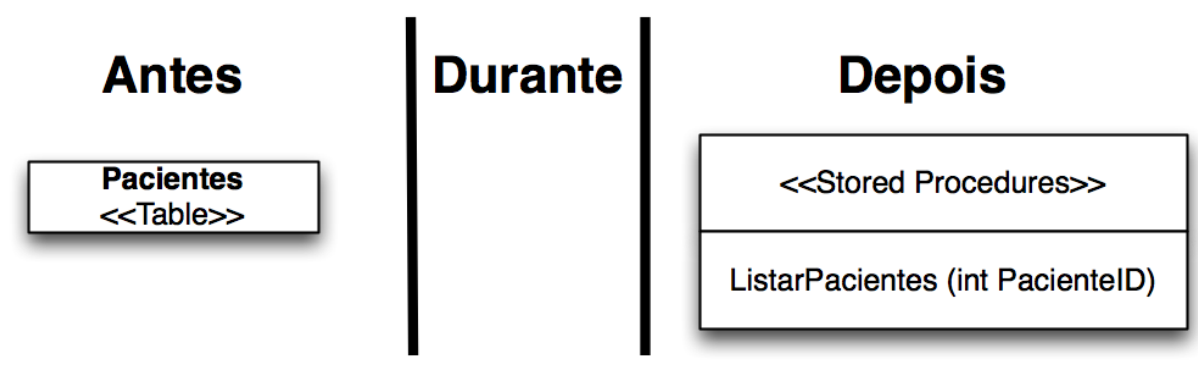

Figura 3.42: Refatoração arquitetural adicionar método de leitura

Motivação - A principal razão para aplicar essa refatoração é encapsular a lógica necessária para realizar uma consulta direto na tabela.

Avaliação - A principal vantagem de encapsular a lógica de recuperação de dados é a facilidade para refatorar o esquema da tabela. Infelizmente, essa abordagem para o encapsulamento de banco de dados tem um custo: os procedimentos armazenados possuem uma baixa portabilidade, visto que a linguagem dos métodos dependem de cada fabricante de banco de dados e pode diminuir o desempenho global desses banco de dados, se eles forem escritos sem cuidado.

Esquema - Não existe um período de transição. É necessário identificar quais dados serão recuperados e escrever a Stored procedure que fará o trabalho.

Dados - Não se aplica.

Aplicativo - Os aplicativos devem ser alterados para acessar a Stored procedure e não terão mais acesso à tabela diretamente.

Exemplo - Foi criado o procedimento no banco de dados ListarPaciente para recuperar todos os dados do paciente e as aplicações foram alteradas para acessar o procedimento. 


\subsubsection{Introduzir índice}

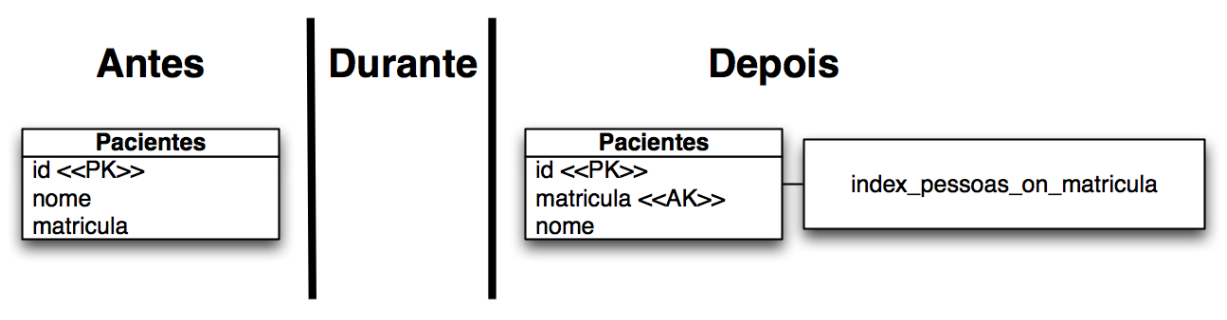

Figura 3.43: Refatoração arquitetural introduzir índice

Motivação - o principal motivo de se introduzir um índice em uma tabela é aumentar o desempenho de consulta em seu banco de dados. Também pode ser necessário a introdução de um índice para criar uma chave primária de uma tabela, ou para apoiar uma chave estrangeira em outra tabela.

Avaliação - A existência de muitos índices em uma tabela irá prejudicar o desempenho das atualizações.

Esquema - Não existe um período de transição. É necessário identificar o tipo de índice que será criado, a tabela em que será criado e usar o comando CREATE INDEX.

Dados - É preciso remover os dados duplicados de uma coluna para introduzir um índice que não aceita repetição.

Aplicativo - As aplicações devem ser capazes de gerenciar as exceções que são geradas pelo banco de dados no caso do índice não permitir valores duplicados. Além disso, devem ser alterados para realizar consultas considerando o novo índice criado, melhorando, assim, o desempenho da consulta.

Exemplo - Foi criado o índice index_pessoas_on_matricula para a tabela Pacientes, garantindo que não haverá valores repetidos para a coluna matricula, melhorando as consultas por matrícula. 


\subsubsection{Trocar método por visão}

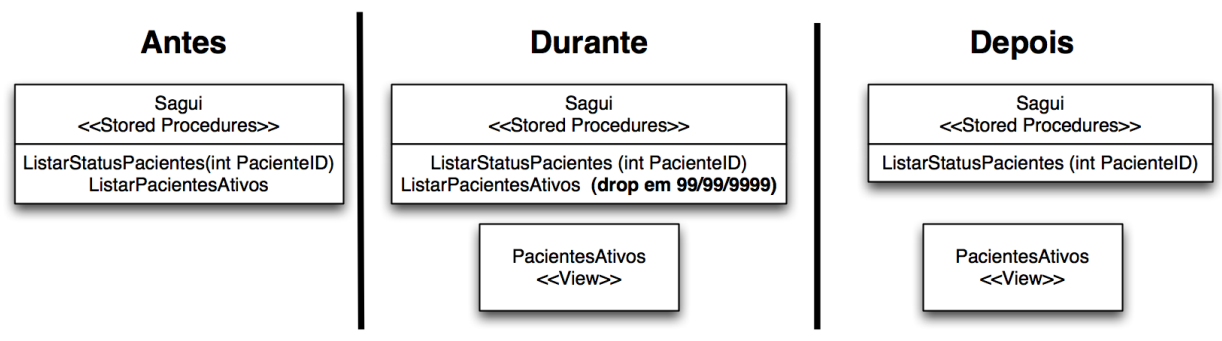

Figura 3.44: Refatoração arquitetural trocar método por visão

Motivação - Trocar método por visão facilita o uso dos dados em ferramentas de relatório, reduz a manutenção e aumenta a portabilidade.

Avaliação - Esssa refatoração é normalmente aplicada para substituir métodos simples, cuja lógica pode ser inserida em uma visão.

Esquema - É necessário primeiro adicionar uma visão utilizando a refatoração Int rodu zir Visão. No período de transição, é necessário alertar os desenvolvedores sobre a eliminação do método e, após o período de transição, removê-lo.

Dados - Não se aplica.

Aplicativo - As aplicações devem ser alteradas para não acessar o método removido e começar a utilizar a visão.

Exemplo - Foi criada a visão PacientesAt i vos para substituir o método ListarPacientesAtivos que recupera todos os pacientes com coluna ativo com valor true. Os desenvolvedores foram alertados do período de transição e após expirar o prazo foi removido o método LerPacientesAtivos. 


\subsubsection{Trocar visão por método}

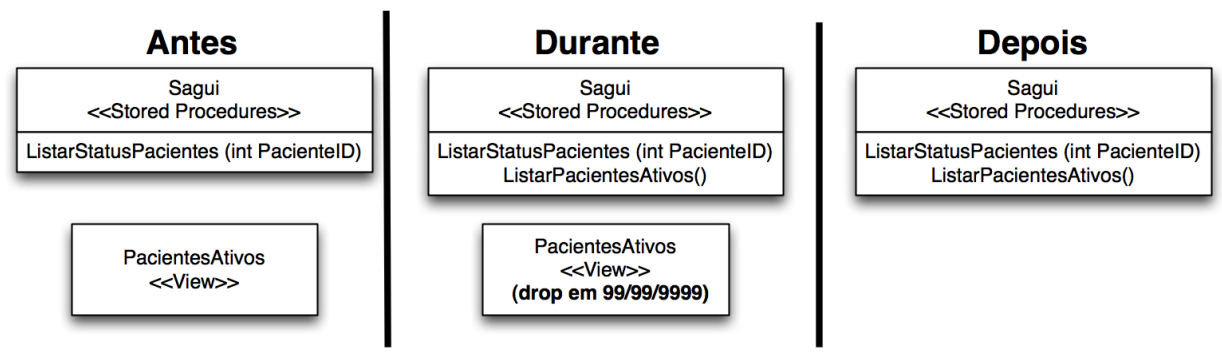

Figura 3.45: Refatoração arquitetural trocar visão por método

Motivação - Trocar visão por método possibilita implementar lógicas mais complexas para recuperação de dados com critérios definidos. Os métodos podem atualizar dados nas tabelas.

Avaliação - Algumas ferramentas de relatório trabalham bem com visões e não com métodos. A portabilidade também fica prejudicada, visto que a linguagem dos métodos depende de cada fabricante de banco de dados.

Esquema - É necessário primeiro adicionar o método que irá substituir a visão. No período de transição, é necessário alertar os desenvolvedores sobre a eliminação da visão e, após o período de transição, removê-la.

Dados - Não se aplica.

Aplicativo - As aplicações devem ser alteradas para não acessar a visão removida e utilizar o método criado.

Exemplo - Foi criado ao método ListarPacientesAt ivos para substituir a visão PacientesAtivos, que recupera todos os pacientes com coluna ativo com valor true. Os desenvolvedores foram alertados do período de transição e, após expirar o prazo, foi removida a visão PacientesAtivos. 


\subsubsection{Usar fonte de dados oficial}

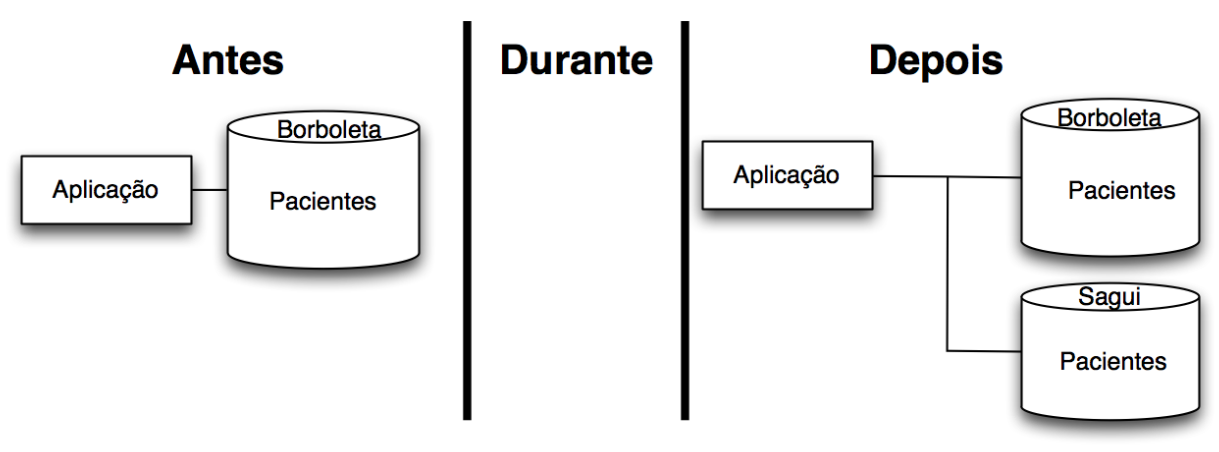

Figura 3.46: Refatoração arquitetural usar fonte de dados oficial

Motivação - Utiliza-se essa refatoração para garantir o uso da versão oficial de um conjunto de dados. Quando os dados são armazenados em vários lugares, você corre o risco de inconsistência e indisponibilidade.

Avaliação - Essa refatoração exige o custo de alterar todas as referências dos aplicativos às tabelas locais e garantir que ambas as fontes de dados utilizem as mesmas estratégias de chaves e que possuam a mesma semântica de dados.

Esquema - É preciso escolher qual a fonte de dados oficial e decidir sobre usar acesso direto à nova fonte de dados ou replicação de dados. Por último, excluir as tabelas que não serão mais usadas.

Dados - Se a semântica de dados local for diferente da oficial, é necessário aplicar replicação de dados e refatorações para converter os valores ao formato adequado.

Aplicativo - Para um acesso direto à nova fonte de dados, os códigos de conexão das aplicações devem ser alterados. Para uma replicação, será necessário desenvolver scripts para sincronizar os dados.

Exemplo - Os dados de pacientes da aplicação Borboleta não são os oficiais. Deste modo, a aplicação irá conectar na base de dados do Sagui para começar a usar a fonte de dados oficial para pacientes. 


\subsubsection{Migrar método de banco de dados}

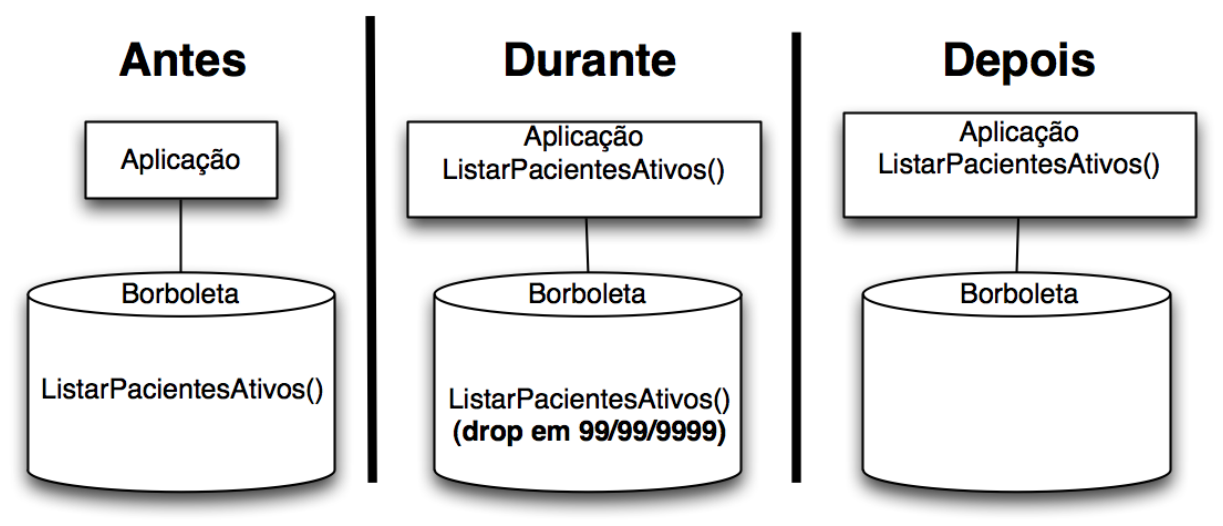

Figura 3.47: Refatoração migrar método de banco de dados

Motivação - Mudanças na lógica de negócio das aplicações podem tornar obsoleto um método escrito no banco de dados. Esta refatoração elimina o problema de portabilidade entre os bancos de dados e facilita a manutenção das aplicações.

Avaliação - Pode-se prejudicar o desempenho principalmente se o método acessa uma quantidade significativa de dados, que teriam que ser passados ao método antes do processamento.

Esquema - No período de transição, é necessário alertar os desenvolvedores sobre a eliminação do método do banco e, após o período de transição, removê-lo. É necessário reescrever a lógica do método nas aplicações.

Dados - Não se aplica.

Aplicativo - As aplicações devem ser alteradas para não acessar o método removido do banco e utilizar o método criado em seu código.

Exemplo - Foi criado o método ListarPacientesAtivos na aplicação para substituir o mesmo método removido do banco de dados Borboleta. 


\subsubsection{Migrar método para banco de dados}

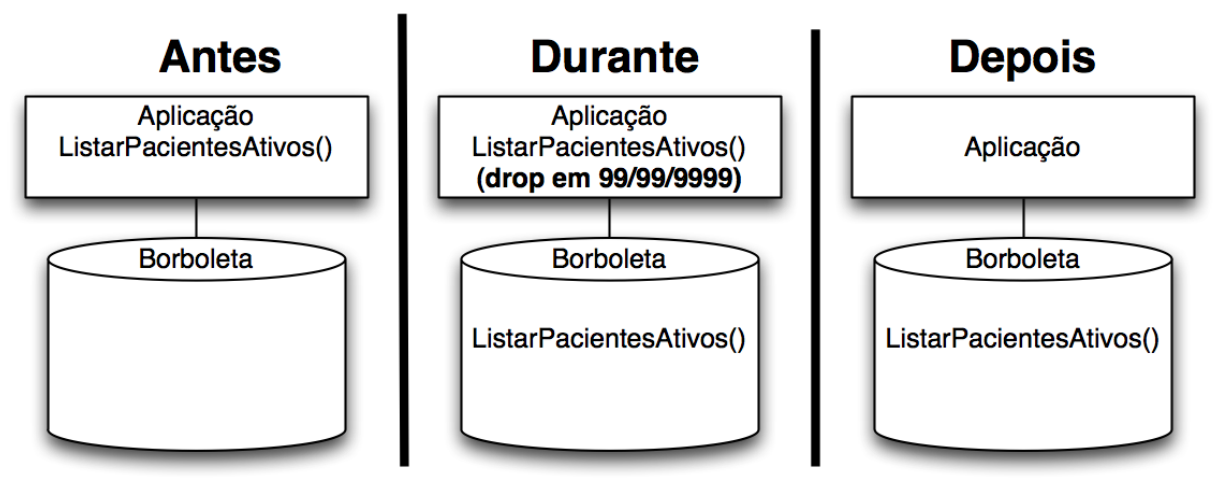

Figura 3.48: Refatoração migrar método para banco de dados

Motivação - Essa refatoração facilita a reutilização de código, pois várias aplicações escritas em diferentes linguagens podem compartilhar métodos de banco de dados (stored procedures, funções ou triggers) e melhora o desempenho principalmente se o procedimento armazenado for processar grandes quantidades de dados, pois evita que grande volume de dados trafegue pela rede.

Avaliação - Migrar métodos para o banco de dados prejudica a portabilidade do código, pois linguagem dos métodos escritos dependem de cada fabricante de banco de dados.

Esquema - No período de transição, é necessário alertar os desenvolvedores sobre a eliminação do método da aplicaçao e, após o período de transição, removê-lo. É necessário reescrever o método dentro do banco de dados.

Dados - Não se aplica.

Aplicativo - As aplicações devem ser alteradas para utilizar o método criado no banco de dados.

Exemplo - Foi criado ao método ListarPacientesAtivos no banco de dados Borboleta para substituir o mesmo método removido da aplicação. 


\subsubsection{Introduzir tabela somente leitura}

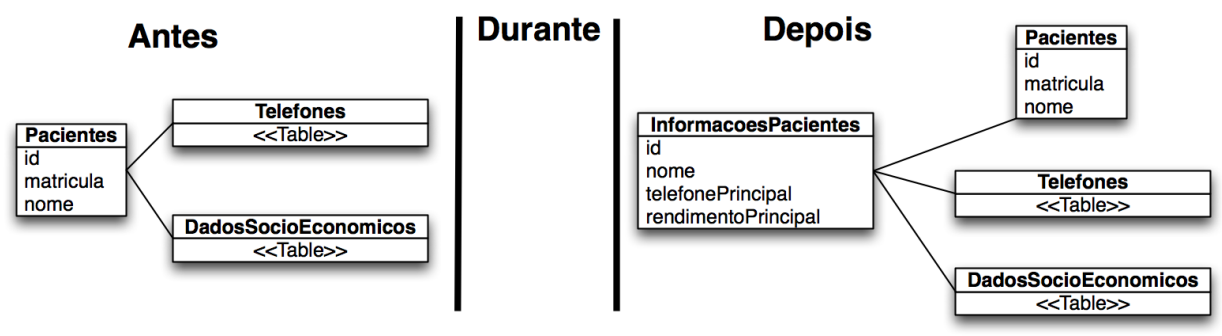

Figura 3.49: Refatoração introduzir tabela somente leitura

Motivação - Essa refatoração pode melhorar o desempenho quando uma consulta é realizada com joins entre várias tabelas. Essa consulta complexa pode ser substituída por uma consulta à apenas uma tabela que concentre todas as colunas necessárias, facilitando o acesso das aplicações. Garante, também, a segurança dos dados, pois aplicações apenas farão acesso de leitura aos dados dessa tabela.

Avaliação - Há um ganho de desempenho na recuperação dos dados, porém há um tempo de inconsistência dos dados até a execução dos scripts para atualização deles na tabela somente de leitura.

Esquema - No período de transição, é necessário alertar os desenvolvedores sobre a criação da tabela somente de leitura, criar a nova tabela e escrever os scripts de atualização.

Dados - Deve-se ter cuidado com a utilização de dados desatualizados, durante o período entre as execuções do script de atualização.

Aplicativo - As aplicações devem ser alteradas para acessar a nova tabela e os usuários devem possuir permissão apenas de leitura à essa tabela.

Exemplo - Antes da refatoração, as aplicações para obter informações de Nome, TelefonePrincipal e Redimentoprincipal, precisavam realizar um join entre as tabelas Pacientes, Telefones e DadosSocioEconomicos. Após a refatoração, as aplicações puderam obter esses dados consultando apenas a tabela somente de leitura InformacoesPacientes. 


\subsection{Conclusão}

As refatoração de banco de dados propostas por Ambler compõem um conjunto muito importante de técnicas e boas práticas já existentes no mundo de banco de dados. A contribuição em retomar essas técnicas em formato de refatoração pode ser justificada pelos seguintes pontos:

1. Colocar um nome bem definido em cada refatoração traz grandes benefícios de comunicação entre os membros de uma equipe de desenvolvimento.

2. Criar um catálogo dessas melhores práticas incentiva o uso e o crescimento desse catálogo com novas técnicas.

3. Os principais cuidados e a experiência em executar uma técnica pode ser documentada em alguma seção da refatoração para que o próximo executor tenha mais sucesso com a refatoração.

No próximo capítulo, apresentaremos uma forma inovadora de replicar os dados para as refatorações que precisam desse cuidado no período de transição. 


\section{Capítulo 4}

\section{Replicação assíncrona em banco de dados evolutivos}

Devido às limitações de implementação do código de apoio na forma de triggers síncronos, apresentas na Seção 2.5, esta tese propõe uma alternativa de organização e estruturação do código de apoio, dividindo a tarefa de manter atualizados os esquemas antigos e novos em três etapas: coleta de informações de transações, mapeamento e execução. As próximas seções detalham cada uma delas. Inicialmente, essa abordagem foi apresentada pelos autores no SBBD [DKF09] e neste capítulo a retomamos com mais informações.

\subsection{Etapa de coleta de informações de transações}

A etapa de coleta de informações de transações é executada por um trigger bastante simples e genérico, denominado trigger coletor, que é utilizado para todos os tipos de refatorações existentes, com o objetivo de capturar todas as informações da transação, i.e., qual foi a operação (inserção, exclusão ou atualização), quais os valores anteriores existentes na tabela e quais os novos valores usados para a atualização. A Figura 4.1 mostra dois triggers coletores em ação, um na tabela Paciente e outro na tabela Dados socioeconômicos.

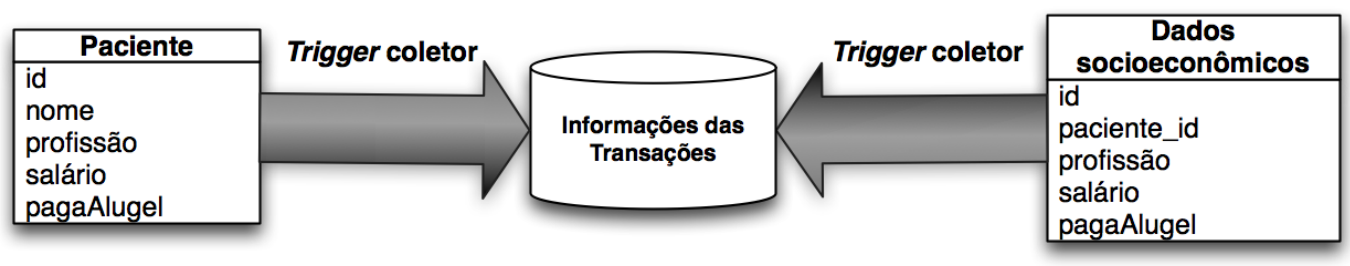

Figura 4.1: Etapa de coleta de informações de transações 
As informações das transações são armazenadas em tabelas temporárias específicas para cada origem. Considerando o exemplo da Figura 4.1, as informações das transações da tabela Paciente são armazendas na tabela Paciente Transactions, e as informações de Dados socioeconômicos são armazendas em Dados socioeconômicos Transactions.

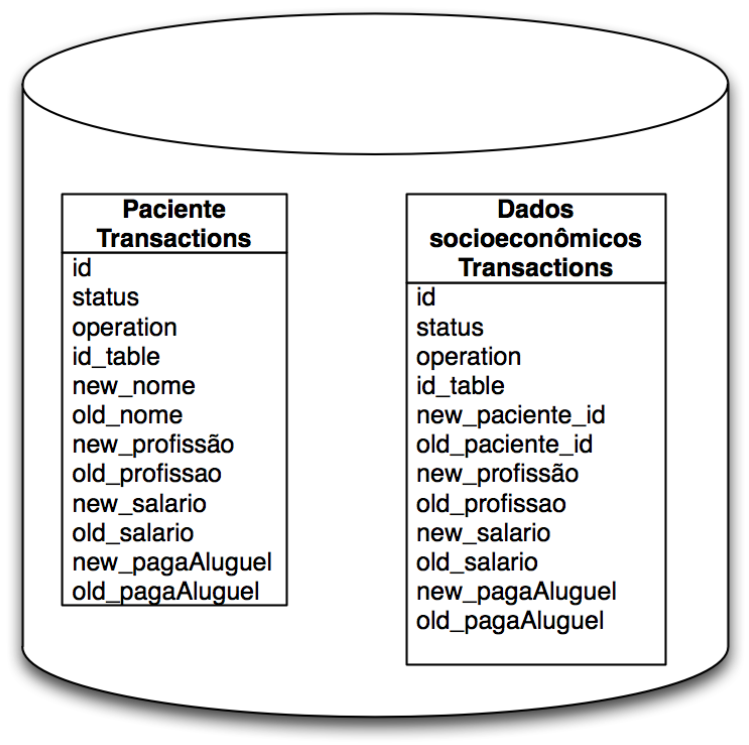

Figura 4.2: Informações armazenadas das transações

A Figura 4.2 mostra duas tabelas temporárias utilizadas pelos triggers coletores para o armazenamento das transações. Elas são estruturadas da seguinte forma:

1. Três colunas de controle: $i d$, status, operation, que correspondem à chave da tabela temporária, estado da replicação da transação e qual é a operação da transação (inclusão, exclusão ou alteração).

2. Chave da tabela origem: é a coluna id_table, que corresponde à coluna id da tabela de origem.

3. Colunas old e new: para cada coluna da tabela de origem, existem duas colunas, uma com prefixo old e outra com new, para armazenar o valor da coluna antes e depois da transação.

\subsection{Etapa de mapeamento}

O objetivo da etapa de mapeamento é definir um mapa da origem para o destino das transações. No exemplo da Seção 2.4, poderíamos ter um mapeamento que informa que o atributo profissão da tabela de pacientes (origem) deve ir para o atributo profissão da tabela de dados socioeconômicos (destino). 


\begin{tabular}{|l|l|l|l|}
\hline \multicolumn{1}{|c|}{ Paciente (pac) } & \multicolumn{1}{c|}{$\begin{array}{l}\text { Dados } \\
\text { Id }\end{array}$} \\
\begin{tabular}{l|l|l|} 
Nome \\
Profissão \\
Salário \\
Paga Aluguel?
\end{tabular} & $\begin{array}{l}\text { Mapa } \\
\text { pac.Profissão = dse.Profissão } \\
\text { pac.Salário = dse. Salário } \\
\text { pac.Paga Aluguel = dse.Paga Aluguel }\end{array}$ & $\begin{array}{l}\text { paciente_id } \\
\text { Profissão } \\
\text { Salário } \\
\text { Paga aluguel? }\end{array}$ \\
\hline
\end{tabular}

Figura 4.3: Etapa de mapeamento

O mesmo mapeamento deve ser feito para todos os outros atributos da tabela de pacientes que serão replicados, conforme mostra a Figura 4.3.

\subsection{Etapa de execução}

Com uma certa frequência, que é definida pelo administrador do banco de dados, o processo de replicação é executado para que os dados dos esquemas antigo e novo fiquem atualizados. O objetivo é processar as informações coletadas na primeira etapa, obedecendo os mapeamentos da segunda. A Figura 4.4 mostra um processo de replicação em funcionamento. Nessa figura, é possível visualizar as principais ações executadas:

1. Leitura do mapeamento: o processo lê o mapa para deduzir a origem e o destino das informações.

2. Consumo das transações coletadas: as informações das transações são lidas e processadas para que seja possível reproduzir as operações na tabela destino.

3. Alteração das tabelas: as tabelas definidas no mapeamento são atualizadas.

4. Gravação dos logs de execução: o resultado é gravado em logs de execução.

Essas três etapas - coleta, mapeamento e execução - fazem todo o trabalho esperado do código de apoio. Quando as três etapas estão dentro dos triggers, no formato proposto por Ambler, a atualização dos esquemas é feita de forma síncrona. Quando somente a etapa de coleta é executada junto com a transação da aplicação e a etapa de execução (que é a etapa que realmente efetua o trabalho de atualização) é realizada em um momento posterior, denominamos a atualização de assíncrona. Como veremos a seguir, essa nova forma de organização do código de apoio permite a resolução dos problemas apontados na abordagem proposta por Ambler. 


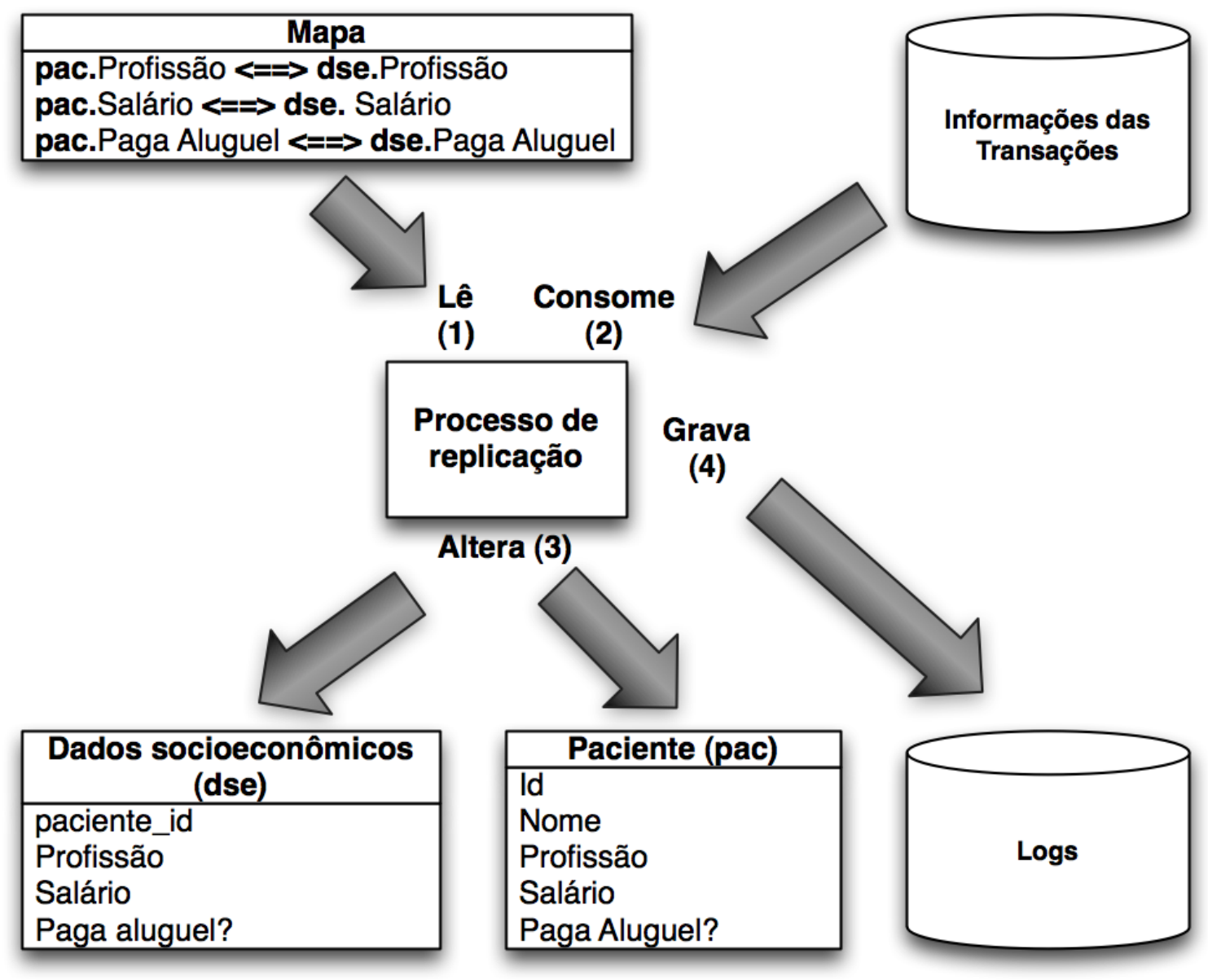

Figura 4.4: Etapa de execução da replicação

\subsection{Avaliação preliminar da replicação assíncrona}

Analisando novamente as dificuldades apresentadas na Seção 2.5, temos a seguinte avaliação preliminar da replicação assíncrona:

1. Codificação específica: não teremos mais um trigger específico para cada tipo de refatoração. $O$ único trigger necessário será o coletor, um trigger genérico que armazena todas as informações existentes em uma transação.

2. Código de tratamento de ciclos: o problema será resolvido em um único ponto: na etapa de execução. $\mathrm{O}$ processo de replicação tem acesso a todos os mapeamentos existentes e também às transações capturadas até o momento. Com isso, é possível inferir a existência de ciclos e evitar o problema. 
3. Transação lenta: a transação da aplicação não ficará lenta, pois o único trigger que será disparado será o coletor, que é bastante simples e executa somente o armazenamento das informações de uma transação.

4. Possível erro desconhecido para a aplicação: um possível erro de replicação não ocorrerá para a aplicação, mas, se houver, o erro será recebido, na etapa de execução, pelo processo de replicação. O processo armazenará todos os $\log s$ necessários, alertando os responsáveis e realizando novamente a replicação quando o problema estiver resolvido.

Além das dificuldades que a replicação assíncrona resolve, obtém-se um grande benefício ao dividir o processo em três etapas: a possibilidade de desenvolver uma ferramenta para os administradores executarem refatorações de banco de dados. Essa possibilidade existe porque não é difícil construir geradores de triggers para a coleta das transações (primeira etapa) e é viável construir uma aplicação para definir os mapeamentos (segunda etapa). Além disso, a ferramenta poderá conter um conjunto predefinido de mapeamentos para cada tipo de refatoração. Para finalizar, basta codificar um processo, que lê os mapeamentos e consome as informações armazenadas das transações, atualizando as tabelas destinos (terceira etapa), que teremos uma ferramenta útil para o administrador.

\subsection{Premissas para a replicação assíncrona}

A principal premissa para replicação assíncrona é a possibilidade das tabelas envolvidas em uma refatoração ficarem com os dados desatualizados durante um certo tempo. O período de tempo, definido pelo administrador do banco de dados, é o intervalo entre execuções do processo de replicação. O administrador poderá decidir que o processo deve ser executado, por exemplo, uma vez ao dia. Em outro caso, ele poderá decidir que o período de tempo com os dados desatualizados deve ser o menor possível (por exemplo, um minuto), pois as informações envolvidas nas tabelas refatoradas são críticas.

A implementação de um processo de replicação que é executado a cada intervalo de minutos, horas ou dia é simples, pois basta utilizar alguma ferramenta de agendamento de execução de processos. Caso o administrador exija um intervalo que seja o menor possível, é preciso que a implementação da ferramenta seja mais sofisticada e utilize recursos específicos de um gerenciador de banco de dados para que o processo de replicação seja notificado quando existe alguma operação pendente e não perca tempo consultando as tabelas que armazenam essas operações.

Um exemplo de implementação sofisticada é desenvolver um processo dedicado de replicação que receba uma notificação do trigger coletor - por exemplo, utilizando o LISTEN [8.3a] e o NOT IFY [8.3b] do PostgreSQL - para que seja feito imediatamente o trabalho necessário. Nessa implementação, o período de tempo com os dados desatualizados pode ser reduzido para a ordem de milissegundos tempo entre o recebimento da notificação pelo processo dedicado e a atualização da tabela destino. 
A violação da consistência dos dados, mesmo que por um tempo pequeno, deve ser explicitamente visualizada pelo domínio da aplicação de modo que os usuários possam avaliar a importância de tal inconsistência. Nas instituições financeiras, por exemplo, é hábito e conhecimento de todos que a situação de uma conta corrente pode ficar inconsistente até a realização de todas as compensações, créditos e/ou estornos. Por outro lado, em outros domínios, como sistemas de saúde para UTIs, algumas informações, como o último relatório do estado de saúde do paciente, não podem ficar inconsistentes pois os profissionais da saúde poderiam realizar intervenções incorretas no paciente. Consequentemente, as consultas aos dados devem informar não apenas o dado como também o seu grau de inconsistência, de modo que os usuários possam tomar decisões de acordo com seus domínios de aplicação específicos.

\subsection{Protótipo: Database Evolution Manager (DEM)}

Para validar a replicação assíncrona, um protótipo foi desenvolvido e testado. Utilizamos Ruby on Rails, como arcabouço para desenvolvimento da aplicação Web, e PostgreSQL como gerenciador de banco de dados. Denominados o protótipo de Database Evolution Manager (DEM) e a sua página inicial é mostrada na Figura 4.5. Nessa figura, é possível visualizar que o protótipo realiza as seguintes atividades disponíveis no menu de opções:

- Tables: explora quais tabelas existem em um banco de dados, permitindo observar a sua estrutura: quais colunas estão definidas e os tipos de dados usados.

- Triggers: gera automaticamente todo o código de apoio: o trigger coletor e a tabela temporária para armazenar as transações coletadas.

- Maps: cria o mapeamento necessário para a replicação de dados.

- Jobs: executa o processo de replicação, que consome as linhas da tabela temporária e atualiza a tabela destino.

- Refactoring: por último, quatro refatorações foram implementadas utilizando as funcionalidades apresentadas nos itens anteriores. As quatros refatorações estão na página inicial do DEM.

Nas próximas seções, descreveremos as principais páginas Web do protótipo DEM para se ter uma idéia do trabalho realizado. 


\section{Database Evolution Manager}

\begin{tabular}{|l|}
\hline MENU \\
\hline Tables \\
\hline Triggers \\
\hline Maps \\
\hline Jobs \\
\hline Refactoring \\
\hline
\end{tabular}

\section{Refactoring}

\begin{tabular}{|c|c|c|c|}
\hline name & description & help & action \\
\hline Move Column & $\begin{array}{l}\text { Migrate a table column, with all of its } \\
\text { data, to another existing table }\end{array}$ & $?$ & Execute \\
\hline $\begin{array}{l}\text { Rename } \\
\text { Column }\end{array}$ & $\begin{array}{l}\text { Rename an existing table column with } \\
\text { a name that explains its purpose }\end{array}$ & $\underline{?}$ & Execute \\
\hline Rename Table & $\begin{array}{l}\text { Rename an existing table with a name } \\
\text { that explains its purpose }\end{array}$ & $\underline{?}$ & Execute \\
\hline Split Table & $\begin{array}{l}\text { Veritically split (e.g., by columns) an } \\
\text { existing table into a new table }\end{array}$ & $\underline{?}$ & Execute \\
\hline
\end{tabular}

\section{CCSL}

BSD Licence 둥 2011

Figura 4.5: Página inicial do DEM 


\subsubsection{Página Triggers}

A página do DEM que permite a criação dos triggers pode ser vista na Figura 4.6. Esta página é útil para o administrador visualizar o código gerado antes de executá-lo no banco de dados. $\mathrm{O}$ trecho do código gerado da figura acima é reproduzido a seguir para ficar mais claro o entendimento.

\section{Database Evolution Manager}

\section{Trigger for table pacientes}

\section{Execute create code}

Cancel

-- Table to store the transaction

CREATE SEQUENCE pacientes_transactions_id_seq;

CREATE TABLE pacientes_transactions (

id integer NOT NULL DEFAULT NEXTVAL('pacientes_transactions_id_seq'), status character varying $(50)$ NOT NULL,

operation character varying(50) NOT NULL,

id_table integer NOT NULL,

NEW_nome character varying(255),OLD_nome character varying(255),

NEW_profissao character varying(255), OLD_profissao character varying(255),

NEW_salario integer,OLD_salario integer,

NEW_pagaAluguel boolean,OLD_pagaAluguel boolean

);

CREATE UNIQUE INDEX pacientes_transactions_id ON pacientes_transactions(id);

-- Function and trigger to f_pacientes_transactions() on UPDATE, INSERT, DELETE.

CREATE OR REPLACE FUNCTION f_pacientes_transactions() RETURNS TRICGER AS

Sf_pacientes_transactions\$

DECLARE

BECIN

IF (TC_OP = 'DELETE') THEN

-- INSERT DELETED ROW

INSERT INTO pacientes transactions (

status,operation,id_table,OLD_nome,OLD_profissao,OLD_salario,OLD_pagaAluguel

)

values (

'NEW','DELETE', OLD.id,OLD.nome,OLD.profissao,OLD.salario,OLD.pagaAluguel );

Figura 4.6: Página de Trigger do DEM 


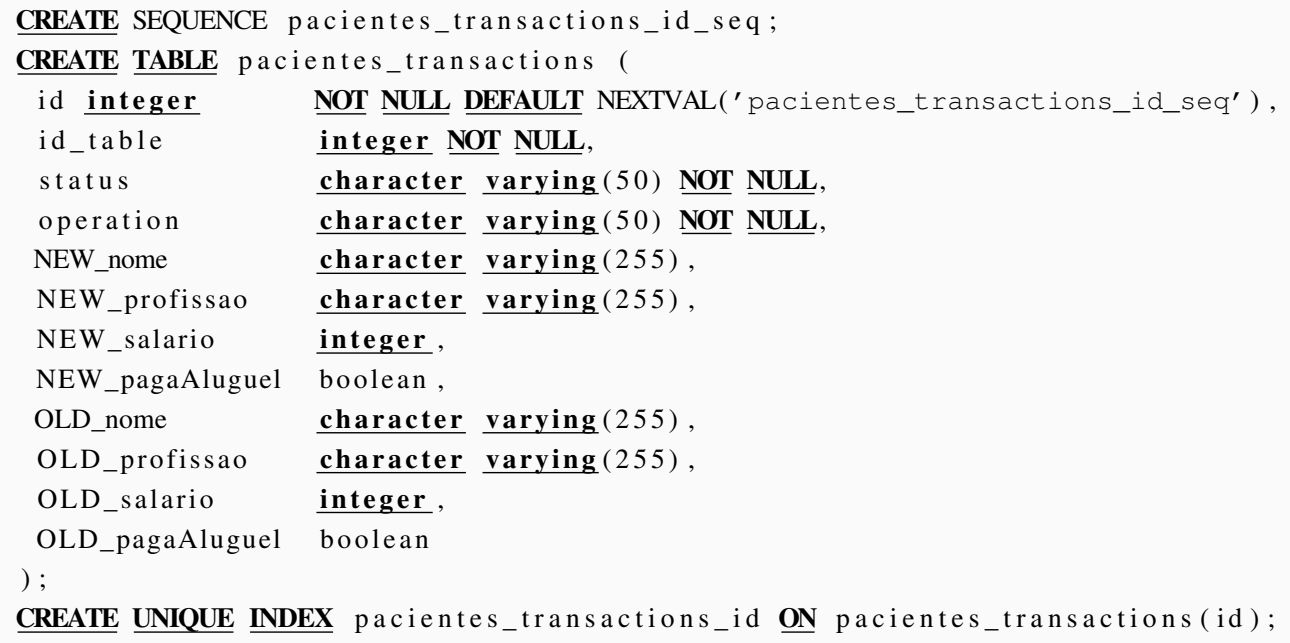

Listagem 4.1: Objetos temporários para o trigger coletor

A tabela temporária pacientes_transactions, apresentada na Listagem 4.1, precisa de explicações para o entendimento do processo de replicação. Sua estrutura é definida a partir da tabela de origem dos dados e contém as seguintes colunas:

1. Colunas ide id_table: a coluna id é apenas um sequencial da tabela pacientes_transactions e a coluna id_table é o sequencial da tabela de pacientes.

2. Coluna status: para todas as linhas incluídas na tabela pacientes_transactions, essa coluna recebe o valor inicial de $N E W$. Após o processo de replicação realizar o seu trabalho, as linhas processadas recebem o valor EXECUTED para essa coluna. As linhas com o valor EXECU$T E D$ na coluna status não são mais utilizadas nas próximas execuções do processo.

3. Coluna operation: contém a operação realizada na tabela de pacientes. Os valores possíveis são: DELETE, UPDATE e INSERT. Essa informação indicará para o processo de replicação o que deve ser feito na tabela de destino.

4. Colunas com nomes NEW + Nome da coluna: são preenchidas com os valores novos provenientes das transações de inclusão e atualização.

5. Colunas com nomes OLD + Nome da coluna: são valores da coluna antes das transações de exclusão e atualização. 


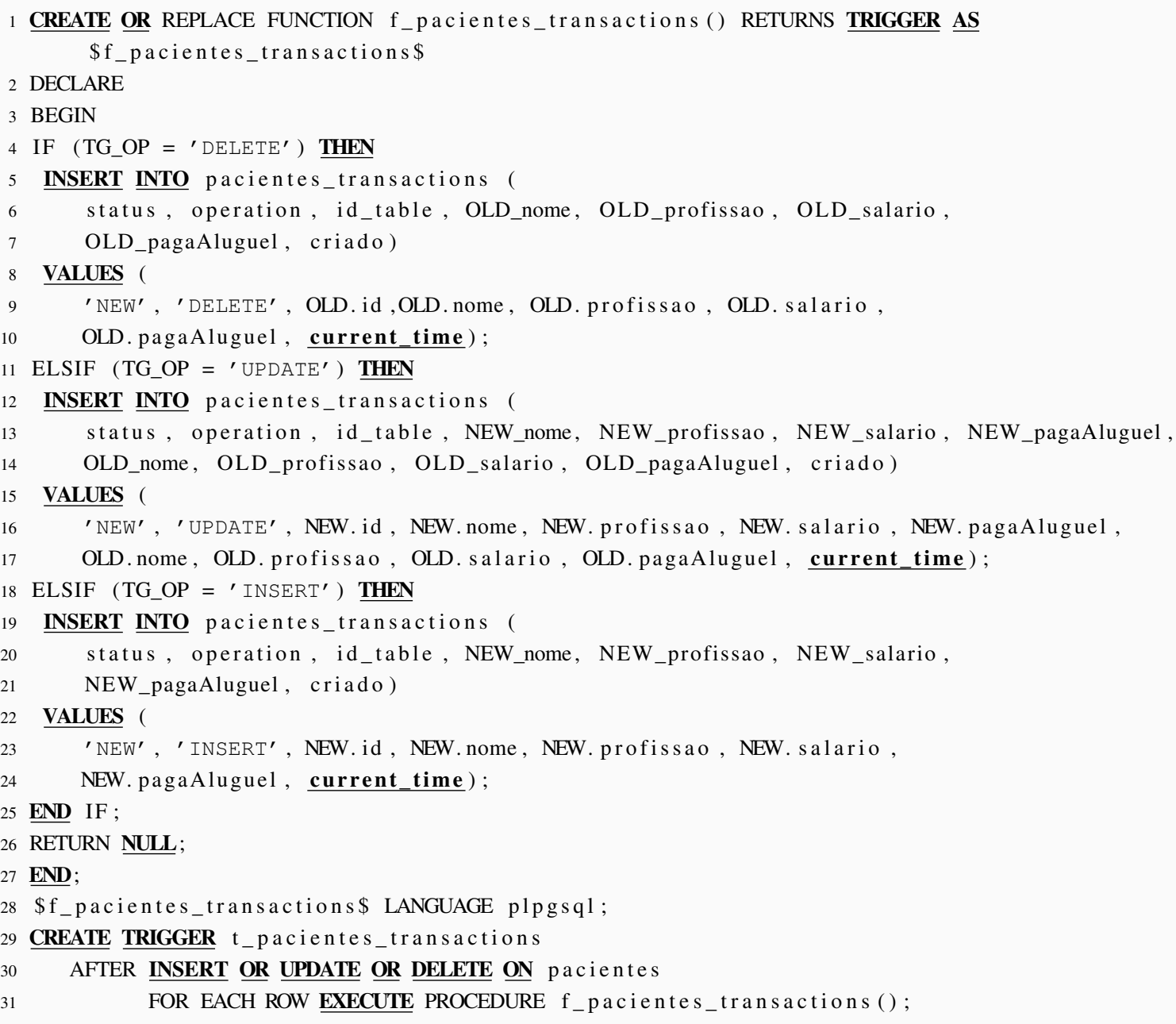

Listagem 4.2: Código exemplo do trigger coletor para a tabela de pacientes

A Listagem 4.2 mostra o código do trigger coletor para a tabela pacientes. Como podemos ver, o código é bastante conciso. Há um comando INSERT na tabela temporária pacientes_transactions (linhas 5, 12 e 19) para cada tipo de operação (linha 4 para DELETE, linha 11 para UPDATE e linha 18 para INSERT). Conforme o tipo da operação, um conjunto de valores devem ser incluídos na tabela temporária. No caso de exclusão, precisamos somente dos valores antigos das colunas da tabela de pacientes, no caso de atualização, os antigos e os novos, e, por último, no caso de inclusão, somente os valores novos. 


\subsubsection{Página Maps}

Antes de executar o processo de replicação é necessário criar um mapeamento das tabelas origem e destino. A Figura 4.7 ilustra um exemplo de mapeamento entre as tabelas do exemplo pacientes e dados_socioeconomicos. Após escolher as duas tabelas em uma lista de todas as tabelas existentes no banco de dados, essa página permite selecinar uma coluna no lado esquerdo (origem) e outra coluna do lado direito (destino) para que, se pressionar o botão Link colunns, o mapeamento das colunas se efetive e apareça na lista logo abaixo do botão pressionado. O mapeamento de três colunas que aparecem na Figura 4.7 é um exemplo de mapeamento entre as tabelas.

\section{Database Evolution Manager}

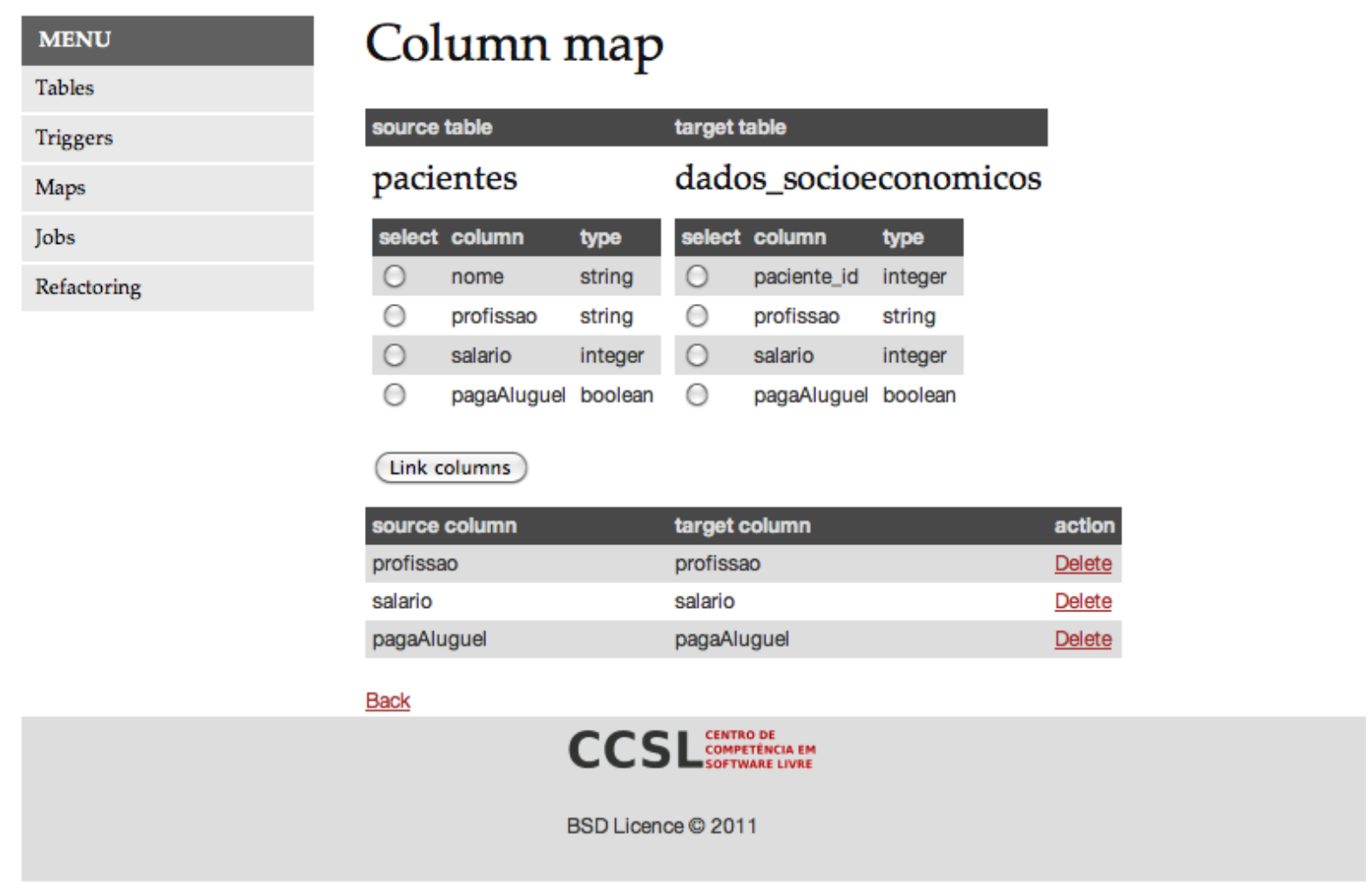

Figura 4.7: Página de Maps do DEM 


\subsubsection{Página Jobs}

A Figura 4.8 mostra a página que gerencia os processos de replicação de dados. Nela é possível visualizar a frequência, estado, origem e destino da replicação e, por último, os logs de execução desse processo.

\section{Database Evolution Manager}

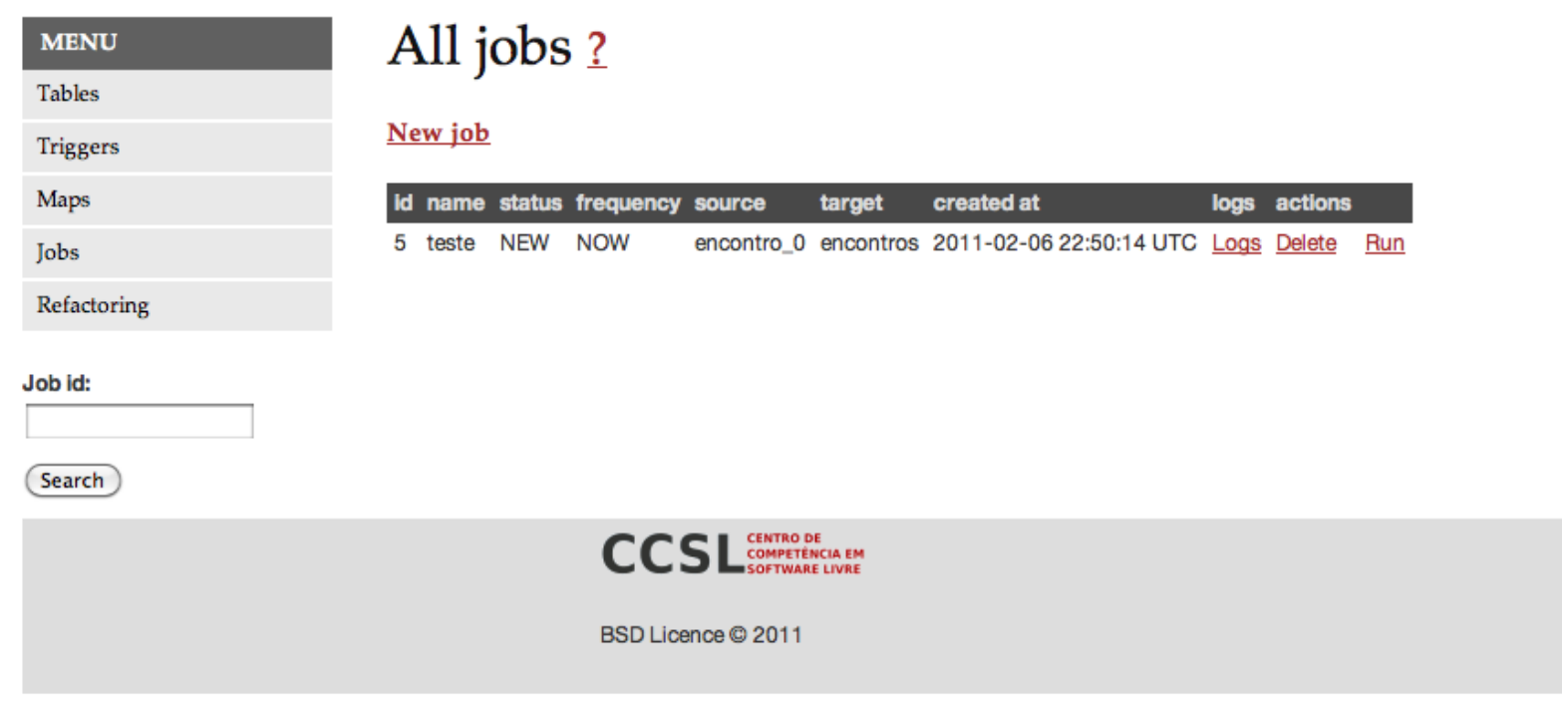

Figura 4.8: Página de jobs do DEM

O processo de replicação implementado no protótipo irá ler todas as linhas da tabela pacientes_ transactions que está com o valor de $N E W$ na coluna status. Para cada uma dessas linhas, o processo descobre qual operação que deve ser replicada (coluna operation) e constroi a operação usando as colunas com prefixo $N E W$ e $O L D$ e a chave id_table. Com a operação construída, basta executá-la na tabela destino e atualizar o estado da operação para EXECUTED. O código completo desse processo pode ser visto no Apêndice C.3.

O protótipo da ferramenta está disponível sob licença BSD na seguinte página: http://ccsl . ime.usp.br/borboleta/DatabaseEvolution. A ferramenta foi desenvolvida no projeto Borboleta, mas ela funciona independentemente do projeto e pode ser usada ou adapatada para qualquer banco de dados relacional que tenha o recurso de triggers. Na página do projeto, é possível obter mais informações e baixar o código da ferramenta. 


\section{Capítulo 5}

\section{Experimento de replicação assíncrona}

Com o objetivo de validar a proposta apresentada nesta tese, realizamos um experimento para comparar a solução atual síncrona de replicação de dados para refatoração [AS06] com a solução assíncrona apresentada no capítulo anterior. A comparação é feita verificando, em vários níveis de concorrência de banco de dados, o desempenho das duas soluções. Como na solução assíncrona a replicação de dados é postergada, o tempo necessário para processar uma atualização pendente é medido para finalizar a validação da proposta.

\subsection{Organização}

Conforme a nomeclatura apresentada no livro de Wohlin [ $\left.\mathrm{WRH}^{+} 00\right]$, o experimento que é adequado para a comparação dos métodos síncrono e assíncrono para refatoração de banco de dados é o experimento de engenharia. Esse tipo de experimento é definido como o método que observa as soluções existentes, sugere as soluções mais adequadas, desenvolve, mede, analisa e repete esse processo até que nenhuma melhoria adicional seja possível.

O autor do livro The Art of Computer Systems Performonce Analysis [Jai91], Raj Jain, define vários passos que devem ser seguidos em um experimento. Dentre eles realizamos os seguintes:

1. Descrição do sistema e dos objetivos do experimento: O primeiro passo, proposto por Raj Jain, é indicar os objetivos do experimento e definir o que constitui o sistema, delineando claramente as fronteiras do sistema. Considerando o mesmo conjunto de hardware e software, a definição do sistema pode variar dependendo de quais são os objetivos do estudo. No caso de replicação de banco de dados, precisamos definir qual é a aplicação cliente do banco, quais tabelas envolvidas e quais operações de banco de dados serão executadas (inclusão, atualizão, exclusão ou consulta). A escolha dos limites do sistema irá afetar a definição das métricas de desempenho, bem como as cargas de trabalho necessárias para comparar os sistemas. 
2. Seleção das métricas: O próximo passo é a seleção dos critérios para comparar o desempenho entre os sistemas. Estes critérios são chamados de métricas e são relacionados com a velocidade, a precisão e a disponibilidade dos serviços. No caso de um experimento em uma rede de dados, o desempenho é medido pela velocidade (taxa de transferência e atraso), pela precisão (taxa de erro), e pela disponibilidade dos pacotes enviados. O desempenho de um banco de dados é medido pela velocidade (tempo necessário para executar) de várias operações (consulta, inclusão, atualização e exclusão).

3. Seleção dos parâmetros: É necessário fazer uma lista de todos os parâmetros que afetam o desempenho. A lista pode ser dividida em parâmetros do sistema e os parâmetros de carga de trabalho. Os parâmetros do sistema incluem a definição do hardware e do software utilizado no ambiente do experimento. Os parâmetros de carga de trabalho são características das requisições dos clientes do banco de dados, tais como: quantidade de clientes, quais operações efetuadas, quantas operações executadas dentro de uma transação etc.

4. Elaboração dos experimentos: Após todos os passos anteriores, é preciso decidir sobre uma sequência de experiências que oferecem o máximo de informação do ambiente analisado com o mínimo esforço. Quantas repetições do experimento são necessárias? Quais parâmetros devem ser modificados ou mantidos em cada uma destas repetições? Como será realizada a coleta das métricas? Todas essas questões devem ser respondidas para iniciar o experimento.

5. Análise e interpretação dos dados: É importante perceber que os resultados de medições e simulações são quantidades aleatórias em que o resultado é diferente cada vez que a experiência é repetida. Portanto, na comparação entre duas alternativas, é necessário tratar a variabilidade dos resultados. Comparar os dados coletados sem usar nenhuma técnica estatística, pode levar a conclusões imprecisas. Interpretar os resultados é o passo mais importante do experimento, pois é neste momento que se produzem as conclusões.

6. Apresentação dos resultados: A etapa final do experimento é apresentar os resultados. É importante que os resultados sejam apresentados de uma forma clara, utilizando gráficos e sem jargão estatístico. Os gráficos devem ser adequadamente dimensionados e de fácil leitura para realizarmos a comparação das duas soluções de replicação de dados.

Os passos acima, propostos por Raj Jain, foram seguidos neste trabalho e, nas próximas seções, apresentaremos os resultados de cada um deles.

\subsection{Descrição do sistema e dos objetivos do experimento}

O ambiente que foi projetado para realizar o experimento é o que podemos definir de mais simples e representativo para realizar a comparação entre as soluções. Decidimos escolher somente uma tabela, 
aquela mais complexa e mais usada no sistema Borboleta [ $\left.\mathrm{DCK}^{+} 08\right]$ : tabela de encontros (Figura 5.1). Essa tabela é o centro da modelagem dos atendimentos realizados nos centros de saúde e contém 19 atributos para coletar as informações necessárias. Devido às regras de funcionamento de um centro de saúde, os encontros já realizados nunca são excluídos, mas podem sofrer alterações para complementar ou corrigir alguma informação. Desse modo, a tabela de encontros recebe inicialmente uma operação de inclusão e, posteriormente, várias atualizações dos profissionais da saúde por meio de sistemas existentes no centro de saúde ou com o uso dos dispositivos móveis do sistema Borboleta. A concorrência de atualização do mesmo encontro por vários profissionais da saúde pode ocorrer e essa concorrência será simulada, em vários níveis, no ambiente do experimento.

\begin{tabular}{|l|}
\hline \multicolumn{1}{|c|}{ Encontros } \\
\hline id \\
data \\
inicial \\
rotina \\
realizada \\
motivonaorealizacao \\
observacao \\
pessoa_id \\
anamnese \\
codigo_retorno \\
descricao_retorno \\
outras_anotacoes \\
reavaliacaomedica \\
reavaliacaoenfermagem \\
reavaliacaofisio \\
ehprofcomapd \\
created_at \\
updated_at \\
login \\
\hline
\end{tabular}

Figura 5.1: Tabela de encontros do projeto Borboleta

O objetivo do experimento é validar as seguintes hipóteses:

- Hipótese 1: o método síncrono gera muitos bloqueios e a quantidade é maior do que o método assíncrono.

- Hipótese 2: o sistema que atualiza o banco de dados com replicação assíncrona tem um desempenho, medido por quantidade de operações por segundo, melhor do que quando o banco utiliza o método síncrono.

- Hipótese 3: o tempo para processar uma operação pendente no método assíncrono é pequeno e está na ordem de dezenas de milissegundos.

As hipóteses 1 e 2 têm o foco em realizar a comparação entre os métodos síncrono e assíncrono 
em termos de desempenho. A primeira olhando para a quantidade de bloqueios e, a segunda, para a quantidade de operações por segundo. A hipótese 3 aborda o período que a tabela de encontros fica inconsistente, pois somente após a execução do processo de replicação é que não existirá mais inconsistência. O tempo médio de processamento de uma operação pendente fornecerá uma estimativa do período de inconsistência da tabela de encontros.

\subsection{Seleção das métricas}

As métricas de um experimento servem para verificar as hipóteses no ambiente de experimentação. Coletando e analisando os valores das métricas, é possível decidir se as hipóteses do experimento são válidas. As seguintes métricas foram selecionadas para serem observadas durante o nosso experimento:

- Métrica 1 - Quantidade de bloqueios: o banco de dados, para controlar a concorrência de acesso a uma mesma linha de tabela, utiliza bloqueios que interrompem a execução de um processo para que um outro termine o que está fazendo. Considerando que os processos escolham de forma aleatória quais linhas de uma tabela que irão atualizar e se fixarmos a quantidade de linhas da tabela, quanto maior o número de processos, maior será a probabilidade de ocorrer bloqueios. Consequentemente, nessa situação, o desempenho médio de todos os processos diminuirá.

- Métrica 2 - Quantidade de operações por segundo: a quantidade de operações realizadas pelo gerenciador de banco de dados em um intervalo de tempo dividida por esse tempo em segundos é o valor desta métrica. Essa métrica serve para medir o desempenho médio dos processos que realizam essas operações no banco de dados.

- Métrica 3 - Tempo de inconsistência: em um ambiente com replicação assíncrona, o tempo de inconsistência pode ser estimado pelo número de operações pendentes vezes o tempo médio necessário para processar uma operação na tabela de destino.

A métrica 1 está direcionada para validar a hipótese 1, apresentada na seção anterior. A métrica 2 será útil para validar a hipótese 2. Por último, a métrica 3 foi elaborada para que possamos verificar a hipótese 3. Com essa organização temos a quantidade de métricas suficiente para realizar o experimento.

Os valores das métricas 1 e 2 são coletadas pela ferramenta Bristlecone Performance Test [Con]. A ferramenta executa um conjunto de testes de desempenho e fornece no final várias informações para avaliação do resultado. A métrica 3 é obtida após o término do experimento, consultando as linhas da tabela temporária criada pelo processo de replicação assíncrona. 


\subsection{Seleção dos parâmetros}

Temos dois tipos de parâmetros para criar um ambiente em laboratório que seja o mais próximo possível do real. O primeiro são os parâmetros de sistema que definem o hardware e software. O segundo são os parâmetros de carga do sistema que controlam o nível de utilização e concorrência de acesso do ambiente. As próximas seções descrevem esses dois tipos de parâmetros.

\subsubsection{Parâmetros de sistema}

Os principais elementos da máquina utilizada no experimento estão na Figura 5.2. Basicamente temos uma máquina real e uma máquina virtual que serão descritas abaixo.

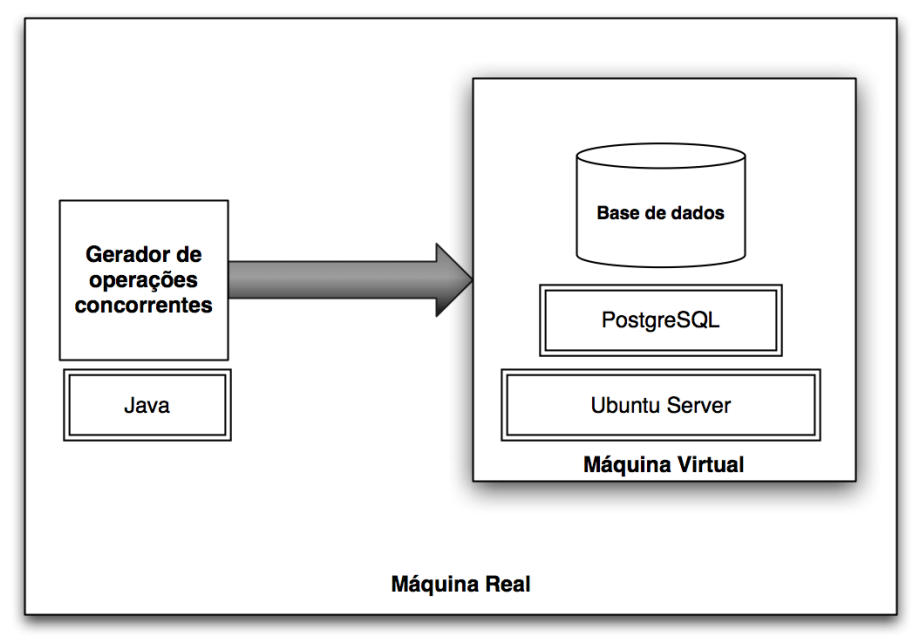

Figura 5.2: Máquina do experimento

\section{Máquina virtual}

A máquina virtual foi criada com o software VMware Fusion [VMw], versão 3.1.2, e tem os seguintes elementos:

1. Recursos: contém $1 \mathrm{~GB}$ de memória, 500GB de disco com um dos dois núcleos do processador Core 2 Duo de $2.8 \mathrm{Ghz}$.

2. Sistema operacional: utilizamos o GNU/Linux, distribuição Ubuntu 9.10 Server 64 bits com instalação padrão.

3. Gerenciador de banco de dados: foi utilizado o gerenciador PostgreSQL versão 8.4, com uma instalação padrão. $\mathrm{O}$ único parâmetro alterado foi a quantidade máxima de conexões. O valor 
configurado foi 200, em decorrência da quantidade de memória da máquina virtual. Quando se tentou configurar um valor maior de conexões, por exemplo 250, ocorreu um erro no PostgreSQL que exigia um aumento do número de semáfaros e memória compartilhada do sistema operacional. Não realizamos essa reconfiguração do sistema operacional porque o objetivo é ter uma instalação padrão e, consequentemente, alterar o mínimo possível as instalações originais do software. Desse modo, assumimos o limite de 200 para a quantidade máxima de conexões. No Apêndice B, apresentamos a configuração completa do PostgreSQL.

\section{Máquina real}

A máquina real é um MacBook Pro com os seguintes elementos:

1. Hardware: contém 7GB de memória, 20GB de disco com processador Core 2 Duo de $2.8 \mathrm{Ghz}$.

2. Sistema operacional: utilizamos Mac OS X, versão 10.6.4 de 64 bits.

3. Gerador de operações concorrentes: a ferramenta Bristlecone Performance Test [Con] foi usada para gerar um grande volume de operações concorrentes no banco de dados. A ferramenta é escrita em Java e possui vários parâmetros para controlar a concorrência. Essa ferramenta foi bastante útil na realização do experimento, pois permite desenvolver código em Java para atender à nossa necessidade. No Apêndice C.4 é possível visualizar o código desenvolvido para essa ferramenta.

4. Java Virtual Machine: a JVM utilizada é a SE Runtime Environment 1.6.0.22 [Sup]. Basicamente a JVM foi utilizada para executar a ferramenta Bristlecone Performance Test. Todos os processos clientes para gerar carga de utilização do ambiente são Threads Java.

Durante todo o experimento, tanto a máquina real quanto a máquina virtual foram monitoradas por ferramentas do próprio sistema operacional (Activity Monitor para Mac OS X e top para Ubuntu) e nenhuma delas apresentou falta de recursos que comprometesse o experimento.

\subsubsection{Parâmetros de carga do sistema}

Para simular vários níveis de utilização do ambiente do experimento, utilizamos os seguintes parâmetros:

- Parâmetro 1: Quantidade de linhas na tabela, no início de cada experimento, são inseridas uma certa quantidade de linhas na tabela de encontros. A quantidade de linhas em relação à quantidade de processos clientes fornece uma medida de possível concorrência entre os processos.

- Parâmetro 2: Quantidade de processos clientes simultâneos, este é o principal parâmetro que irá controlar o nível de concorrência à tabela de encontros. O valor máximo deste parâmetro é 
limitado pelo número máximo de conexões simultâneas no banco de dados que tem o valor de 200, como já descrito na Seção 5.4.1.

- Parâmetro 3: Tempo de duração de um experimento, os processos que geram carga ao ambiente de experimento são controlados por um período máximo que disparam transações para o banco de dados. Esse período, medido em segundos, é o tempo de duração de um experimento e, no seu término, podemos obter os valores das métricas. Para tratar estatisticamente os valores obtidos, os experimentos serão repetidos em uma quantidade suficiente para termos segurança na análise que será realizada posteriormente.

- Parâmetro 4: Tempo de espera entre cada operação, um tempo de espera é realizado entre o término de uma operação e o início de outra para simular o usuário digitando algum dado.

- Parâmetro 5: Quantidade de operações em cada transação, cada processo cliente abre uma transação no banco de dados, executa uma quantidade de operações e, no final deste ciclo, fecha a transação, efetivando as operações no banco de dados (commit). É importante observar que, durante uma transação, todas as linhas alteradas estarão bloqueadas para outros processos até o fechamento da transação. Desse modo, este parâmetro também controla a concorrência à tabela de encontros.

\subsection{Elaboração dos experimentos}

Elaboramos três cenários para testar as hipóteses propostas na Seção 5.2. Todos os cenários têm o mesmo processo gerador de operações concorrentes e as mesmas tabelas de encontros. O que diferencia os cenários é a existência ou não de triggers e o seu tipo: síncrono ou assíncrono.

\subsubsection{Cenários}

Foram criadas duas tabelas de encontros (encontros_0 e encontros_1) com a mesma estrutura, mas com nomes diferentes. Quando há replicação de dados, a tabela encontros_0 é a origem dos dados e a tabela encontros_1 é o destino. Abaixo, temos a descrição de cada cenário:

- Cenário 1 - Sem trigger: as duas tabelas de encontros não têm replicação de dados, isto é, não existe nenhum trigger associado às duas tabelas. Este cenário tem como objetivo verificar qual é o maior desempenho do ambiente de simulação. A Figura 5.3 representa o cenário sem replicação.

- Cenário 2 - Trigger síncrono: o objetivo deste cenário é avaliar o desempenho da solução atual de replicação de dados em refatorações de banco de dados. A Figura 5.4 mostra as tabelas e o trigger síncrono. Este trigger é o mais simples e eficiente possível, ele só realiza a atualização da 


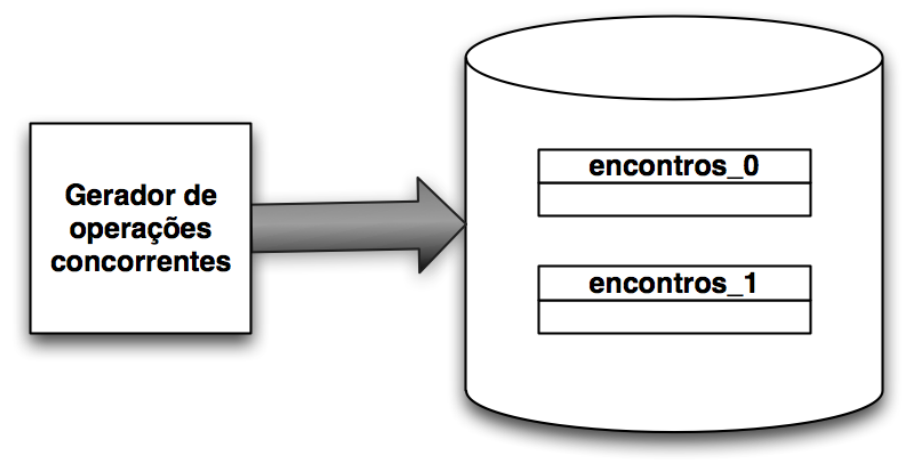

Figura 5.3: Cenário 1 - Sem triggers

tabela encontros_1 a partir dos dados da tabela encontros_0. O Apêndice C.1 apresenta o código utilizado.

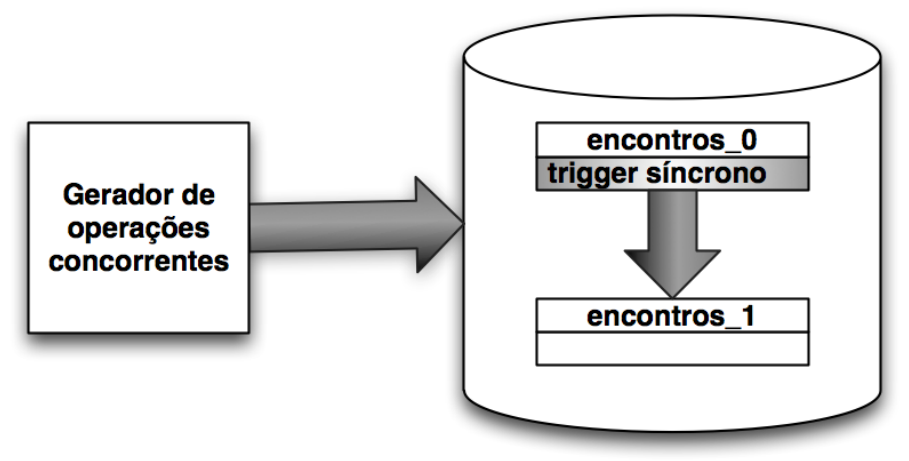

Figura 5.4: Cenário 2 - Trigger síncrono

- Cenário 3 - Trigger assíncrono: este cenário tem como objetivo avaliar a proposta de replicação assíncrona em bancos de dados. A Figura 5.5 mostra as tabelas envolvidas e o trigger assíncrono gravando os dados das operações em uma tabela temporária (temp) e o processo de replicação executando simultaneamente com o processo de gerador de operações concorrentes. O processo de replicação, apresentado no Apêndice C.3, e o trigger assíncrono, Apêndice C.2, são parte da ferramenta Database Evolution Manager (DEM) descrita na Seção 4.6.

\subsubsection{Etapas do experimento}

Para execução do experimento, temos duas etapas bem definidas: a primeira é a de preparação do ambiente, a segunda é a de execução de operações concorrentes no banco de dados. As duas etapas são iguais para todos os cenários do experimento. 


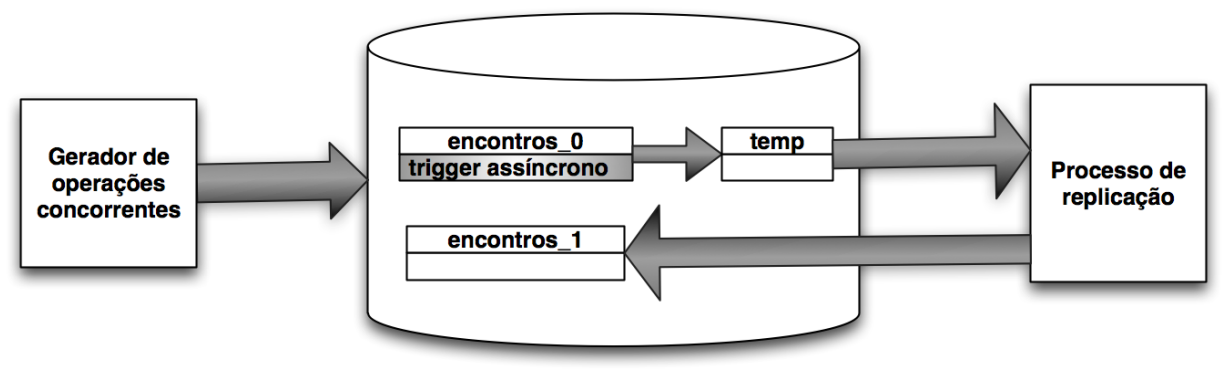

Figura 5.5: Cenário 3 - Trigger assíncrono

A primeira etapa é composta pelos seguintes passos:

1. Eliminação das tabelas: caso as tabelas encontros_0 e encontros_1 existam, elas são eliminadas do banco de dados com o comando drop table.

2. Criação das tabelas: as tabelas de encontros são criadas com o comando create table.

3. Carga dos dados: dados aleatórios são gerados e inseridos nas duas tabelas de encontro. A quantidade de linhas inseridas em cada tabela é o parâmetro 1, conforme foi definido na Seção 5.4.

Após a primeira etapa, são criados os processos clientes, conforme o parâmetro 2. Cada processo repete, pelo tempo de duração de um experimento, parâmetro 3, os seguintes passos:

1. Escolha aleatória de uma tabela: é sorteada qual das duas tabelas de encontros será atualizada.

2. Escolha aleatória de uma linha: considerando a quantidade de linhas na tabela, um número aleatório é gerado para sortear qual linha será atualizada.

3. Atualização da linha sorteada: todas as colunas da linha sorteada são atualizadas com um único comando update, que é enviado ao banco de dados. Entre um comando e outro, ocorre um tempo de espera, conforme parâmetro 4.

4. Execução do commit: caso a quantidade já realizada de operações (update) seja igual ao parâmetro 5, o comando commit é executado para efetivar as atualizações.

Uma visão completa do experimento pode ser descrita da seguinte maneira:

1. Escolha de um cenário (1, 2 ou 3).

2. Configuração da quantidade de processos clientes (10, 50, 100, 150 ou 200).

3. Execução do experimento (primeira e segunda etapa). 
4. Coleta das métricas (métricas 1,2 e 3 ).

5. Repetição de 50 vezes os itens 3 e 4 para obter os valores médio, mínimo, máximo e o desvio padrão das métricas.

As 50 repetições do experimento são importantes para tratar a variabilidade dos resultados e, consequentemente, para que sejam calculados os valores médios das métricas do experimento. Com essa quantidade de repetições, os desvios padrões ficaram pequenos (por volta de $9 \%$ do valor da média). Para quantidade menores de repetições, notou-se um desvio padrão muito grande e inviável para ser usado.

Para termos somente uma estimativa do tempo de duração do experimento, podemos fazer o seguinte cálculo: como temos três cenários, cinco quantidades de processos clientes e 50 execuções do experimento para cada parâmetro, o total de execuções do experimento será de 750. Cada execução demora 60 segundos, portanto uma estimativa para duração do experimento é de 12 horas e meia.

\subsubsection{Exemplo de uma execução do experimento}

Para ficar mais claro o entendimento de todas as etapas e passos para uma execução do experimento, considere os parâmetros da Tabela 5.1.

\begin{tabular}{|l|r|}
\hline Parâmetros & Valores \\
\hline Cenário & 1 (sem trigger $)$ \\
\hline Tempo de duração & 60 segundos \\
\hline Qtde de processos clientes & 100 processos \\
\hline Qtde de operações em cada transação & 10 operações \\
\hline Qtde de linhas na tabela & 2000 linhas \\
\hline Tempo de espera entre cada operação & 20 milissegundos \\
\hline
\end{tabular}

Tabela 5.1: Parâmetros do exemplo de execução do experimento

Uma execução do experimento com os parâmetros acima irá na primeira etapa, preparação de ambiente, criar as tabelas encontros_0 e encontros_1, inserir 2000 linhas em cada uma e não criar nenhum trigger (cenário 1). O último passo da primeira etapa é a criação de 100 processos para executar as operações de atualização no banco de dados.

Na segunda etapa, cada um dos 100 processos irá, durante 60 segundos, repetir os seguintes passos:

1. Abrir uma transação (begin transaction).

2. Sortear qual das duas tabelas (encontros_0 e encontros_1) será atualizada.

3. Escolher aleatoriamente qual linha, dentre as 2000, que receberá uma operação de atualização (update), esperando 20 milissegundos para enviar a operação ao banco de dados. 
4. Repetir 10 vezes os passos 2 e 3 .

5. Fechar a transação (commit).

Após os 60 segundos de execução, os 100 processos são destruídos e a coleta de dados é realizada para definir um valor das métricas.

\subsubsection{Simulação da concorrência}

A concorrência de acesso a uma linha da tabela de encontros está diretamente relacionada com a quantidade de processos que realizam atualizações na tabela e com a aleatoriedade da escolha de qual linha deve ser atualizada. Devido a essa aleatoriedade, pode ocorrer uma situação em que todos os processos querem atualizar a mesma linha da tabela. Ainda é possível que todos os processos escolham linhas distintas e, consequentemente, não haverá concorrência de acesso. A última situação deve ocorrer mais frequentemente quando há poucos processos, e a primeira, quando há muitos processos em relação à quantidade de linhas existentes na tabela.

\begin{tabular}{|c|r|r|}
\hline Níveis de concorrência & Qtde de Processos & Classificação \\
\hline 1 & 10 & Baixo \\
\hline 2 & 50 & Médio \\
\hline 3 & 100 & Médio \\
\hline 4 & 150 & Máximo \\
\hline 5 & 200 & Máximo \\
\hline
\end{tabular}

Tabela 5.2: Níveis de concorrência

Seguindo esse conceito, para simular vários níveis de concorrência, foram escolhidas cinco quantidades de processos clientes. O valor máximo de processos foi definido igual ao valor máximo de conexões do banco de dados. O valor de 200 conexões está diretamente relacionado à configuração da máquina virtual, conforme a Seção 5.4.1, pois para uma máquina de $1 \mathrm{~GB}$ de memária RAM não foi possível ter mais conexões simultâneas sem afetar o desempenho da máquina. Considerando esse limite, os valores escolhidos foram 10, 50, 100, 150 e 200 para a quantidade de processos clientes simultâneos. Esses valores representam os níveis baixo, médios e máximos de concorrência. A Tabela 5.2 resume essas informações. Os outros parâmetros de carga do sistema, definidos na Seção 5.4.2, foram fixados conforme Tabela 5.3 e não houve necessidade de variá-los entre as execuções do experimento.

O exemplo da Seção 5.5.3 tem um nível de concorrência 3 que consideramos médio, pois a quantidade de processos é 100, conforme Tabela 5.2

\subsubsection{Simulação de isolamento}

A simulação do ambiente de isolamento permite observar se existe algum fator do ambiente que afeta o desempenho, mesmo não havendo concorrência. Caso esse fator exista, ele também irá contribuir para 


\begin{tabular}{|l|r|}
\hline Parâmetros & Valores \\
\hline Tempo de duração & 60 segundos \\
\hline Qtde de operações & 10 \\
\hline Qtde de linhas & 2000 \\
\hline Tempo de espera & $20 \mathrm{~ms}$ \\
\hline
\end{tabular}

Tabela 5.3: Parâmetros de carga do sistema

perda de desempenho quando houver concorrência. Em um ambiente real sempre ocorre um nível de concorrência de acesso conforme a quantidade de usuários e as características do sistema de informação. Para avaliar o impacto da concorrência no desempenho do ambiente do experimento, foi necessário simular um ambiente irreal onde, garantidamente, não ocorrerá concorrência de acesso, para isolar todos os outros possíveis fatores que afetam o desempenho do ambiente além da concorrência de acesso. Para simular esse ambiente, alteramos os processos geradores de operações para que cada processo atualizasse um conjunto distinto de linhas da tabela de encontros. Para implementar essa alteração foi tirada a aleatoriedade da escolha das linhas e cada processo atualizou sequencialmente as linhas do seu conjunto.

Considerando que a tabela de encontros terá 2000 linhas, a quantidade de operações por processo é 10 e cada processo atualiza linhas distintas devido ao isolamento, podemos calcular a cobertura das operações dentre o total de linhas da tabela de encontros. A Tabela 5.4 mostra para cada quantidade de processo, quantas linhas são atualizadas e o cálculo do nível de cobertura.

\begin{tabular}{|r|r|r|}
\hline Qtde de Processos & Qtde de linhas atualizadas & Cobertura da tabela \\
\hline 10 & 100 & $5 \%$ \\
\hline 50 & 500 & $25 \%$ \\
\hline 100 & 1000 & $50 \%$ \\
\hline 150 & 1500 & $75 \%$ \\
\hline 200 & 2000 & $100 \%$ \\
\hline
\end{tabular}

Tabela 5.4: Níveis de cobertura para uma tabela de 2000 linhas

\subsection{Análise e interpretação dos dados}

Nesta seção apresentamos e analisamos os resultados obtidos no experimento. As análises dos gráficos foram feitas a partir das médias, mas no Apêndice A é possível visualizar os valores máximos, mínimos e o desvio padrão das métricas. 


\subsubsection{Operações por segundo}

\begin{tabular}{|r|r|r|r|}
\hline & Cenário 1 & Cenário 2 & Cenário 3 \\
\hline Processos & Sem trigger & Síncrono & Assíncrono \\
\hline 10 & 51 & 49 & 46 \\
\hline 50 & 200 & 69 & 149 \\
\hline 100 & 88 & 13 & 45 \\
\hline 150 & 27 & 6 & 15 \\
\hline 200 & 14 & 4 & 9 \\
\hline
\end{tabular}

Tabela 5.5: Operações por segundo

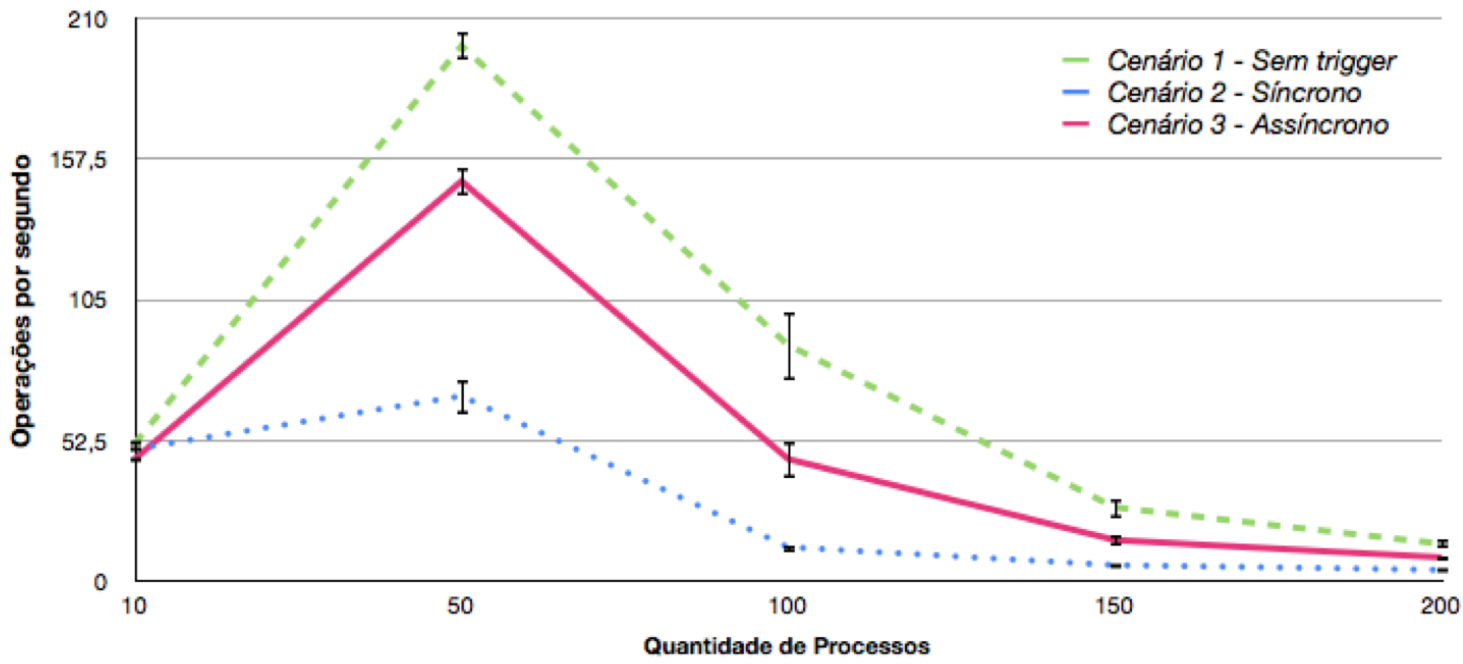

Figura 5.6: Desempenho (vazão) por nível de concorrência

Cada linha do gráfico representa um cenário que foi explicado na Seção 5.5.1. Para cada valor medido, mostramos no gráfico as barras de erro dos desvios padrões obtidos.

Podemos verificar na Tabela 5.5 e na Figura 5.6 que somente para 10 processos, nível baixo de concorrência, é que o trigger síncrono tem um desempenho ligeramente melhor que o assíncrono. Para todas as outras quantidades de processos, a solução assíncrona tem no mínimo o dobro de quantidades de operações por segundo em relação ao síncrono. A maior diferença ocorreu quando temos 100 processos. Nesse momento, foi medido que o assíncrono (45 operações/segundo) teve mais que o triplo de desempenho em relação ao síncrono (13 operações/segundo). 


\subsubsection{Taxa de operações que bloqueiam}

\begin{tabular}{|r|r|r|r|}
\hline & Cenário 1 & Cenário 2 & Cenário 3 \\
\hline Processos & Sem trigger & Síncrono & Assíncrono \\
\hline 10 & $0,02 \%$ & $0,11 \%$ & $0,05 \%$ \\
\hline 50 & $0,22 \%$ & $2,03 \%$ & $0,42 \%$ \\
\hline 100 & $1,76 \%$ & $10,27 \%$ & $3,18 \%$ \\
\hline 150 & $5,06 \%$ & $20,27 \%$ & $8,22 \%$ \\
\hline 200 & $9,03 \%$ & $28,24 \%$ & $13,60 \%$ \\
\hline
\end{tabular}

Tabela 5.6: Taxa de operações que bloqueiam

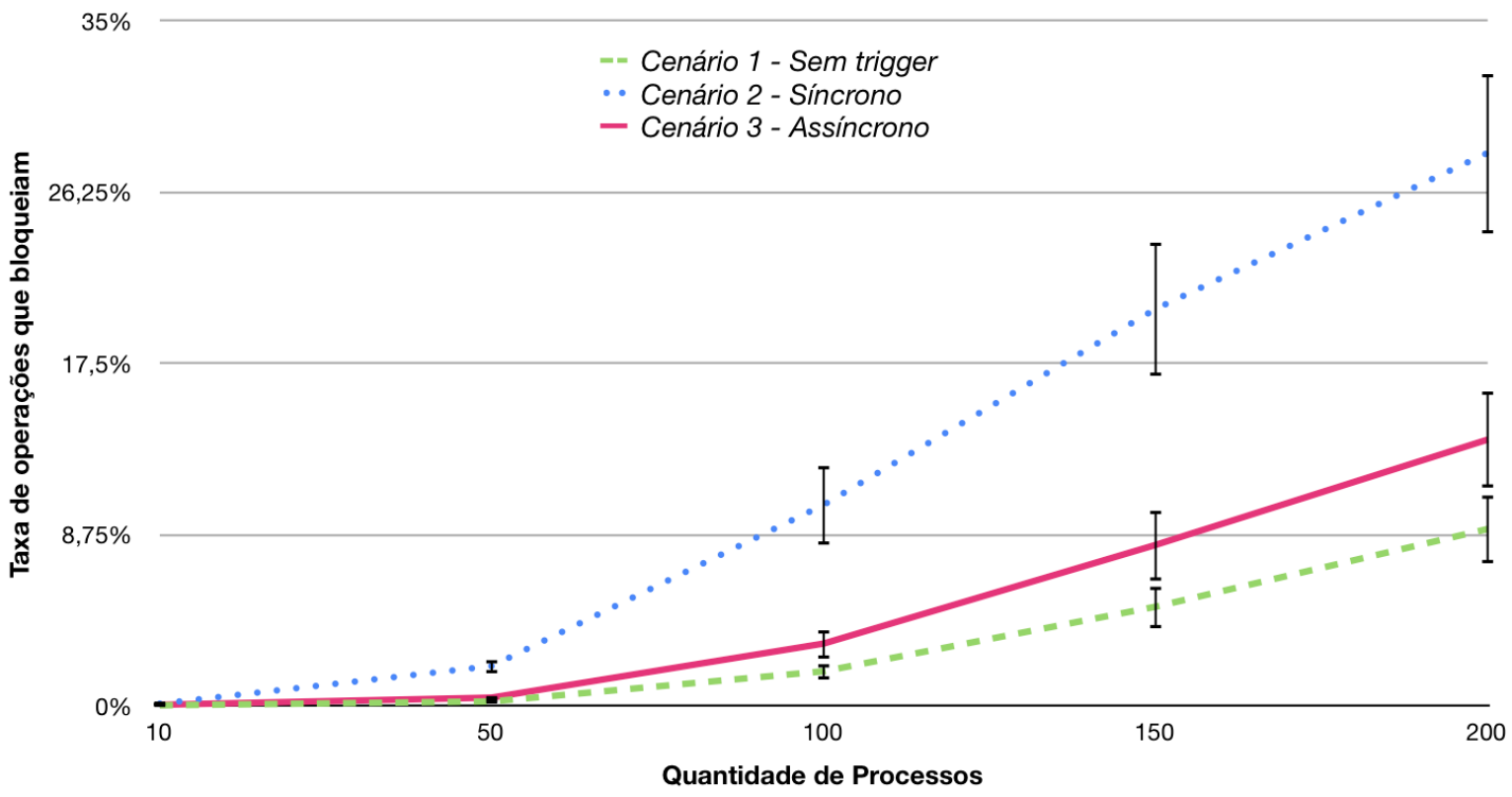

Figura 5.7: Evolução da taxa de operações que bloqueiam por nível de concorrência

A taxa de operações que bloqueiam é um cálculo realizado a partir da divisão do total de bloqueios pela quantidade de operações realizadas. Essa taxa é usada para analisar a métrica 1 da Seção 5.3.

A Tabela 5.6 e a Figura 5.7 mostram que, em termos de taxa de operações que bloqueiam, o cenário assíncrono é próximo ao cenário sem trigger para todas as quantidades de processos. Por outro lado, a taxa no cenário síncrono cresce rapidamente com a quantidade de processos. Além da curva do síncrono ser sempre maior que a do assíncrono, a taxa de operações que bloqueiam do síncrono é, no mínimo, o dobro do assíncrono para todos os níveis de concorrência. 


\subsubsection{Operações por segundo em ambiente isolado}

\begin{tabular}{|r|r|r|r|}
\hline & Cenário 1 & Cenário 2 & Cenário 3 \\
\hline Processos & Sem trigger & Síncrono & Assíncrono \\
\hline 10 & 48 & 47 & 47 \\
\hline 50 & 236 & 235 & 226 \\
\hline 100 & 454 & 388 & 322 \\
\hline 150 & 456 & 359 & 292 \\
\hline 200 & 429 & 328 & 269 \\
\hline
\end{tabular}

Tabela 5.7: Operações por segundo (ambiente isolado)

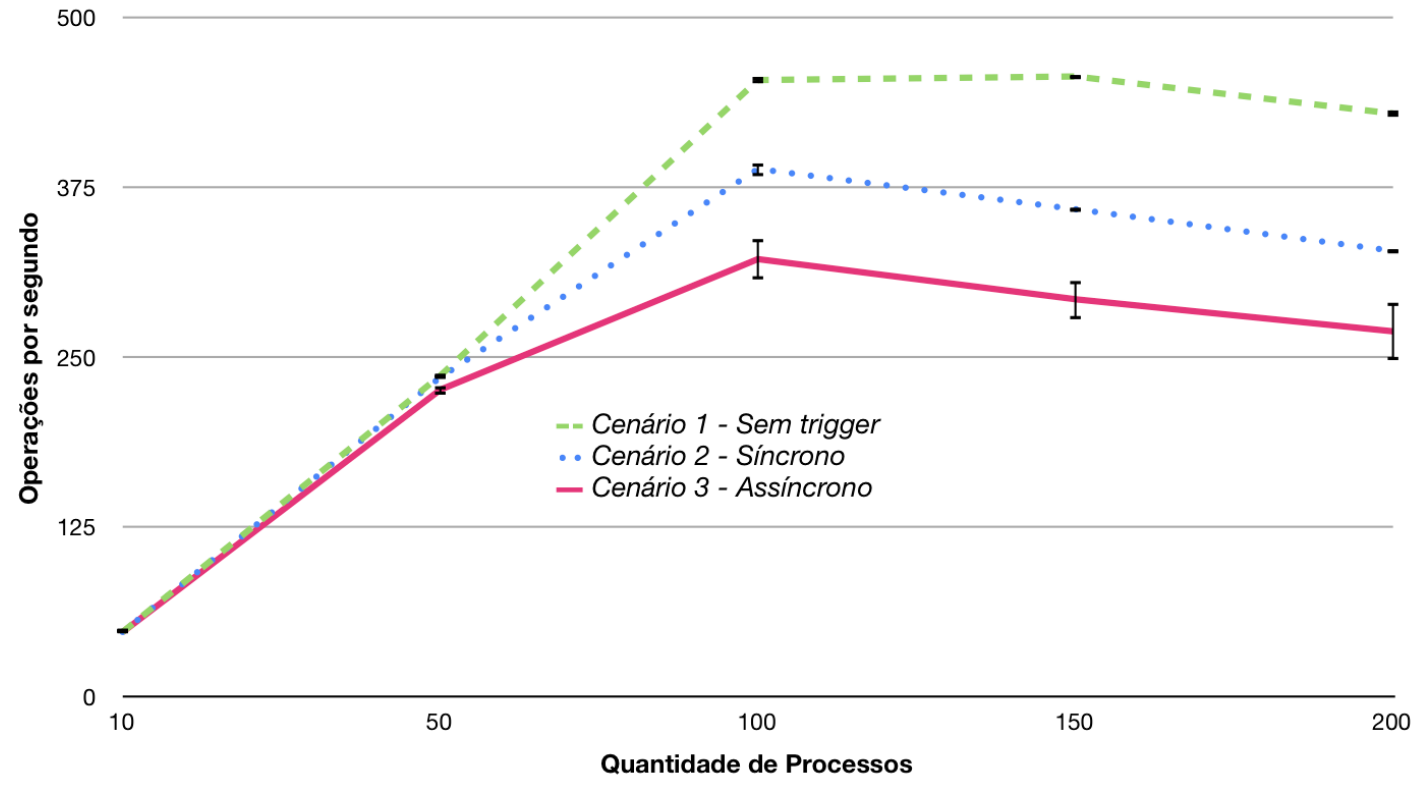

Figura 5.8: Desempenho (vazão) por nível de concorrência (ambiente isolado)

Esse experimento mostra o desempenho em um ambiente irreal no qual não há concorrência de acesso conforme justificado na Seção 5.5.5. É interessante notar que, conforme a Tabela 5.7 e a Figura 5.8, o desempenho para as quantidades de processos 10 e 50 é muito próximo ao desempenho quando ocorre concorrência. Por outro lado, para a quantidade de 100 processos, o desempenho duplica e, depois, cai suavemente para as quantidades 150 e 200. Esse comportamento confirma que o único fator que fez cair drasticamente o desempenho a partir de 100 processos na Figura 5.6 foram os bloqueios decorrentes da concorrência de acesso ao banco de dados. É interessante notar que o método síncrono sempre ganha do assíncrono quando não há concorrência. Isso é explicado pelo trabalho trabalho adicional do método assíncrono de gravar todas as operações em uma tabela temporária para que, posteriormente, o processo de replicação faça a atualização da tabela destino, conforme exposto no Capítulo 4. 


\subsubsection{Duração do processamento}

\begin{tabular}{|r|r|r|r|}
\hline Processos & Mínimo (ms) & Média (ms) & Máximo (s) \\
\hline 10 & 1,5 & 4,0 & 1,1 \\
\hline 50 & 1,6 & 5,7 & 3,7 \\
\hline 100 & 1,6 & 8,2 & 15,5 \\
\hline 150 & 1,6 & 17,6 & 38,7 \\
\hline 200 & 1,6 & 29,6 & 64,8 \\
\hline
\end{tabular}

Tabela 5.8: Duração do processamento

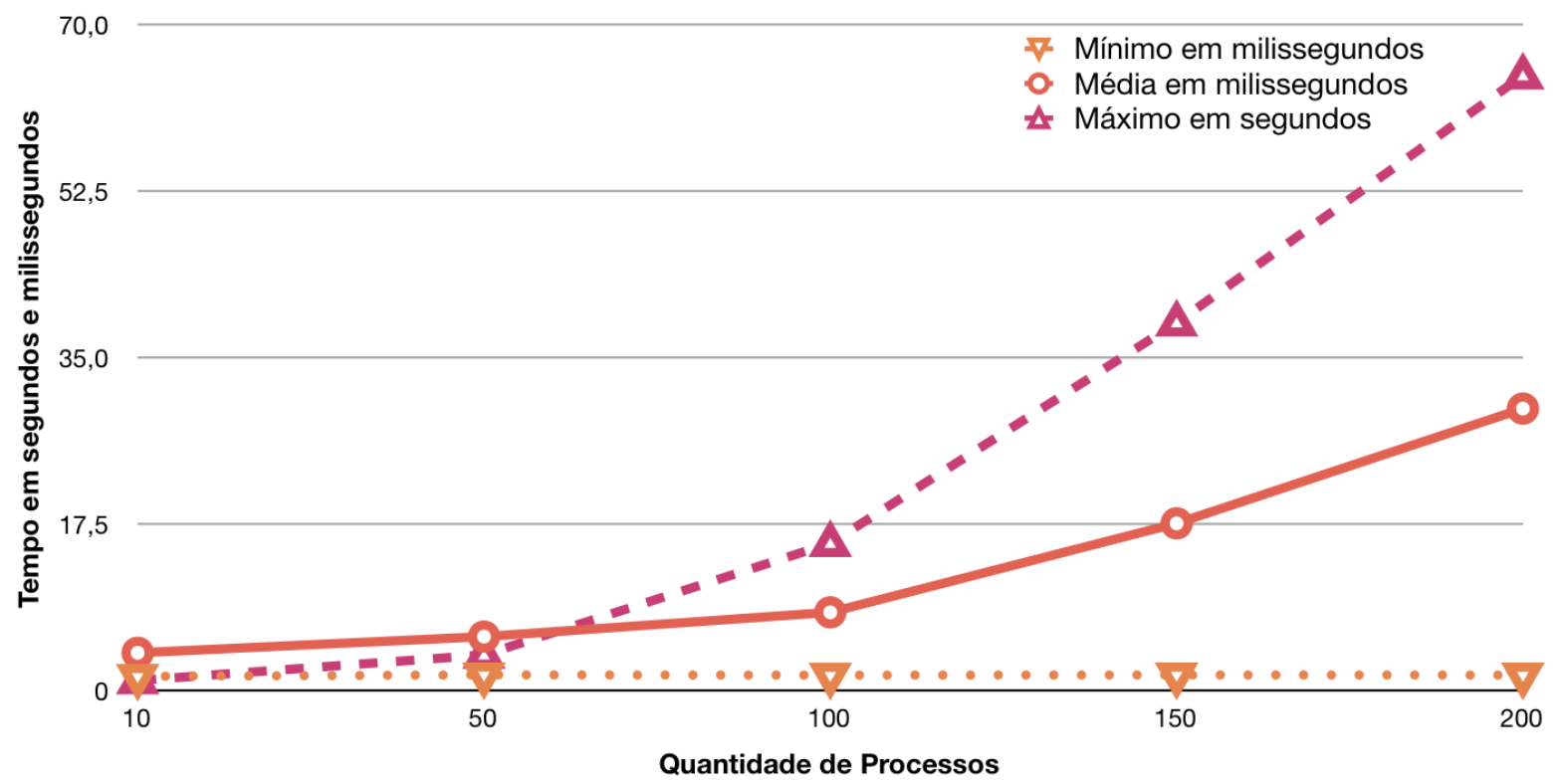

Figura 5.9: Evolução da duração do processamento por nível de concorrência

A Tabela 5.8 e a Figura 5.9 mostram o tempo gasto para o processo de replicação consumir uma operação pendente. O processo de replicação, quando lê uma operação pendente, sinaliza o início do processamento. Quando a tabela destino foi atualizada, temos o final do processamento. A diferença entre o fim e o início nos dá a duração do processamento da operação. Podemos notar que os valores médios estão na ordem de milissegundos, mas os máximos já começam maior que um segundo. O tempo máximo de duração do processamento pode ser visto como o pior caso na decisão de se o tempo de inconsistência é aceitável para uma aplicação que usa o método assíncrono. 


\subsubsection{Tempo de fila em segundos}

\begin{tabular}{|r|r|r|r|r|}
\hline Processos & Mínimo (s) & Média (s) & Máximo (s) & Qtde. de operações \\
\hline 10 & 0,2 & 5,0 & 71,1 & 688.803 \\
\hline 50 & 0,3 & 144,3 & 264,6 & 2.238 .943 \\
\hline 100 & 0,5 & 69,4 & 106,6 & 694.599 \\
\hline 150 & 0,7 & 56,4 & 92,3 & 237.906 \\
\hline 200 & 1,0 & 66,8 & 102,2 & 148.205 \\
\hline
\end{tabular}

Tabela 5.9: Tempo de fila

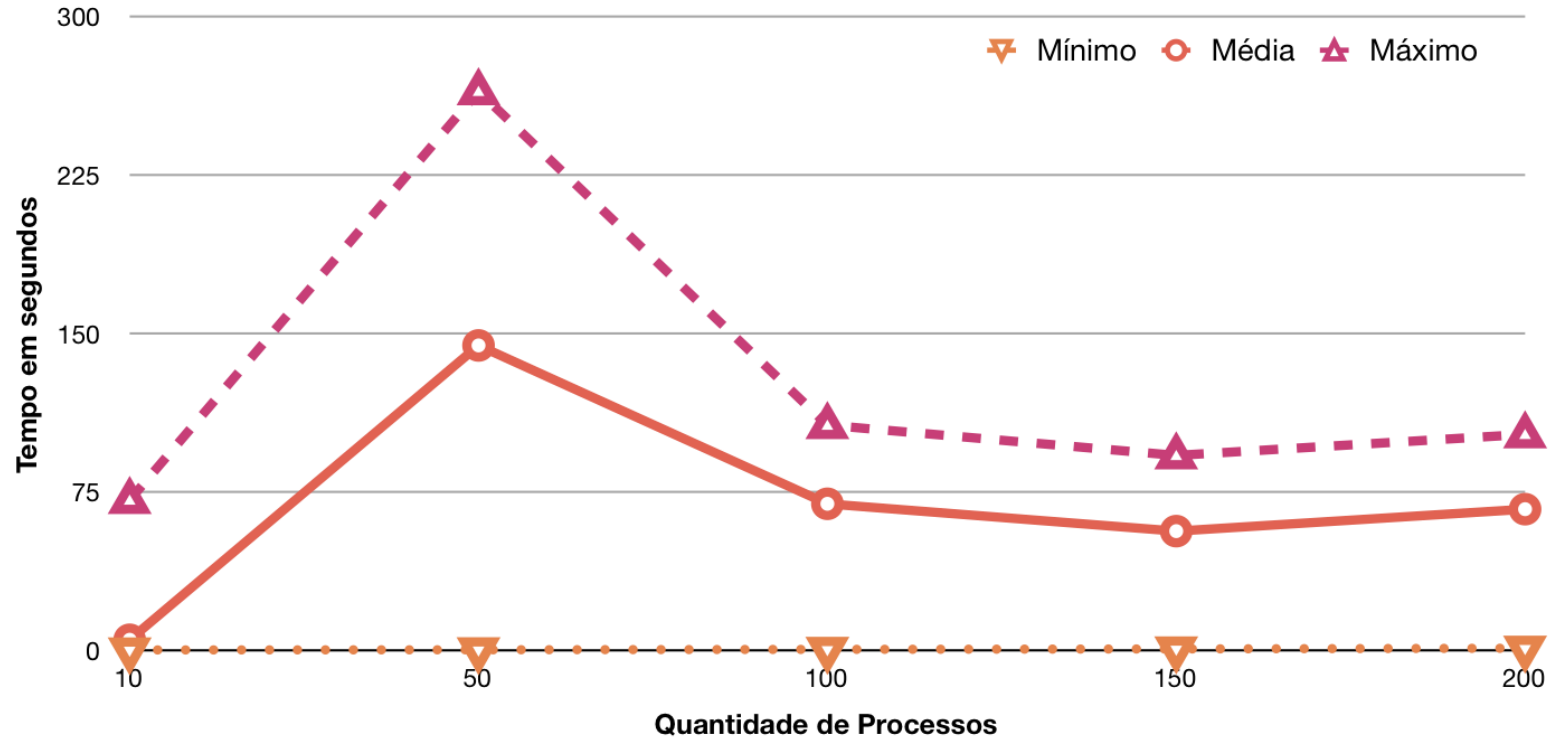

Figura 5.10: Evolução do tempo de fila por nível de concorrência

Antes do processo de replicação consumir uma operação pendente, essa operação pode ficar um tempo na fila esperando o processo iniciar o seu trabalho. O processo usado no experimento é bastante simples e não tem nenhuma otimização possível, ele simplesmente pega sequencialmente todas as operações e realiza o seu trabalho. A Tabela 5.9 e a Figura 5.10 mostram um pico do tempo em fila para a 50 processos, mas depois há uma estabilização por volta de 75 segundos para as outras quantidades de processos. A explicação para essa estabilização é que, apesar da concorrência aumentar, o que provoca a diminuição do desempenho do processo de replicação e consequentemente aumentaria o tempo de fila, temos simultaneamente a diminuição da quantidade de operações pendentes na fila, conforme ilustra a última coluna da Tabela 5.9. Desse modo, observamos que o tempo médio que uma operação pendente fica na fila se estabiliza. 


\subsection{Apresentação dos resultados}

Nesta seção iremos rever as hipóteses do experimento (Seção 5.2) com o apoio das análises já realizadas na seção anterior.

1. Hipótese 1: o método síncrono gera muitos bloqueios e a quantidade é maior do que o método assíncrono.

A Seção 5.6.3, que contém uma análise da Figura 5.7, mostrou que a hipótese 1 é verdadeira. Em todos os níveis de concorrência o método síncrono gera, no mínimo, três vezes mais bloqueios que o ambiente sem trigger e, no mínimo, o dobro do que o método assíncrono.

2. Hipótese 2: o sistema que atualiza o banco de dados com replicação assíncrona tem um desempenho, medido por quantidade de operações por segundo, melhor do que quando o banco utiliza o método síncrono.

A Figura 5.6 na Seção 5.6.1 mostrou que a hipótese 2 é verdadeira para os níveis médio e alto de concorrência. A exceção é quando o nível de concorrência é baixo, no qual o método síncrono tem um desempenho melhor devido à quantidade de bloqueios não interferir no seu desempenho.

3. Hipótese 3: o tempo para processar uma operação pendente no método assíncrono é pequeno e está na ordem de dezenas de milissegundos.

O tempo para processar uma operação pendente, devido à característica do método assíncrono de postegar a replicação dos dados, pode ser visualizado na Figura 5.9 da Seção 5.6.4. A hipótese 3 é verdadeira por que o tempo médio gasto para processar uma operação pendente variou de 4 milissegundos a 30 milissegundos para todos os níveis de concorrência.

A exceção explicitada na hipótese 2 nos orienta que o método síncrono é a melhor solução para ambientes de baixa concorrência. Além do melhor desempenho, não há o trabalho adicional de processar as operações pendentes e assumir um tempo de inconsistência durante esse processamento. Nessa situação, não há nenhuma vantagem em trabalhar de forma assíncrona. É importante observar que muitos sistemas não críticos trabalham em regime de baixa concorrência e, portanto, a aplicabilidade da solução síncrona não é pequena.

Por outro lado, para os sistemas críticos típicos, que têm um nível médio ou alto de concorrência, a melhor solução é o método assíncrono para replicação de dados. O desempenho é um fator chave nesta situação e ganhos de $100 \%$ em relação ao método síncrono podem justificar claramente o tempo de inconsistência em um grande número de aplicações em geral. Considerando uma aplicação específica, podemos analisar e definir uma parte do modelo de dados que pode aceitar, sem grandes impactos, um tempo de inconsistência. 


\section{Capítulo 6}

\section{Trabalhos relacionados}

A forma como implementamos a etapa de coleta de informações de transação (vide Seção 4.1) é utilizando triggers, que é uma maneira fácil e rápida para inserir um código no banco de dados. $\mathrm{O}$ conceito de trigger se origina em uma discussão mais ampla sobre banco de dados ativos, como veremos na Seção 6.1.

Existem muitos trabalhos e ferramentas em replicação de dados, mas nenhuma trata de replicação para uso em refatorações, que é um caso normalmente mais simples por se tratar de replicação dentro de um banco de dados: duas tabelas no mesmo banco ou duas colunas na mesma tabela, por exemplo. Os casos gerais de replicação de dados serão abordados na Seção 6.2.

As ferramentas ETL, descritas na Seção 6.3, poderiam ser uma alternativa para auxiliar refatorações de banco de dados se elas fossem mais simples e não tivessem o foco em banco de dados analíticos. Por último, abordaremos trabalhos em evolução de esquemas na Seção 6.4, que, apesar de terem as mesmas motivação dessa tese, tem o objetivo de manter operacional todas as versões dos esquemas de um banco de dados. No nosso caso, mantemos apenas a versão anterior e somente durante o período de transição.

\subsection{Banco de dados ativos}

Bancos de dados ativos [WC96] fornecem um mecanismo integrado ao gerenciador do banco de dados para criar e executar regras. As regras seguem o paradigma: evento, condição e ação [MD89]. Os eventos de uma regra são um subconjunto relevante dos eventos possíveis. Quando ocorre um desses eventos relevantes, a regra define um conjunto de condições que serão avaliadas. Caso todas as condições sejam satisfeitas, as ações da regra serão executadas [ $\mathrm{ZCF}^{+}$97]. Os triggers são exemplos de implementação de regras em um banco de dados. A criação do trigger de exemplo, na Listagem 4.2, define quais eventos são relevantes: AFTER INSERT OR UPDATE OR DELETE ON pacientes, qualé a condição que deve ser atendida: $F O R$ EACH ROW e, finalmente, qual é a ação que deve ser executada: EXECUTE PROCEDURE f_pacientes_transactions. 
Zaniolo et al. descrevem a replicação de dados utilizando triggers no capítulo de exemplos de aplicações de banco de dados ativos [ $\mathrm{ZCF}^{+}$97]. Eles consideram que para realizar replicação são necessários dois módulos: captura e aplicação. O primeiro captura as alterações da cópia principal e o segundo aplica essas alterações na cópia secundária. A forma de replicação é similar ao nosso trabalho, mas ele não considera uma possível transformação ou mapeamento que podem ser realizados entre a captura e a aplicação.

\subsection{Replicação de dados}

Wiesmann et al. definem conceitualmente cinco fases no protocolo para replicação de dados [WPS $\left.{ }^{+} 00\right]$ :

1. Requisição: o cliente submete uma operação para uma ou mais réplicas.

2. Coordenação dos servidores: os servidores, responsáveis pelas réplicas, comunicam-se para sincronizar a execução da operação (ordenando as operações concorrentes).

3. Execução: a operação iniciada pelo cliente é executada na réplica.

4. Resultado da execução: os servidores se comunicam para saber o resultado da operação executada.

5. Resposta: o resultado da operação é transmitido de volta para o cliente.

Segundo Wiesmann et al., os protocolos de replicação de dados difereciam-se na organização dessas cinco fases. A proposta desta tese está muito próxima ao protocolo denominado replicação postergada no artigo de Wiesmann et al. . A Figura 6.1 ilustra o protocolo, ressaltando que o cliente recebe a resposta da atualização sem esperar pelas outras atualizações que seguem para as réplicas. A vantagem desse modelo de replicação é o baixo tempo de resposta ao cliente, mas a desvantagem é um possível processo de reconciliação que deve ser executado para resolver conflitos. Nosso trabalho se diferencia dessa abordagem em três pontos. Primeiro, na nomenclatura, chamando o modelo de assíncrono, e não utilizando o termo postergado. Segundo, acrescentamos a fase de mapeamento para realizar as adaptações necessárias antes da atualização da réplica. Por último, consideramos que a fase de execução é quando as réplicas são atualizadas e a tarefa de reconciliação, se necessária, executada.

\subsection{Ferramentas ETL}

As ferramentas tradicionais de ETL (Extract, Transform and Load) funcionam de forma semelhante ao processo em lote (batch) de Ambler. Os possíveis problemas de desempenho são decorrentes do processo de extração que precisa percorrer toda a tabela origem para verificar o que foi alterado e acrescentado. Trabalhos recentes [SBLY08, ZAL08] em Data Warehouse de tempo real utilizam a técnica 


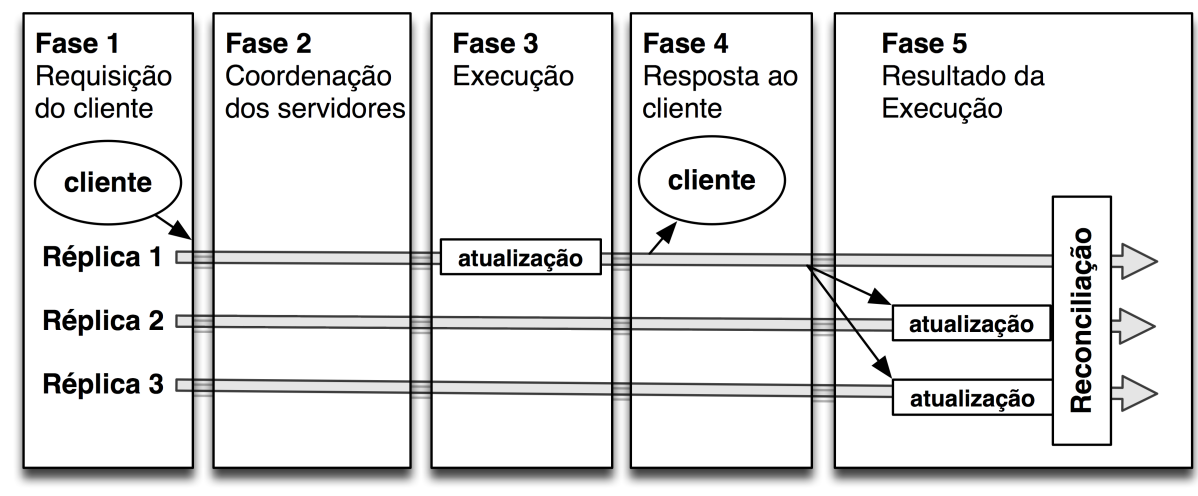

Figura 6.1: Protocolo de replicação postergada de dados

CDC, Change Data Capture, em oposição ao processo de extração para melhorar o desempenho de geração de dados para análise.

A questão da atualização de dados é muito importante para sistemas que implementam um data warehouse de tempo real. Em [SBLY08] é proposto um modelo de dados para captura e extração de dados no sentido de melhorar sua qualidade, em seguida os dados são colocados numa fila processada pelo algoritmo de agendamento de dados.

Após esse processamento, o sistema carrega os dados em um Data Warehouse de tempo real (realtime data warehouse, RTDWH) e armazena no banco de dados para servir posteriormente ao suporte a decisão. Essa mudança proposta pelo artigo é baseada em logs de extração e captura no RTDWH. As estratégias de tempo real para o escalonamento incluem inserir os dados na fila; controlar o acesso à CPU com o controle de prioridade das tarefas; suspender a fila, armazenando os dados que não estão sendo usados no momento e monitorar a taxa de uso da CPU, o estado de cada tarefa e os seus resultados, assegurando assim um processamento eficiente dos dados.

Em [ZAL08] é proposto um método que utiliza armazenamento de dados baseados na arquitetura SOA. Esse método utiliza serviços web e XML para acessar banco de dados em diversas fontes, dado que os ETL's tradicionais não podem realizar com segurança a atualização de dados em tempo real. Utiliza também um sistema de cache multinível em tempo real para armazenamento de dados. Este artigo relata que na literatura a maioria dos pesquisadores propõe o CTF (Capture-conversion-Floe) para o processo de atualização em tempo real, que consiste em uma tecnologia simples para transferência de dados heterogêneos.

Apesar de o foco desses trabalhos ser em banco de dados analíticos, aproveitamos, durante a implementação do protótipo, apenas parte do CDC na etapa de coleta de transações da nossa proposta. 


\subsection{Evolução de esquemas}

A evolução do banco de dados, que representa um sério problema para sistemas tradicionais de informação, é ainda mais crítica para os sistemas de informação na web [BSHS06], principalmente quando se trata da gestão do histórico de informações de banco de dados. Esse problema está se tornando ainda mais complexo com o crescimento rápido de difusão de informações na web, como o caso do Wikipedia.

Converter o banco de dados do antigo para um novo após cada mudança de esquema pode comprometer a qualidade de arquivamento do histórico do banco de dados. Informações e relações incoporadas no banco de dados original são frequentemente perdidas, especialmente aquelas que não são bem compreendidas ou são consideradas irrelevantes pelo administrador quando executada a conversão. Para evitar esse problema e conseguir arquivamento perfeito, é necessário armazenar os dados em suas versões originais do esquema. Esse requisito importante, no entanto, apresenta um sério desafio para o SGBD para gerenciar a consulta e o tempo de transação nos esquemas de evolução do banco de dados.

Em trabalhos mais recentes, encontramos esforços direcionados para auxiliar as evoluções de esquemas em bancos de dados temporais. Em Curino et al. [CMZ08] é proposto um método de publicações do histórico do banco de dados relacional utilizando XML, no qual a evolução do esquema e sua base dados é representado de uma forma unificada, tornando mais fácil a pesquisa do histórico em qualquer versão do esquema usando o padrão XQUERY, que é uma linguagem para consulta de dados em XML. Outro ponto importante é que a evolução do esquema é transparente para o usuário que escreve consultas válidas para diferentes versões de esquema. Foi desenvolvida uma nova solução capaz de encontrar uma forma correta e eficiente de reescrever consultas com base na sua taxonomia, caracterizando uma entrada temporal de consulta, com base nos critérios predefinidos e análise dos algoritmos de consulta.

Apesar de garantir que a reescrita de consulta está correta e eficiente, o algoritmo de reformulação em si precisa ser eficiente também. Isto acaba sendo outro grande desafio, pois no mundo real, como a evolução do esquema do Wikipedia, é necessário gerenciar centenas de versões de esquema. Para a realização da consulta entre diferentes versões de esquema dentro de um prazo limite prático, foi desenvolvida a ferramenta PRISMA, que introduz modificações de esquema de operadores (Schema Modification Operators, SMOs) que representam os mapeamentos entre as sucessivas versões do esquema. Esta ferramenta utiliza uma linguagem XML com restrição de integridade (XML integrity constraint language, XIC) de forma eficiente para reescrever consultas usando restrições estabelecidas pelas SMOs. Os resultados da abordagem foram medidos utilizando dados reais do banco de dados histórico do Wikipedia. Atualmente, o desempenho e a escalabilidade do PRISMA são limitado pelos recursos da XQuery.

Para Moon et al. [ $\left.\mathrm{MCD}^{+} 08\right]$ sistemas modernos de informação na web necessitam de frequentes alterações no esquema do banco de dados e necessitam preservar a evolução histórica do esquema. Nesse trabalho foi descrita a Panta Rhei, uma ferramenta que permite a evolução do esquema e orienta o administrador do banco de dados no planejamento e na avaliação das mudanças; faz um arquivamento 
eficaz do histórico de dados e metadados; realiza consultas temporais complexas sobre o histórico. No mesmo artigo, ainda é apresentada a ferramenta HMN, que facilita o processo de documentação e consulta da evolução do esquema. O HMM explora a representação $S M O$-based da evolução do esquema para fornecer aos usuários uma melhor compreensão da semântica de cada mudança de esquema. As duas ferramentas são usadas para análise da evolução do esquema de dados do Wikipedia como exemplo.

O histórico de metadados pode ser efetivamente explorado no âmbito do esquema de correspondência automática para desenvolver conhecimento sobre a história de heurísticas correspondente. Para Moon et al. a pesquisa pode evoluir para utilização de modelos de dados semânticos, capturando uniformemente alterações de esquema e realizando esquemas de mapeamentos em um modelo semanticamente rico, o que pode permitir um rápido entendimento da evolução do esquema.

Nosso trabalho possui as mesmas motivações que Curino et al. e Moon et al., ou seja, sistemas de informações com muitas e frequentes alterações nos esquemas de banco de dados, que geram necessidades de ferramentas para gerenciar essas evoluções. No entanto, enquanto a proposta deles é baseada em reescrita automática de consultas para permitir o acesso a esquemas antigos, nossa proposta utiliza replicação assíncrona de dados durante o período de transição, permitindo o uso de qualquer gerenciador de banco de dados que tenha triggers. Outra vantagem é que não precisamos interceptar nenhuma consulta ao banco de dados, apenas coletamos dados para que seja feita a replicação de forma assíncrona.

\subsection{Ferramentas de gerenciamento de alterações de banco de dados}

Liquibase [Liq] é um software de código aberto, com licença Apache 2.0, que funciona em qualquer banco de dados para rastrear, gerenciar e aplicar as alterações do modelo dados. Ele é construído sobre uma simples premissa: todas as alterações do banco de dados são armazenados em uma forma legível e rastreável em um controlador de versão.

Dbdeploy [Dbd] é uma ferramenta para desenvolvedores ou DBAs que querem evoluir seu projeto de banco de dados - ou refatorar seu banco de dados - de uma forma simples, controlada e flexível. O problema recorrente com o desenvolvimento de banco de dados é que em algum momento você precisará atualizar um banco de dados existente e preservar o seu conteúdo. Em ambientes de desenvolvimento reconstruir o banco de dados é frequentemente possível e até mesmo desejável, mas esta abordagem não pode ser levado adiante em ambientes mais controlados, como testes e produção. A ferramenta trabalha de uma maneira fácil, permitindo que as pessoas mudem o banco de dados usando scripts SQL delta (diferenças entre duas versões). É importante assegurar que os scripts usados para construir ambientes de desenvolvimento são exatamente os mesmos usado em teste e produção. Manter esses scripts pode rapidamente se tornar uma sobrecarga significativa e dbdeploy pretende resolver esta questão.

Essas duas ferramentas e outras, tais como SqlPrompt [Red], são ferramentas de gerenciamento de mudanças do banco de dados. O objetivo é ter o controle de todas as alterações realizadas e possivelmente regredir uma versão de banco dados se for necessário. Essas ferramentas não se preocupam em 
manter funcionando duas versões simultâneas de modelo de dados e, possivelmente, realizar replicação de dados entre essas versões. Deste modo, o objetivo dessas ferramentas é controlar os scripts de alteração do banco de dados. Por outro lado, o Database Evolution Manager (DEM), Seção 4.6), se preocupa exclusivamente com as replicação de dados durante o período de transição das refatorações. 


\section{Capítulo 7}

\section{Conclusões}

Devido à alta complexidade das aplicações de grande porte e à velocidade das mudanças no domínio, as metodologias ágeis recomendam que se deve modelar somente uma parte do domínio de negócio de cada vez. Deve-se dar prioridade à parte que possibilita a implementação dos requisitos de maior valor para o cliente e evoluir a modelagem conforme a necessidade. Nesse contexto, a prática de modelagem evolutiva cria a necessidade de gerenciar corretamente a evolução de banco de dados.

Logo após a entrada em produção de um banco de dados, o usuário começa a armazenar e atualizar os dados do seu domínio de negócio. A partir daí, para cada evolução no banco de dados, é necessário tratar os dados existentes. O desafio de realizar evolução em um banco de dados é ainda maior quando o banco é utilizado simultaneamente por várias aplicações. Cada aplicação terá dificuldades distintas e gastará tempos diferentes para realizar as adaptações necessárias. Um período de transição com os esquemas antigos e novos coexistindo é bastante útil, mas exige um código de apoio, que na solução de Ambler é síncrono, para manter os esquemas atualizados.

O principal objetivo para esta tese foi propor uma alternativa assíncrona para manter os esquemas atualizados, organizando o código de apoio em três etapas: coleta, mapeamento e execução. A divisão do código de apoio permite que ferramentas sejam desenvolvidas para auxiliar as evoluções do banco de dados. Implementamos um protótipo de ferramenta (Database Evolution Manager) para validar essa possibilidade e constatamos que realmente é viável a construção de ferramentas quando a replicação é assíncrona.

A principal vantagem da replicação assíncrona é não exigir a reescrita dinâmica das consultas SQL para as várias versões existentes de esquemas de banco de dados. Em nossa abordagem, as versões dos esquemas são transitórias e devem coexistir com replicação de dados até que todas as aplicações sejam atualizadas para usarem a versão mais nova do esquema.

O limite da nossa solução é quando o ambiente tem baixa concorrência de acesso. Nessa situação, o método síncrono tem melhor desempenho e não há o trabalho adicional de processar as operações pendentes e aceitar um tempo de inconsistência durante esse processamento. Em todos os outros níveis 
de concorrência, o método assíncrono tem um desempenho muito melhor, e essa diferença é a justificativa para as aplicações asssumirem um tempo de inconsistência.

\subsection{Trabalhos futuros}

Os seguintes trabalhos podem ser feitos para avançar a pesquisa nesta área:

1. Melhorar a implementação da ferramenta Database Evolution Manager. Atualmente como protótipo, ela foi útil para validar as hipóteses e nos mostrar que é possível construir uma ferramenta para auxiliar as refatorações de banco de dados. Por outro lado, principalmente no processo de replicação de dados, não foi feita nenhuma otimização para diminuir o tempo de inconsistência. Acreditamos que, com um esforço de desenvolvimento na ferramenta, ela pode se tornar rapidamente uma ferramenta de uso comum para os administradores de banco de dados.

2. Após a implementação da ferramenta, será importante colocá-la em uso em um ambiente real com um banco de dados utilizado por um grande número de aplicações distintas e heterogêneas. Nesse ambiente, será necessário refazer o experimento para verificar o comportamento da replicação assíncrona. Apesar do desempenho da solução ser um fator relevante para ser medido e verificado, poderemos, em um ambiente real, definir métricas adicionais relativas a usabilidade que nos informarão se realmente, com a ferramenta, as refatorações de banco de dados podem ser executadas de uma forma fácil e intuitiva. Desse modo, nesse item temos dois trabalhos relativos a ferramenta em um ambiente real: primerio, o desempenho da ferramenta nesse ambiente, segundo, a usabilidade dela pelos administradores de banco de dados.

3. As mudanças nos bancos de dados são frequentemente grandes alterações. Assim, é muito importante saber responder uma pergunta: é possível transformar grandes alterações em uma sequência de pequenas refatorações? Se soubermos responder a essa pergunta de forma afirmativa e descobrirmos como fazer essas transformações, tudo que foi desenvolvido e validado neste trabalho poderá ser usado para grandes alterações de banco de dados. Na organização de uma sequência de refatorações, devemos pensar nas posssibilidades de realizar uniões (merges), aninhamentos e intercalações de refatorações. Uma organização bem feita irá minimizar a duração de uma grande alteração de banco de dados.

4. O catálogo de refatoração de banco de dados poderá ser muito mais útil se estiver disponível na web de uma forma que toda a comunidade de métodos ágeis e de banco de dados possam contribuir, melhorando as descrições, fazendo comentários das suas experiências na execução dessas refatorações e acrescentando novas refatorações ao catálogo. Essa forma de compartilhar informações e de se obter contribuições entre equipes de desenvolvimento tem se mostrado bastante eficiente em muitas áreas de software livre. 
5. A violação de consistência durante o período de transição devido à replicação assíncrona pode ser quantificada e auditada com base nos logs pendentes. Este trabalho futuro irá auxiliar o administrador de banco de dados na avaliação dos custos e benefícios da solução de replicação assíncrona.

\subsection{Contribuições originais}

As principais contribuições desta tese são as seguintes:

1. A proposta da abordagem assíncrona para replicação de dados em refatoração, apresentada no Capítulo 4, é uma contribuição inédita. Essa abordagem permite realizar rapidamente uma sequência de refatorações de banco de dados, devido à facilidade de gerar o código de apoio e à não necessidade de reescrever consultas como Curino et al. [CMZ08] fazem.

Em relação ao método síncrono, recomendado por Ambler, o experimento realizado, descrito no Capítulo 5, mostrou claramente que o método assíncrono tem um desempenho muito superior ao síncrono em ambientes com média e alta concorrência de acesso ao banco de dados. Essa constatação, além de provar a utilidade da abordagem para refatoração de banco de dados, leva a pesquisa a procurar alternativas assíncronas em qualquer área de banco de dados em que o desempenho das soluções é um ponto chave.

2. A documentação e a organização de todo o catálogo de refatorações apresentadas nesta tese, Capítulo 3, é uma contribuição importante porque será bastante útil para os administradores começarem efetivamente a evoluir os seus bancos de dados. O catálogo original não fornece nenhuma orientação sobre uma possível sequência de uso das refatorações, não tem uma seção de exemplos bem definida e não expõe claramente quais refatorações exigem replicação de dados, que são consideradas as mais críticas porque exigem uma decisão sobre o método de replicação de dados.

Durante a análise de cada refatoração, houve uma preocupação constante em manter a descrição da refatoração simples e resumida para que uma página fosse suficiente para expor os itens mais relevantes. Dessa forma, os administradores podem consultar rapidamente uma refatoração e verificar se é a refatoração que se planeja executar e descobrir os passos e os cuidados necessários nessa execução.

3. Por último, temos o desenvolvimento de um protótipo de ferramenta para refatoração de banco de dados, descrito na Seção 4.6. Essa contribuição é relevante porque há uma grande carência de ferramentas para refatoração que se preocupem com bancos de dados, apesar de existirem muitas ferramentas para refatoração de código e replicação de dados. A código atual do protótipo está disponível na web, no endereço http://ccsl.ime.usp.br/borboleta/ DatabaseEvolution, sob licença BSD, para que a comunidade de métodos ágeis possam contribuir com o seu desenvolvimento. 


\subsection{Publicações}

As seguintes publicações foram resultantes da pesquisa de doutorado:

- O autor e os orientadores desta tese ministraram um curso intitulado Evolução de Banco de Dados em Métodos Ágeis [DKF08] no Simpósio Brasileiro de Banco de Dados, expondo todos os conceitos de evolução e as técnicas de refatoração de bancos de dados.

- O objetivo do artigo Análise e Modelagem Conceitual de um Sistema de Prontuário Eletrônico para Centros de Saúde $\left[\mathrm{DCK}^{+} 08\right]$ foi descrever a modelagem evolutiva de um sistema para centros de saúde, descrevendo as principais entidades e conceitos presentes nesse tipo de sistema.

- O artigo Replicação Assíncrona em Modelagem Evolutiva de Banco de Dados [DKF09] expôs à comunidade de banco de dados uma nova forma de organização do código de apoio para que seja possível realizar replicação assíncrona de dados durante um período de transição.

- Durante a implementação dos projetos Borboleta e SaguiSaúde, houve a necessidade de decidir uma estratégia de modelagem de dados dos dois projetos. O artigo Heterogeneidade como solução para banco de dados móveis em um sistema de saúde [DDKF09] defende a heterogeneidade entre os bancos de dados do projeto, permitindo evoluções independentes desses bancos.

- O artigo Borboleta and SaguiSaúde - Open Source Mobile Telehealth for Public Home Healthcare $\left[\mathrm{DCL}^{+} 10\right]$ apresenta os projetos Borboleta e SaguiSaúde. São apresentadas as principais características dos dois projetos, com foco nos desafios de manter sincronizadas as bases de dados. 


\section{Apêndice A}

\section{Dados do experimento}

Neste apêndice, apresentamos os dados coletados durante o experimento de validação da replicação assíncrona. Após o término de todas as execuções e verificado que todos os dados coletados passaram no teste de normalidade de Kolmogorov-Smirnov/Lilliefor [Lil67], foi possível gerar as tabelas abaixo.

As tabelas apresentam, para cada tipo de cenário, as médias, desvios padrões, mínimos e máximos para os cinco níveis de concorrência (10, 50, 100, 150 e 200 processos concorrentes).

\begin{tabular}{|r|r|r|r|r|}
\hline Qtde. Processo & Média & Desvio Padrão & Mínimo & Máximo \\
\hline 10 & 51,33 & 0,28 & 50,67 & 51,82 \\
50 & 199,71 & 5,16 & 184,23 & 211,30 \\
100 & 87,98 & 12,74 & 62,06 & 121,80 \\
150 & 27,42 & 3,69 & 20,11 & 35,03 \\
200 & 13,80 & 1,87 & 9,86 & 18,05 \\
\hline
\end{tabular}

Tabela A.1: Cenário 1 - Sem trigger - Operações por segundo - Figura 5.6

\begin{tabular}{|r|r|r|r|r|}
\hline Qtde. Processo & Média & Desvio Padrão & Mínimo & Máximo \\
\hline 10 & 49,24 & 0,49 & 48,18 & 50,35 \\
50 & 69,00 & 6,70 & 55,11 & 85,93 \\
100 & 12,59 & 1,49 & 9,62 & 15,71 \\
150 & 5,86 & 0,66 & 4,62 & 7,24 \\
200 & 4,09 & 0,48 & 3,31 & 5,34 \\
\hline
\end{tabular}

Tabela A.2: Cenário 2 - Trigger síncrono - Operações por segundo - Figura 5.6 


\begin{tabular}{|r|r|r|r|r|}
\hline Qtde. Processo & Média & Desvio Padrão & Mínimo & Máximo \\
\hline 10 & 45,54 & 0,49 & 43,42 & 46,18 \\
50 & 149,18 & 5,53 & 138,89 & 160,65 \\
100 & 45,46 & 6,82 & 33,46 & 61,74 \\
150 & 15,22 & 2,00 & 11,23 & 20,46 \\
200 & 8,76 & 0,93 & 6,70 & 11,04 \\
\hline
\end{tabular}

Tabela A.3: Cenário 3 - Trigger assíncrono - Operações por segundo - Figura 5.6

\begin{tabular}{|r|r|r|r|r|}
\hline Qtde. Processo & Média & Desvio Padrão & Mínimo & Máximo \\
\hline 10 & $0,02 \%$ & $0,028 \%$ & $0,00 \%$ & $0,053 \%$ \\
50 & $0,22 \%$ & $0,056 \%$ & $0,17 \%$ & $0,281 \%$ \\
100 & $1,76 \%$ & $0,419 \%$ & $1,40 \%$ & $2,242 \%$ \\
150 & $5,06 \%$ & $1,102 \%$ & $4,11 \%$ & $6,309 \%$ \\
200 & $9,03 \%$ & $1,747 \%$ & $7,49 \%$ & $10,987 \%$ \\
\hline
\end{tabular}

Tabela A.4: Cenário 1 - Sem trigger - Taxa de operações que bloqueiam - Figura 5.7

\begin{tabular}{|r|r|r|r|r|}
\hline Qtde. Processo & Média & Desvio Padrão & Mínimo & Máximo \\
\hline 10 & $0,11 \%$ & $0,056 \%$ & $0,05 \%$ & $0,164 \%$ \\
50 & $2,03 \%$ & $0,368 \%$ & $1,70 \%$ & $2,434 \%$ \\
100 & $10,27 \%$ & $2,036 \%$ & $8,47 \%$ & $12,547 \%$ \\
150 & $20,27 \%$ & $3,416 \%$ & $17,15 \%$ & $23,982 \%$ \\
200 & $28,24 \%$ & $4,114 \%$ & $24,42 \%$ & $32,649 \%$ \\
\hline
\end{tabular}

Tabela A.5: Cenário 2 - Trigger síncrono - Taxa de operações que bloqueiam - Figura 5.7

\begin{tabular}{|r|r|r|r|r|}
\hline Qtde. Processo & Média & Desvio Padrão & Mínimo & Máximo \\
\hline 10 & $0,05 \%$ & $0,051 \%$ & $0,00 \%$ & $0,105 \%$ \\
50 & $0,42 \%$ & $0,090 \%$ & $0,33 \%$ & $0,514 \%$ \\
100 & $3,18 \%$ & $0,773 \%$ & $2,52 \%$ & $4,066 \%$ \\
150 & $8,22 \%$ & $1,828 \%$ & $6,62 \%$ & $10,277 \%$ \\
200 & $13,60 \%$ & $2,453 \%$ & $11,36 \%$ & $16,270 \%$ \\
\hline
\end{tabular}

Tabela A.6: Cenário 3 - Trigger assíncrono - Taxa de operações que bloqueiam - Figura 5.7

\begin{tabular}{|r|r|r|r|r|}
\hline Qtde. Processo & Média & Desvio Padrão & Mínimo & Máximo \\
\hline 10 & 47,51 & 0,01 & 47,33 & 47,67 \\
50 & 236,11 & 0,85 & 232,37 & 236,87 \\
100 & 453,78 & 2,37 & 448,27 & 458,90 \\
150 & 456,41 & 2,02 & 451,33 & 461,48 \\
200 & 429,10 & 2,37 & 423,53 & 433,73 \\
\hline
\end{tabular}

Tabela A.7: Cenário 1 - Sem Trigger - Operações por segundo - Ambiente isolado - Figura 5.8 


\begin{tabular}{|r|r|r|r|r|}
\hline Qtde. Processo & Média & Desvio Padrão & Mínimo & Máximo \\
\hline 10 & 47,44 & 0,08 & 47,25 & 47,52 \\
50 & 234,88 & 0,43 & 233,82 & 235,53 \\
100 & 388,31 & 5,31 & 361,88 & 397,93 \\
150 & 358,67 & 1,95 & 354,57 & 363,60 \\
200 & 328,06 & 1,93 & 323,67 & 331,43 \\
\hline
\end{tabular}

Tabela A.8: Cenário 2 - Trigger síncrono - Operações por segundo - Ambiente isolado - Figura 5.8

\begin{tabular}{|r|r|r|r|r|}
\hline Qtde. Processo & Média & Desvio Padrão & Mínimo & Máximo \\
\hline 10 & 47,33 & 0,16 & 47,00 & 47,57 \\
50 & 225,77 & 3,66 & 220,50 & 232,60 \\
100 & 321,95 & 14,95 & 277,60 & 342,57 \\
150 & 292,40 & 14,72 & 255,78 & 317,75 \\
200 & 268,77 & 21,17 & 209,07 & 293,88 \\
\hline
\end{tabular}

Tabela A.9: Cenário 3 - Trigger assíncrono - Operações por segundo - Ambiente isolado - Figura 5.8

\begin{tabular}{|r|r|r|r|r|}
\hline Qtde. Processo & Média & Desvio Padrão & Mínimo & Máximo \\
\hline 10 & 0,00396 & 0,01522 & 0,00148 & 1,05266 \\
50 & 0,00566 & 0,03383 & 0,00164 & 3,73333 \\
100 & 0,00821 & 0,14109 & 0,00160 & 15,47340 \\
150 & 0,01757 & 0,44836 & 0,00163 & 38,65901 \\
200 & 0,02963 & 0,84455 & 0,00162 & 64,62637 \\
\hline
\end{tabular}

Tabela A.10: Duração do processamento - Figura 5.9

\begin{tabular}{|r|r|r|r|r|r|}
\hline Qtde. Processo & Média & Desvio Padrão & Mínimo & Máximo & Qtde. de transações \\
\hline 10 & 5,00226 & 6,22851 & 0,18960 & 71,14326 & 688803 \\
50 & 144,31706 & 60,53142 & 0,26964 & 264,59412 & 2238943 \\
100 & 69,36799 & 10,24828 & 0,45597 & 106,59344 & 694599 \\
150 & 56,42685 & 14,92738 & 0,66979 & 92,26200 & 237906 \\
200 & 66,82346 & 18,12001 & 1,00188 & 102,22753 & 148205 \\
\hline
\end{tabular}

Tabela A.11: Tempo de fila - Figura 5.10 


\section{Apêndice B}

\section{Configuração do PostgreSQL}

Abaixo, apresentamos o arquivo de configuraçãoo postgresql . conf utilizado na máquina virtual do experimento. Para reduzir o tamanho do arquivo, todos os parâmetros comentados foram suprimidos e entende-se que, neste caso, o valor padrão é o que está em vigor.

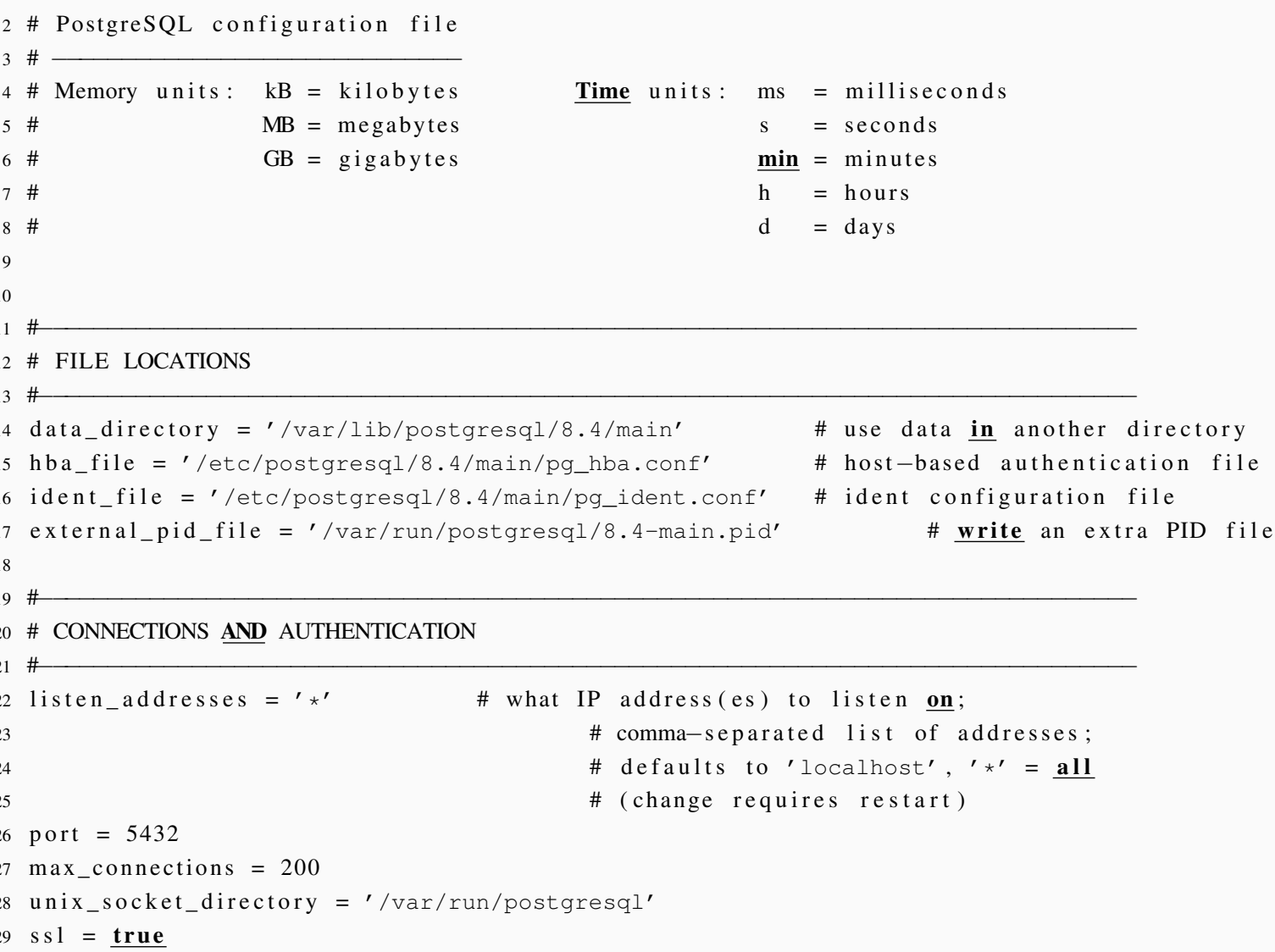




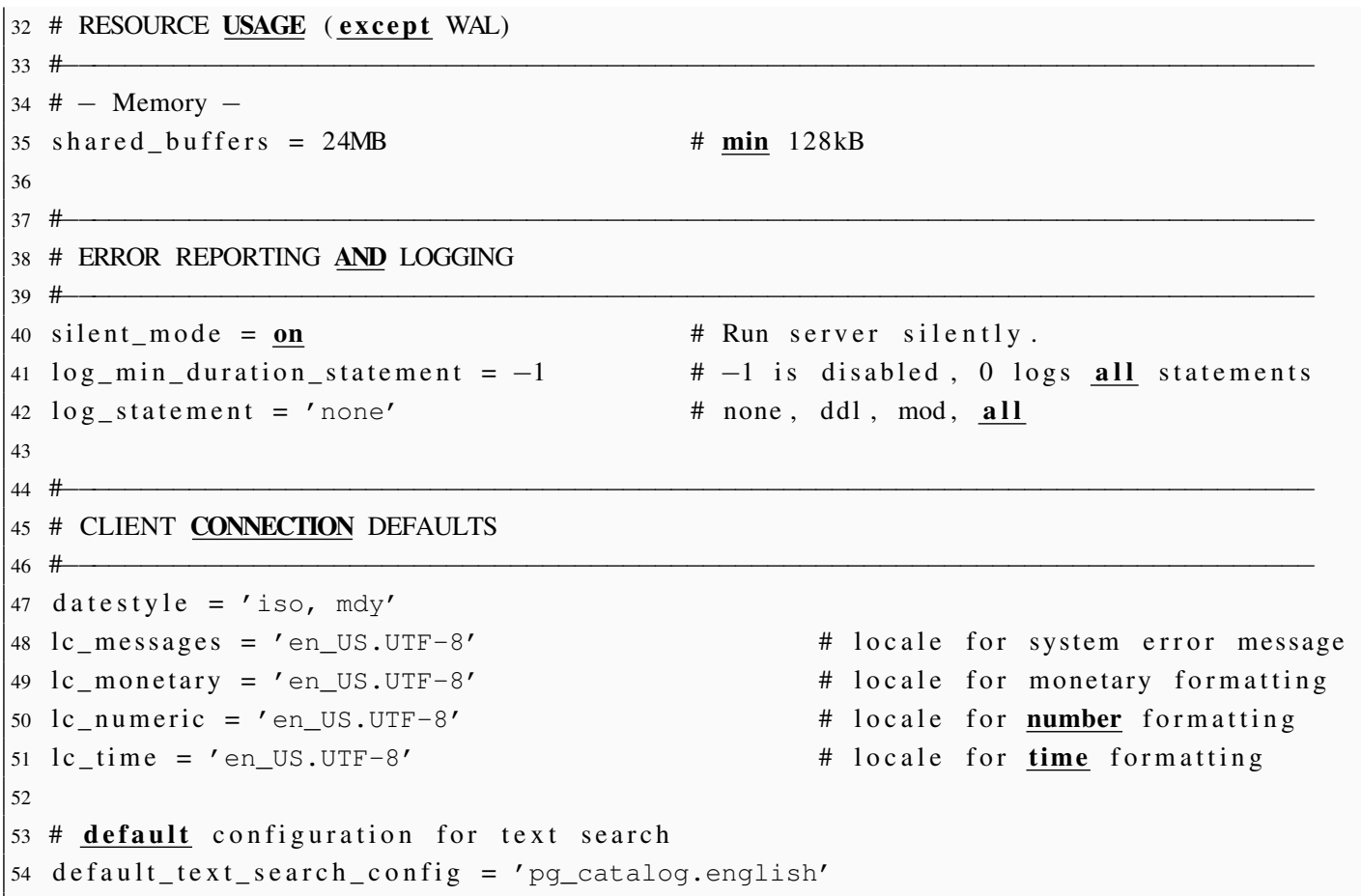

Listagem B.1: Arquivo postgresql.conf 


\section{Apêndice C}

\section{Códigos utilizados no experimento}

\section{C.1 Trigger síncrono}

Abaixo, apresentamos o código do trigger síncrono utilizado no experimento.

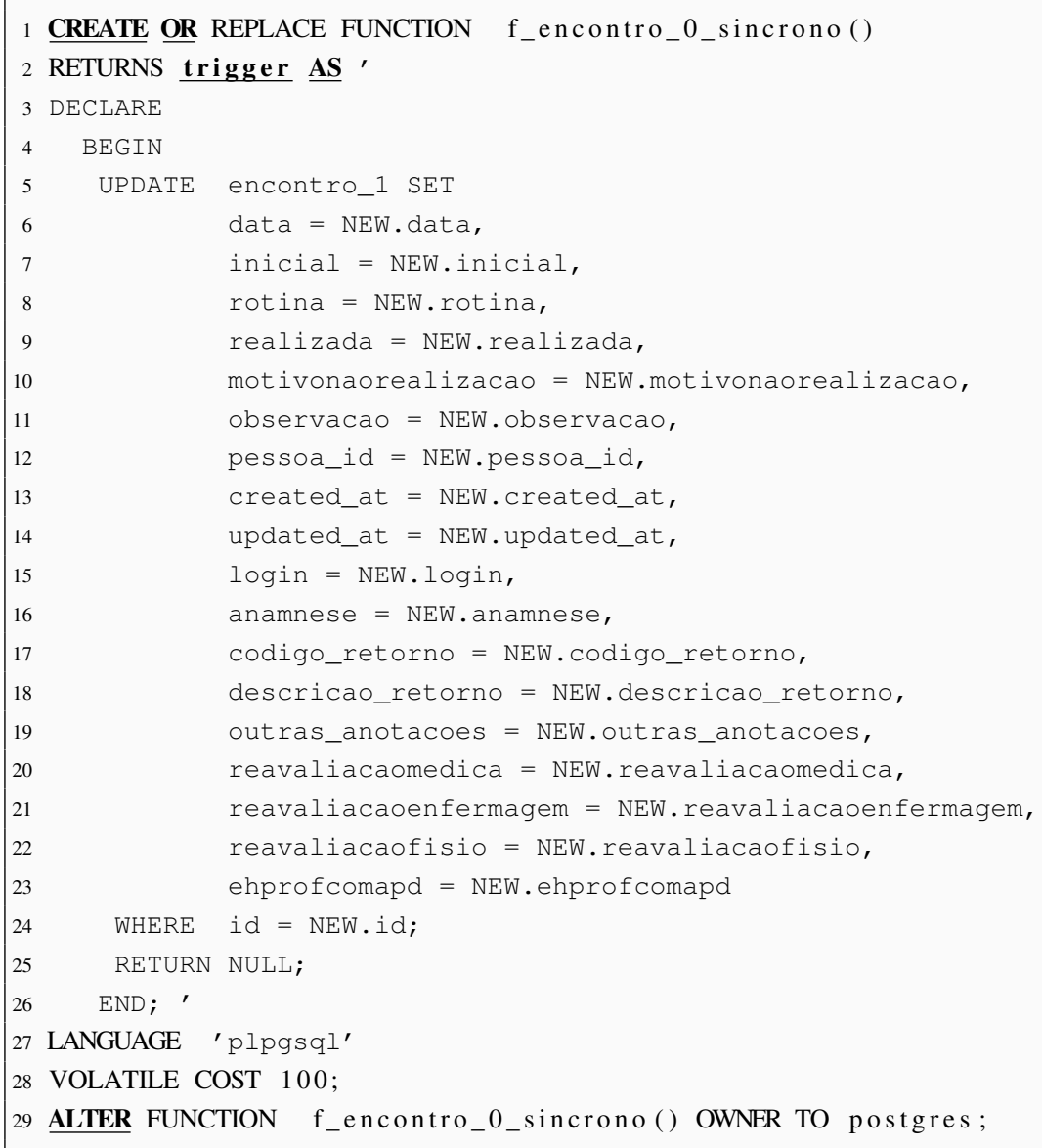

Listagem C.1: Trigger síncrono 


\section{C.2 Trigger assíncrono}

A seguir apresentamos o código do trigger assíncrono utilizado no experimento.

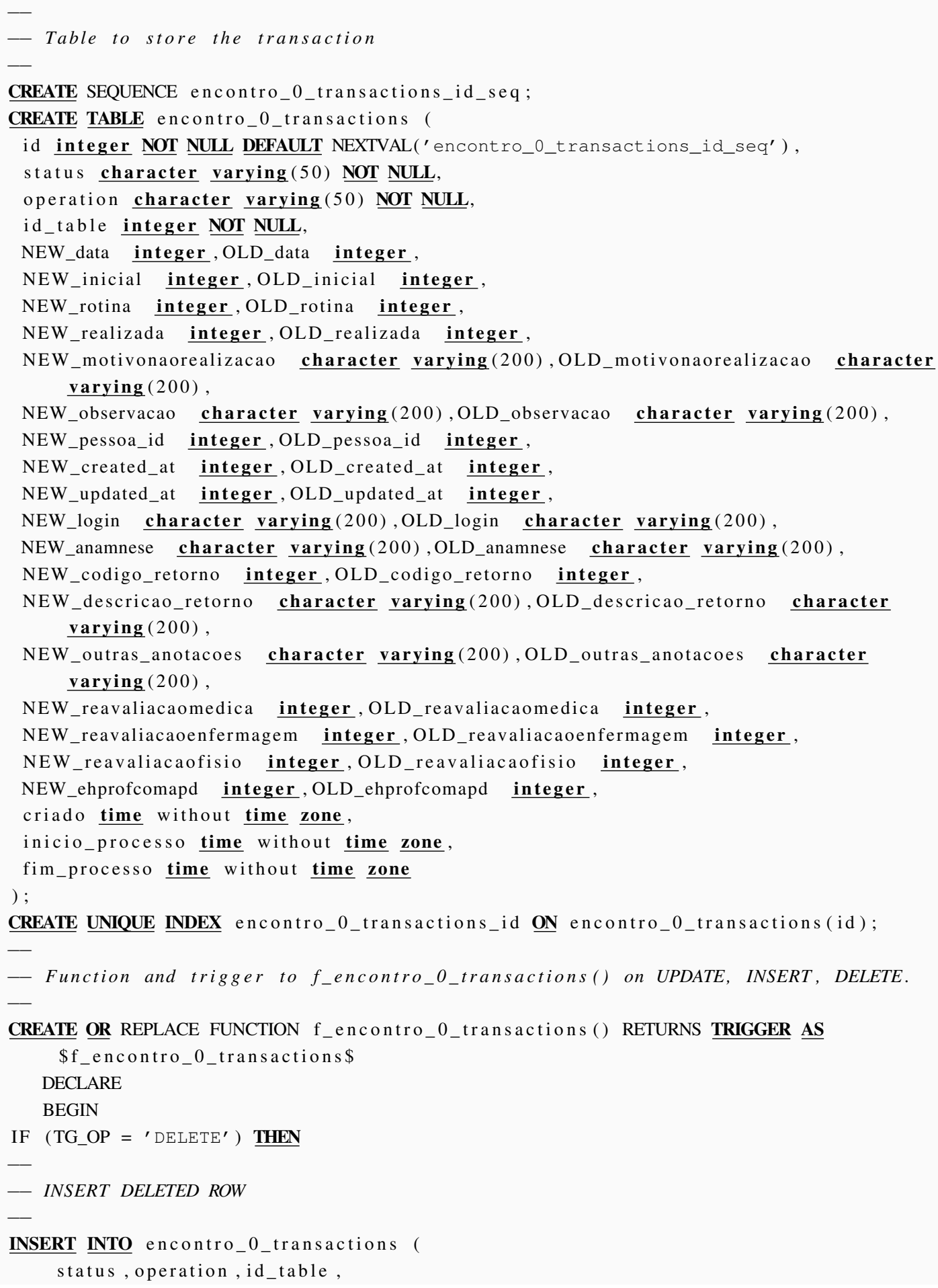




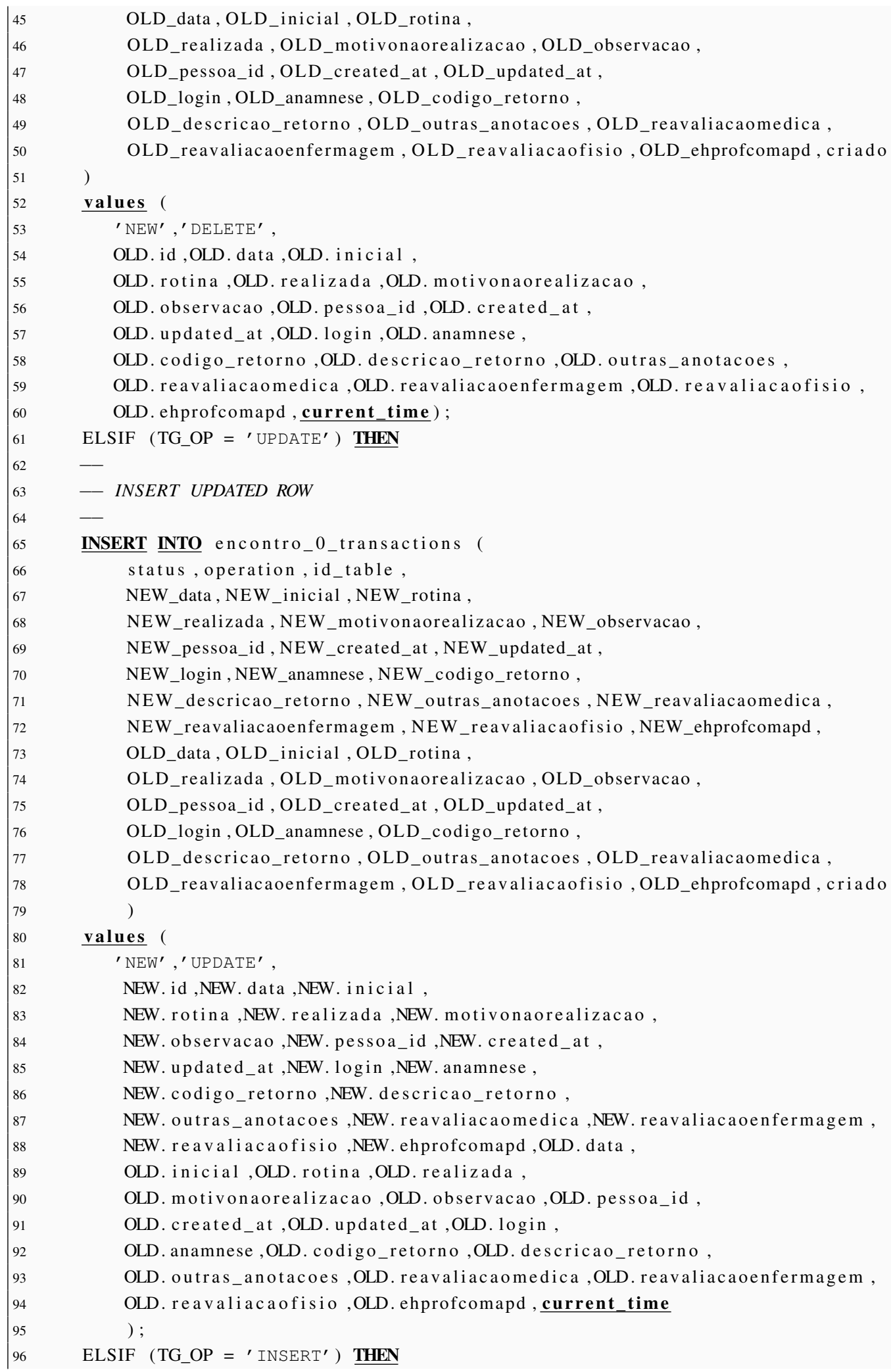




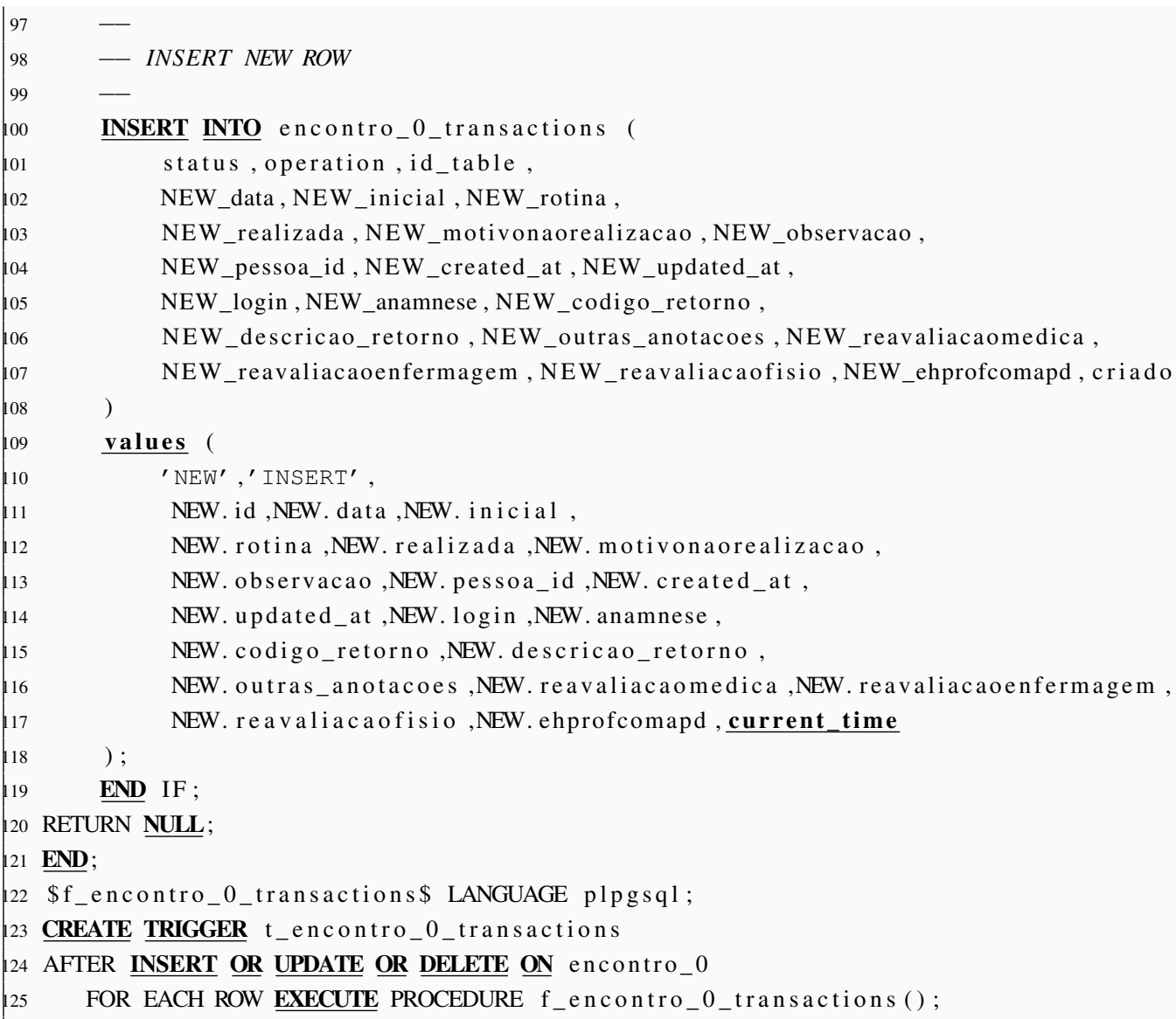

Listagem C.2: Trigger assíncrono 


\section{C.3 Processo de replicação}

A seguir, apresentamos o código do processo de replicação utilizado no experimento.

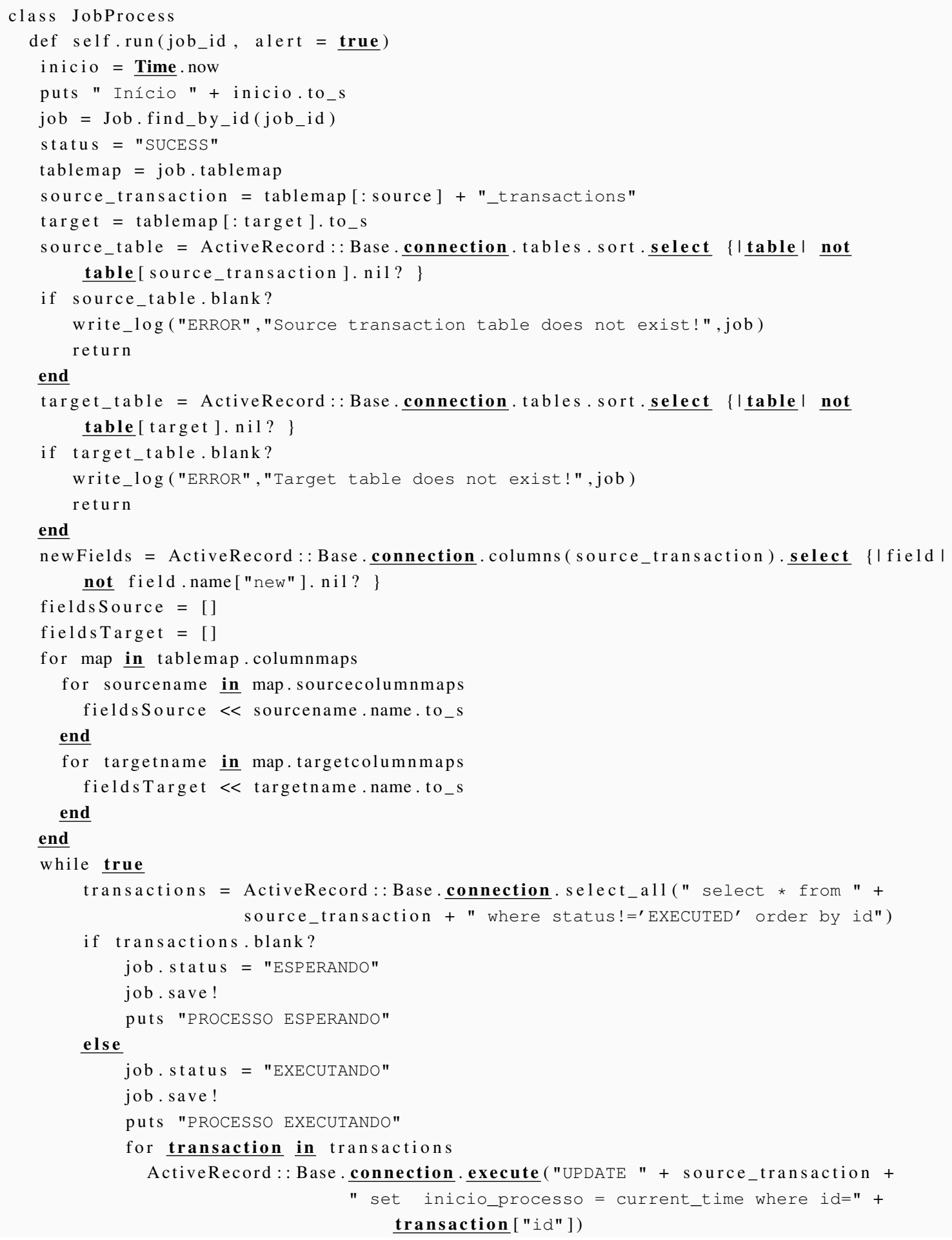




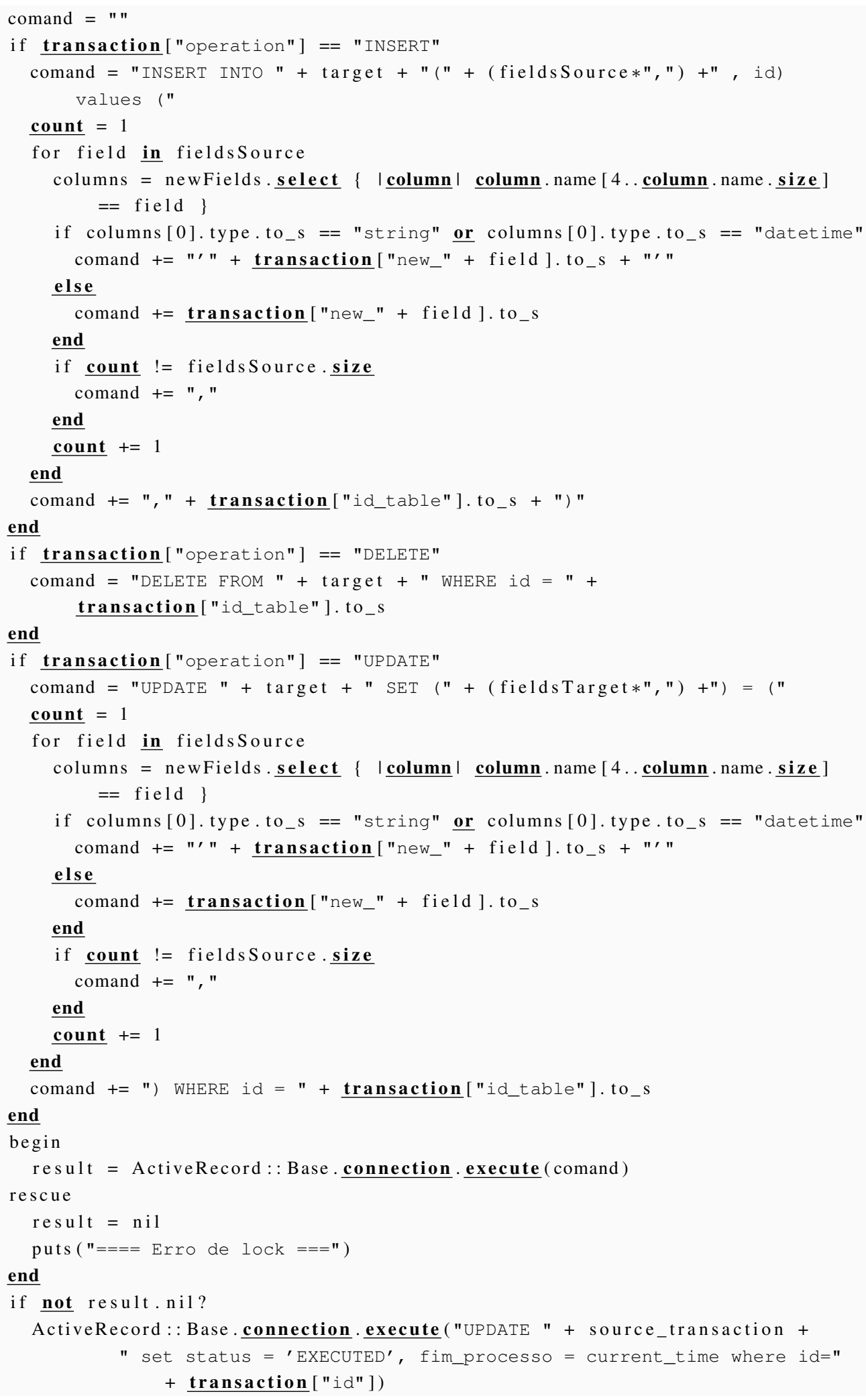




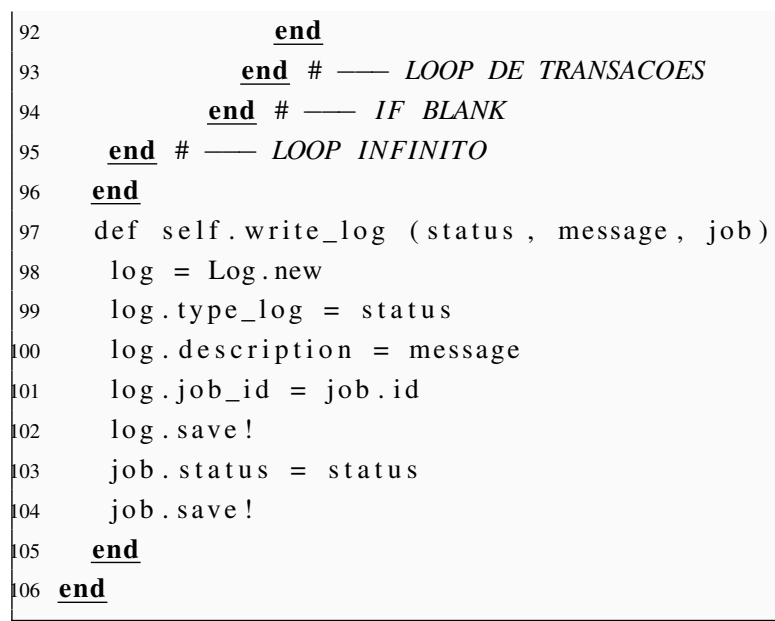

Listagem C.3: Processo de replicação 


\section{C.4 Código do processo de atualização}

A seguir, apresentamos o código do processo de atualização utilizado no experimento.

package com. continuent. bristlecone. benchmark. scenarios ;

4 import java.sql. PreparedStatement;

5 import java.sq1.SQLException:

6 import com. continuent. bristlecone.benchmark. db. SqlDialect;

7 import com. continuent.bristlecone.benchmark.db. Table ;

I** Simula um operações na tabela de encontro */

public class EncontroScenario extends ScenarioBase

\{

private int operations $=1$;

private long delaymillis $=0$;

private boolean autocommit = false

protected PreparedStatement [] pstmtArray;

public void setOperations (int operations)

\{

this operations $=$ operations;

\}

public void setDelaymillis(long delaymillis)

\{

this.delaymillis = delaymillis;

\}

public void setAutocommit (boolean autocommit)

\{

this autocommit = autocommit;

\}

public void prepare() throws Exception

\{

Sq1Dialect dialect $=$ helper.getSqlDialect ();

Table tables [] = tableSet.getTables ();

pstmtArray $=$ new PreparedStatement [tables.length];

for ( int $\mathrm{i}=0 ; \mathrm{i}<$ tables.length; $\mathrm{i}++$ )

\{

String sql = dialect.getUpdateByKey (tables [i ]);

pstmtArray $[\mathrm{i}]=$ conn .prepareStatement $(\mathrm{sql})$;

\}

\}

public void iterate(long iterationCount) throws Exception

\{

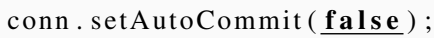

try

\{

for $(\underline{\text { int }} \mathrm{i}=0 ; \mathrm{i}<$ operations $; \mathrm{i}++)$

\{

$\underline{\text { int }} \underline{\text { index }}=$ (int) (Math random () * pstmtArray. length);

$\underline{\text { int }} \underline{\text { key }}=$ (int $)$ (Math. random ()$*$ this . datarows); 


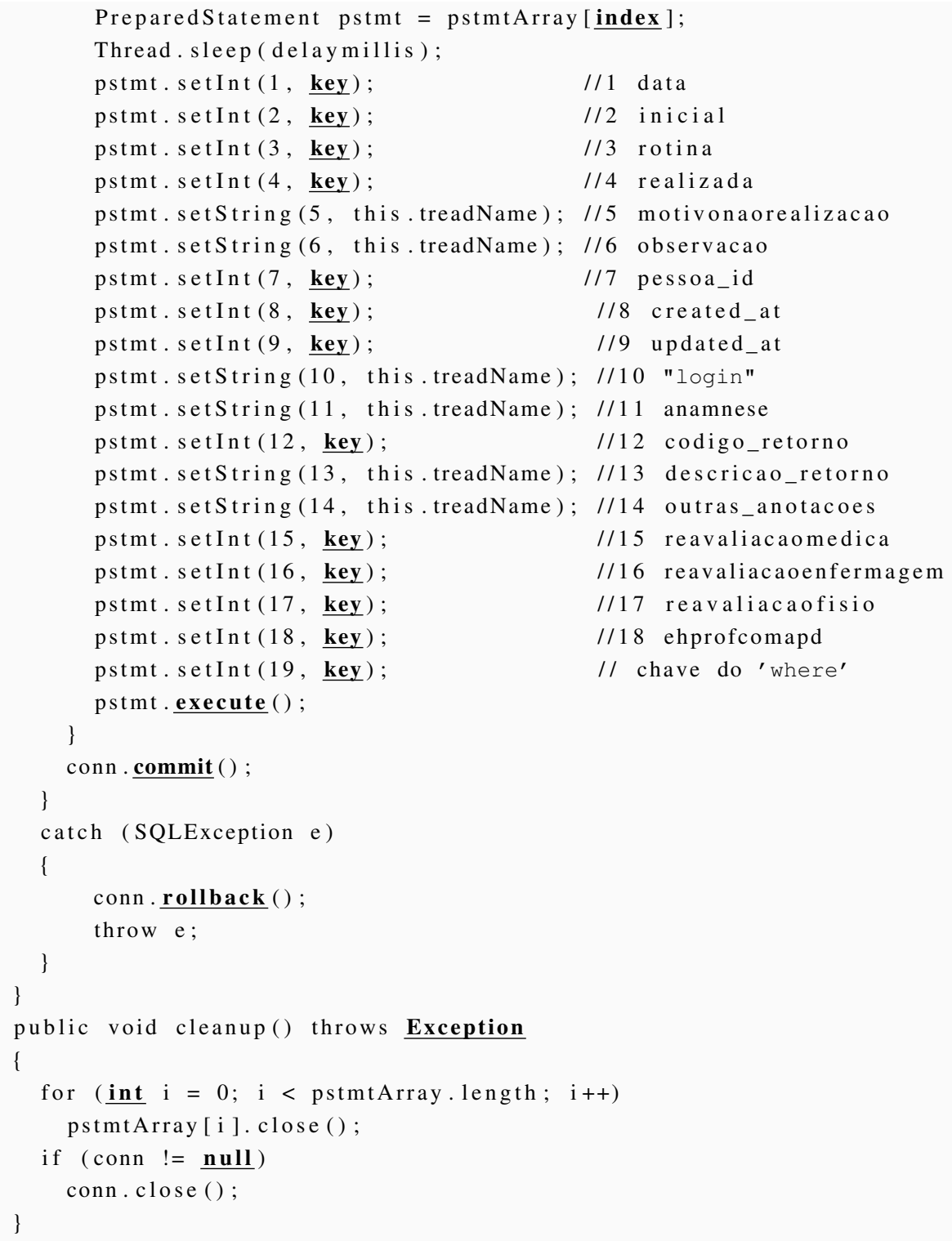

Listagem C.4: Processo de atualização 


\section{C.5 Código do processo de atualização, ambiente isolado}

A seguir, apresentamos o código do processo de atualização isolado utilizado no experimento.

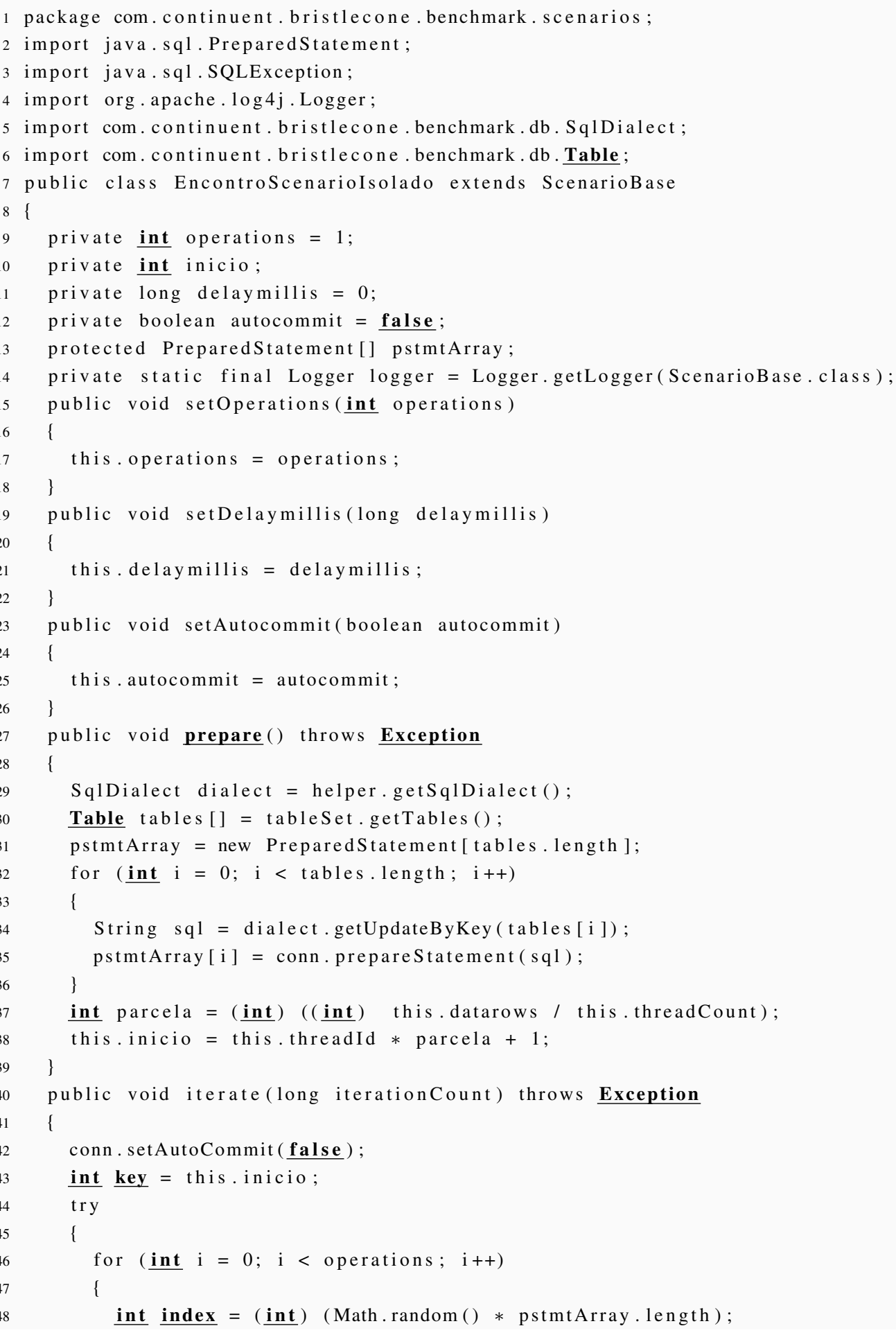




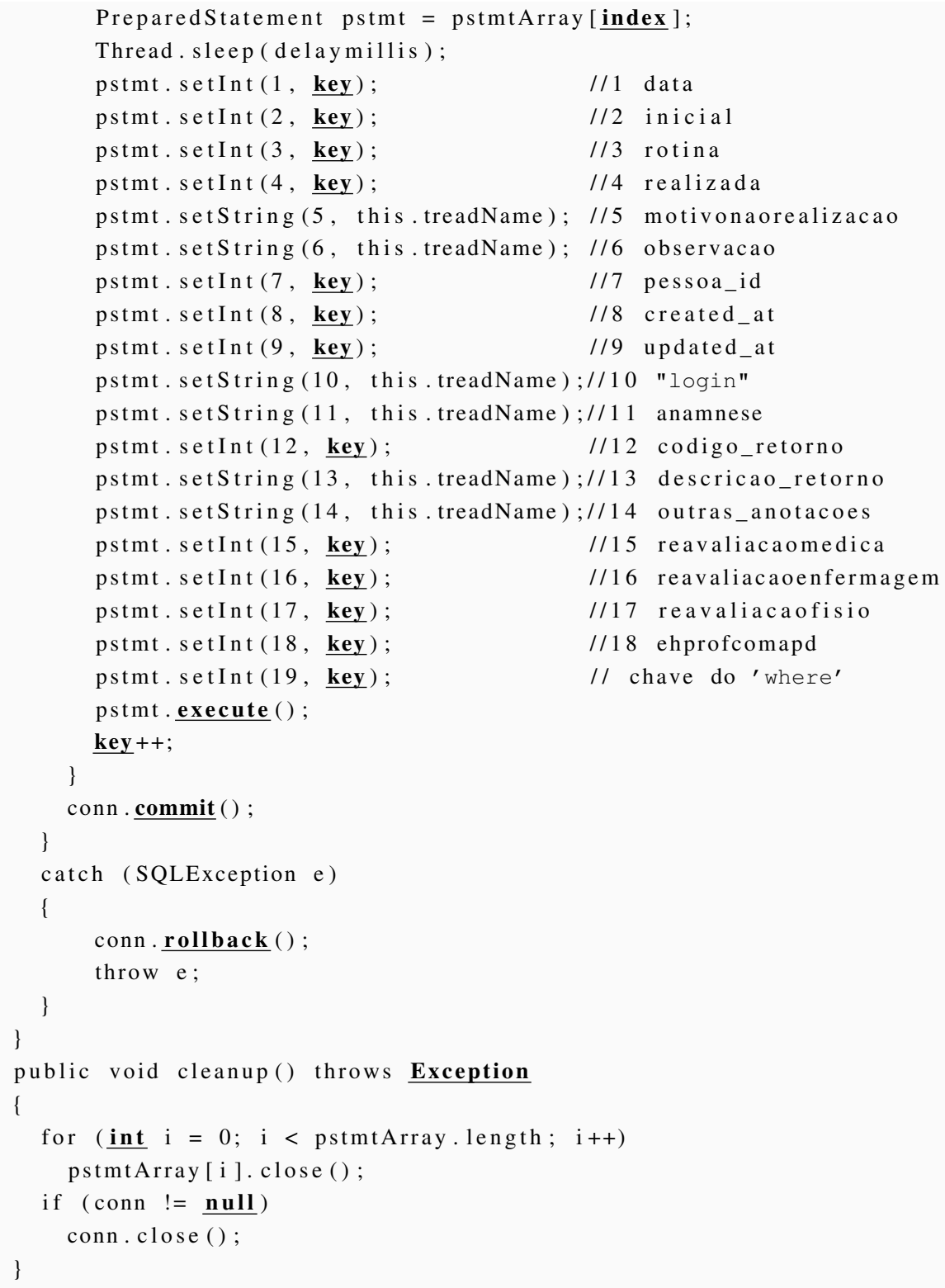

Listagem C.5: Processo de atualização, ambiente isolado 


\section{Referências Bibliográficas}

[8.3a] PostgreSQL version 8.3. Listen documentation. http://www.postgresql.org/ docs/8.3/static/sql-listen.html. Último acesso em 18/2/2011.

[8.3b] PostgreSQL version 8.3. Notify documentation. http://www.postgresql.org/ docs/8.3/static/sql-notify.html. Último acesso em 18/2/2011.

[Amb02] Scott W. Ambler. Agile modeling: effective practices for eXtreme programming and the unified process. John Wiley and Sons, 2002.

[Amb03] Scott W. Ambler. Agile Database Techniques. John Wiley \& Sons Inc, 2003.

[AS06] Scott W. Ambler e Pramodkumar J. Sadalage. Refactoring Databases: Evolutionary Database Design (Addison Wesley Signature Series). Addison-Wesley Professional, 2006.

[BA04] Kent Beck e Cynthia Andres. Extreme Programming Explained: Embrace Change. Addison-Wesley, segunda edição, 2004.

[BdBC01] Herman Balsters, Bert de Brock e Stefan Conrad, editors. Database Schema Evolution and Meta-Modeling. Springer, 2001.

$\left[\mathrm{BLW}^{+}\right.$97] Jesus Bisbal, Deirdre Lawless, Bing Wu, Jane Grimson, Vincent Wade, Ray Richardson e D. O'Sullivan. An overview of legacy information system migration. Em Software Engineering Conference and International Computer Science Conference, páginas 529-530, 1997.

[BSHS06] Sebastian Bossung, Hans-Werner Sehring, Patrick Hupe e Joachim W. Schmidt. Open and dynamic shcema evolution in content-intensive web applications. Em International Conference on Web Information Systems and Technologies, páginas 109-116, 2006.

[CMZ08] Carlo Curino, Hyun J. Moon e Carlo Zaniolo. Managing the history of metadata in support for DB archiving and schema evolution. Em Fifth International Workshop on Evolution and Change in Data Management, páginas 78-88. Springer-Verlag, 2008.

[Coc04] Alistair Cockburn. Crystal clear a human-powered methodology for small teams. AddisonWesley Professional, 2004.

[Coc06] Alistair Cockburn. Agile Software Development: The Cooperative Game. Addison-Wesley Longman, segunda edição, 2006. 
[Con] Continuent. Bristlecone performance test. http://www.continuent.com/ community/lab-projects/bristlecone. Último acesso em 18/2/2011.

[Dbd] Dbdeploy. Database change management tool. http://dbdeploy.com/. Último acesso em 19/6/2011.

[DCK ${ }^{+}$08] Helves Domingues, Rafael Correia, Fabio Kon, Rubens Kon e João Eduardo Ferreira. Análise e modelagem conceitual de um sistema de prontuário eletrônico para centros de saúde. Em SBC - Workshop de Informática Médica, páginas 31-40. Belém, Brasil, 2008.

$\left[\mathrm{DCL}^{+} 10\right]$ Gustavo Luiz Duarte, Rafael Correia, Pedro Leal, Helves Domingues, Fabio Kon, Rubens Kon e João Eduardo Ferreira. Borboleta and saguisaúde - open source mobile telehealth for public home healthcare. Em The 8th International eHealth, Telemedicine and Health ICT Forum (Med-e-Tel). Luxembourg, Luxembourg, 2010.

[DDKF09] Gustavo L. Duarte, Helves Domingues, Fabio Kon e João E. Ferreira. Heterogeneidade como solução para banco de dados móveis em um sistema de saúde. Em SBC - Workshop de Informática Médica. Bento Gonçalves, Brazil, 2009.

[DKF08] Helves Domingues, Fabio Kon e João Eduardo Ferreira. Evolução de banco de dados em métodos ágeis. SBBD e SBES - 23rd Simpósio Brasileiro de Banco de Dados, XXII Simpósio Brasileiro de Engenharia de Software, 2008. Minicurso administrado pelos autores.

[DKF09] Helves Domingues, Fabio Kon e João Eduardo Ferreira. Replicação assíncrona em modelagem evolutiva de banco de dados. Em SBBD - XXIV Simpósio Brasileiro de Banco de Dados, páginas 121-135. Ceará, Brazil, 2009.

[EN06] Ramez Elmasri e Shamkant B. Navathe. Fundamentals of Database Systems. AddisonWesley Longman Publishing Co., Inc., Boston, MA, USA, quinta edição, 2006.

[FBB ${ }^{+99]}$ Martin Fowler, Kent Beck, John Brant, William Opdyke e Don Roberts. Refactoring: Improving the Design of Existing Code. Addison-Wesley Professional, 1999.

[Fow03] Martin Fowler. Evolutionary database design. http://www.martinfowler.com/ articles/evodb.html, 2003. Último acesso em 18/2/2011.

[HH06] Jean-Marc Hick e Jean-Luc Hainaut. Database application evolution: A transformational approach. Data \& Knowledge Engineering, 59(3):534-558, 2006.

[Jai91] Raj Jain. The Art of Computer Systems Performance Analysis: techniques for experimental design, measurement, simulation, and modeling. Wiley, 1991.

[LFST08] Andrea De Lucia, Rita Francese, Giuseppe Scanniello e Genoveffa Tortora. Developing legacy system migration methods and tools for technology transfer. Software: Practice and Experience, 38(13):1333-1364, 2008.

[Li167] Hubert W Lilliefors. On the kolmogorov-smirnov test for normality with mean and variance unknown. Journal of the American Statistical Association, 62(318):399-402, 1967. 
[Liq] Liquibase. Database change management. http://www.liquibase.org/. Último acesso em 19/6/2011.

$\left[\mathrm{MCD}^{+}\right.$08] Hyun J. Moon, Carlo A. Curino, Alin Deutsch, Chien-Yi Hou e Carlo Zaniolo. Managing and querying transaction-time databases under schema evolution. Em Very Large Data Base Endowment Conference, páginas 882-895, 2008.

[MD89] Dennis McCarthy e Umeshwar Dayal. The architecture of an active database management system. ACM SIGMOD Record, 18(2):215-224, 1989.

[OS89] Fredy Oertly e Gerald Schiller. Evolutionary database design. Em Fifth International Conference on Data Engineering, páginas 618-624, 1989.

[Ou03] Rong Ou. Extreme Programming and Agile Methods - XP/Agile Universe 2003, chapter Test-Driven Database Development: A Practical Guide, páginas 82-90. Springer Berlin Heidelberg, 2003.

[RB06] Erhard Rahm e Philip A. Bernstein. An online bibliography on schema evolution. SIGMOD Rec., 35:30-31, December 2006.

[Red] Redgate. Sql prompt 5.1. http://www.red-gate.com/products/ sql-development/sql-prompt/. Último acesso em 19/6/2011.

[RS05] Awais Rashid e Peter Sawyer. A database evolution taxonomy for object-oriented databases. Journal of Software Maintenance and Evolution: Research and Practice, 17(2):93-141, 2005.

[Sad07] Pramodkumar J. Sadalage. Recipes for Continuous Database Integration. Addison-Wesley, 2007.

[SB01] Ken Schwaber e Mike Beedle. Agile Software Development with Scrum. Prentice Hall, 2001.

[SBLY08] JinGang Shi, YuBin Bao, FangLing Leng e Ge Yu. Study on log-based change data capture and handling mechanism in real-time data warehouse. Em International Conference on Computer Science and Software Engineering, páginas 478-481. IEEE Computer Society, 2008.

[Sup] Apple Support. Java for mac os x 10.5 update 8. http: / / support.apple.com/kb/ DL971. Último acesso em 18/2/2011.

[TLN05] Toby Teorey, Sam Lightstone e Tom Nadeau. Database Modeling and Design. Morgan Kaufmann, quarta edição, 2005.

[VMw] VMware. Desktop products, vmware fusion 3. http://www. vmware.com/ products / fusion. Último acesso em 18/2/2011.

[WC96] Jennifer Widom e Stefano Ceri. Active database systems: triggers and rules for advanced database processing. Morgan Kaufmann, segunda edição, 1996. 
[WPS $\left.{ }^{+} 00\right]$ Matthias Wiesmann, Fernando Pedone, André Schiper, Betina Kemme e Gustavo Alonso. Understanding replication in databases and distributed systems. Em 20th International Conference on Distributed Computing Systems, páginas 264-274. IEEE Computer Society, 2000.

[WRH $\left.{ }^{+} 00\right]$ Claes Wohlin, Per Runeson, Martin Host, Magnus C. Ohlsson, Bjorn Regnell e Anders Wesslen. Experimentation in Software Engineering: An Introduction. Kluwer, 2000.

[ZAL08] Youchan Zhu, Lei An e Shuangxi Liu. Data updating and query in real-time data warehouse system. Em International Conference on Computer Science and Software Engineering, páginas 1295-1297. IEEE Computer Society, 2008.

$\left[\mathrm{ZCF}^{+}\right.$97] Carlo Zaniolo, Stefano Ceri, Christos Faloustos, Richard T. Snodgrass, V. S. Subrahmanian e Roberto Zicari. Advanced Database Systems. Morgan Kaufmann, 1997. 